\title{
Physical Properties Models for Simulation of Processes to Treat INEEL Tank Farm Waste: Thermodynamic Equilibrium
}

T. T. Nichols

D. D. Taylor

July 2002

Idaho National Engineering and Environmental Laboratory Bechtel BWXT Idaho, LLC 


\title{
Physical Properties Models for Simulation of Processes to Treat INEEL Tank Farm Waste: Thermodynamic Equilibrium
}

\author{
Todd T. Nichols
}

Dean D. Taylor

July 2002

Idaho National Engineering and Environmental Laboratory High Level Waste Program Idaho Falls, Idaho 83415

Prepared for the

U.S. Department of Energy

Assistant Secretary for Environmental Management

Under DOE Idaho Operations Office

Contract DE-AC07-99ID13727 


\begin{abstract}
A status is presented of the development during FY2002 of a database for physical properties models for the simulation of the treatment of Sodium-Bearing Waste (SBW) at Idaho National Engineering and Environmental Laboratory. An activity coefficient model is needed for concentrated, aqueous, multi-electrolyte solutions that can be used by process design practitioners. Reasonable firstorder estimates of activity coefficients in the relevant media are needed rather than an incremental improvement in theoretical approaches which are not usable by practitioners. A comparison of the Electrolyte Non-Random Two-Liquid (ENRTL) and Pitzer ion-interaction models for the thermodynamic representation of SBW is presented. It is concluded that Pitzer's model is superior to ENRTL in modeling treatment processes for SBW. The applicability of the Pitzer treatment to high concentrations of pertinent species and to the determination of solubilities and chemical equilibria is addressed. Alternate values of Pitzer binary parameters for $\mathrm{HCl}, \mathrm{H}_{2} \mathrm{SO}_{4}$, and $\mathrm{HNO}_{3}$ are proposed, applicable up to $16 \mathrm{~m}, 20 \mathrm{~m}$, and $12 \mathrm{~m}$, respectively. Partial validation of the implementation of Pitzer's treatment within the commercial process simulator ASPEN Plus was performed.
\end{abstract}




\section{SUMMARY}

A status is presented of the development during FY2002 of a database for physical properties models for the simulation of the treatment of liquid Sodium-Bearing Waste (SBW) at Idaho National Engineering and Environmental Laboratory (INEEL). Because steam reforming is now considered a major contender for treating SBW, INEEL process development efforts funded by the Tank Focus Area TFA were re-directed in FY02 from vitrification to steam reforming. Process simulation efforts have been re-targeted to support the latter option as well.

Modeling of INEEL SBW treatment processes has been done in the past using linked EXCEL spreadsheets which lack a physical properties database. The objective for FY-2002 was to continue the transition away from the spreadsheet-based simulation toward a full-fledged commercial simulation software package with thermodynamic simulation capability based on a compatible physical properties database. ASPEN Plus has been tentatively chosen as the commercial process simulator to generate the mass balance for treatment of SBW. The capability of the ASPEN Plus simulator to calculate chemical and phase partitioning (vapor-liquid, liquid-solid, or vapor-liquid-solid) of a set of chemicals in a process stream will be used to characterize the performance of unit operations where equilibrium may be assumed. Consequently, the primary focus of model development during FY2002 has been on thermodynamic modeling of non-ideal aqueous solutions to support the development of the process flowsheet and associated mass balance for steam reforming of SBW.

An activity coefficient model of reasonable fidelity is needed in the near future. Conceptual Design of alternatives for treatment and disposal of sodium-bearing waste is scheduled to begin in FY03. By that time a design tool is needed that can provide reasonable first-order estimates of activity coefficients in the relevant media. ASPEN Plus includes both the Electrolyte Non-Random TwoLiquid (ENRTL) (Chen et al., 1982) and the Pitzer ion-interaction (Pitzer, 1973 and 1991)models as property method options for aqueous electrolyte solutions. Since the preferred simulation approach is to find a practical activity coefficient model supported by the selected commercial simulator, ASPEN Plus, the first task was to compare the ENRTL and Pitzer models.

The single-salt systems NaCl- $\mathrm{H}_{2} \mathrm{O}$ and $\mathrm{HCl}-\mathrm{H}_{2} \mathrm{O}$, the ternary system $\mathrm{HCl}-\mathrm{NaCl}-\mathrm{H}_{2} \mathrm{O}$, and the quarternary system $\mathrm{HCl}-\mathrm{NaCl}-\mathrm{KCl}-\mathrm{H}_{2} \mathrm{O}$ were investigated to compare the accuracies of the ENRTL and Pitzer models. The Pitzer model was 7-13 times more accurate than ENRTL for predicting stoichiometric activity coefficients in these systems up to an ionic strength of 7.0 molal. Consequently, the second task became assessing the viability of the Pitzer model as a tool for the practitioner and validating its implementation in ASPEN Plus.

The Pitzer model was originally focused on concentrations below 6 molal, and the ionic strength of SBW is approximately 10 molal. Additionally, the Pitzer model can be problematic for predicting solid-liquid equilibria in multi-electrolyte solutions because the binary parameter values regressed from single-salt data many times do not extrapolate well for mixtures that involve ionic strengths that exceed saturation of the component, single salts (Furst and Renon, 1982; Weber, 2000). The relatively high ionic strength of SBW exceeds the saturation ionic strength of many of the component single salts. It has also been shown that the thermodynamic representation of highly soluble, self-associating salts is greatly improved at higher ionic strengths by the inclusion of ionicstrength dependency in higher-order virial coefficients of the Pitzer model (Archer, 1991; Clegg et al., 1994; Pitzer et al., 1999). SBW has several associating electrolytes such as hydrofluoric, sulfuric, and nitric acids, as well as many complexing species such as chlorides, nitrates, and fluorides. This need for higher-order virial coefficients would dramatically increase the number of adjustable parameters required to model the thermodynamics of SBW.

Consequently, the focus of the effort in FY2002 to assess the applicability of the Pitzer model addressed these three concerns regarding ionic strengths higher than 6 molal, the prediction of 
precipitation, and the calculation of chemical equilibrium. The $\mathrm{HCl}-\mathrm{H}_{2} \mathrm{O}, \mathrm{HCl}-\mathrm{NaCl}-\mathrm{H}_{2} \mathrm{O}, \mathrm{HCl}-\mathrm{NaCl}-$ $\mathrm{KCl}-\mathrm{H}_{2} \mathrm{O}, \mathrm{H}_{2} \mathrm{SO}_{4}-\mathrm{H}_{2} \mathrm{O}$, and $\mathrm{HNO}_{3}-\mathrm{H}_{2} \mathrm{O}$ systems were investigated to gain insight. Alternate values for the Pitzer binary parameters for the strong acid $\mathrm{HCl}$ and the self-associating acids $\mathrm{H}_{2} \mathrm{SO}_{4}$ and $\mathrm{HNO}_{3}$ were obtained by regressing stoichiometric activity coefficient and fractions of dissociation data. The new parameter values are shown in Table B2 and are recommended for concentrations up to $16 \mathrm{~m}$, $20 \mathrm{~m}$, and $12 \mathrm{~m}$, respectively.

Partial validation was performed regarding the implementation of the Pitzer model in the ASPEN Plus simulator. There appears to be an error in the implementation of the Pitzer model evidenced by the failure for the $\mathrm{H}_{2} \mathrm{SO}_{4}-\mathrm{H}_{2} \mathrm{O}$ system to reproduce the Debye-Huckel limit and to calculate activity coefficients consistent with the Pitzer model as defined in the user's manual (Aspen Technology, 2001). Also, the full model doesn't appear to be utilized by the software - the user's manual suggests that important mixing terms are ignored. Consequently, the implementation of the Pitzer model in ASPEN Plus is suspect at the moment, and attempts are being made to resolve these concerns with the software developer, Aspen Technology.

The following broad conclusions result from the physical properties database/model development during FY2002:

- Use of the ENRTL model should be phased out as a properties model for the simulation of INEEL SBW treatment as Pitzer parameter data become available to support full use of the Pitzer model. A summary of the comparison between the Pitzer and ENRTL models is presented in Table 11. The Pitzer model performed appreciably better than the ENRTL model for all systems studied, leading us to conclude that the Pitzer formalism provides greater opportunity to improve the accuracy of thermodynamic calculations for complex electrolyte solutions than does ENRTL.

- For the practitioner, the Pitzer formalism is robust enough to deal with ionic strengths much higher than the traditionally imposed limit of 4-6 molal. The analyses with $\mathrm{HCl}, \mathrm{H}_{2} \mathrm{SO}_{4}$, and $\mathrm{HNO}_{3}$ suggest that the Pitzer model can adequately deal with solutions with ionic strengths up to $10 \mathrm{~m}$ (comparable to that of SBW) without requiring inclusion of higher-order virial terms.

- It is not yet clear whether or not the Pitzer model can handle in a practical manner the complex chemical and phase equilibria occurring in SBW mixtures. Although the analyses of the HCl$\mathrm{NaCl}-\mathrm{H}_{2} \mathrm{O}, \mathrm{HCl}-\mathrm{NaCl}-\mathrm{KCl}-\mathrm{H}_{2} \mathrm{O}, \mathrm{H}_{2} \mathrm{SO}_{4}-\mathrm{H}_{2} \mathrm{O}$, and $\mathrm{HNO}_{3}-\mathrm{H}_{2} \mathrm{O}$ systems suggest that the Pitzer model is satisfactory for the practitioner for systems containing up to three electrolytes, the accuracy of a practical implementation of the Pitzer model for complex multi-electrolyte mixtures such as SBW has yet to be determined. It is recommended that future efforts be focused on completing this assessment.

- The issues of the error and apparent lack of some mixing terms in the implementation of the Pitzer model in ASPEN Plus need to be resolved before the software can continue to be used to simulate electrolyte solutions in efforts to further assess the Pitzer model. 


\section{CONTENTS}

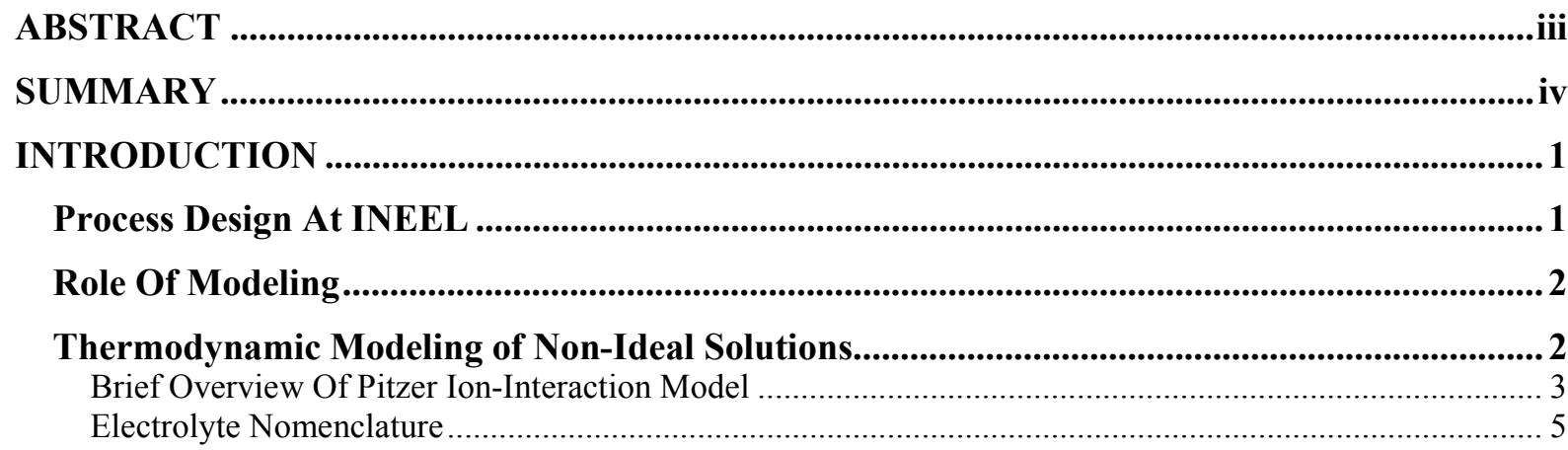

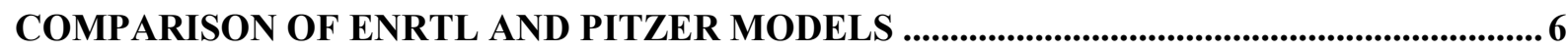

Single-Salt Systems .................................................................................................................................... 6

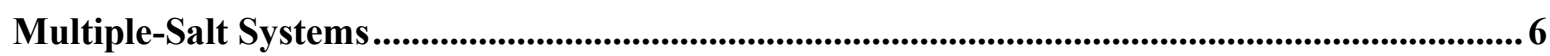

ASSESSMENT OF THE PITZER ION-INTERACTION MODEL.............................................. 7

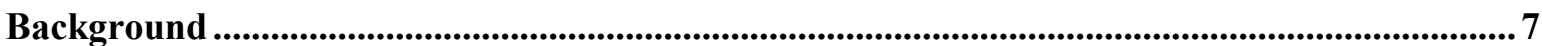

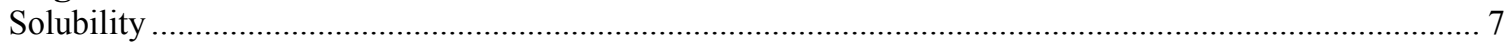

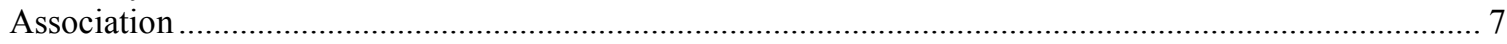

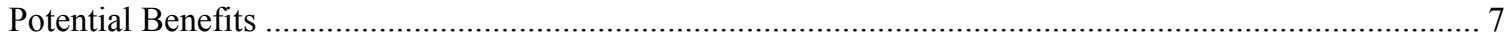

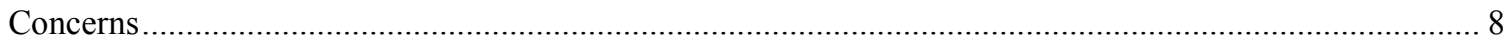

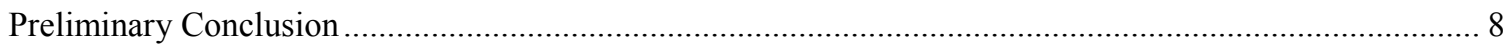

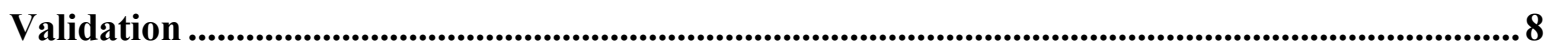

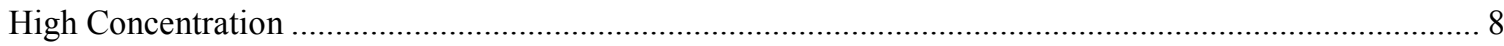

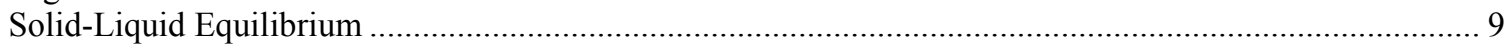

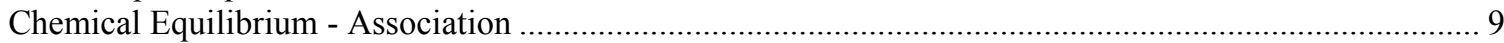

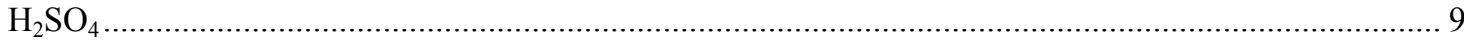

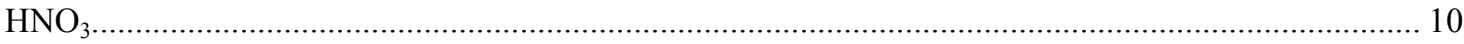

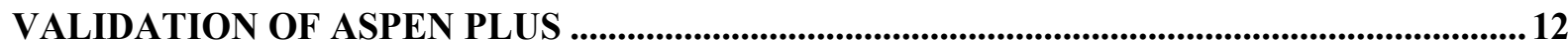

Binary Interaction Terms For Ions Of Unlike Sign $\left(\beta^{(0)}, \beta^{(1)}, C^{\phi}\right)$.......................................... 12

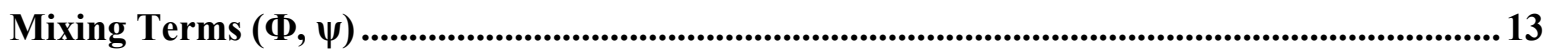

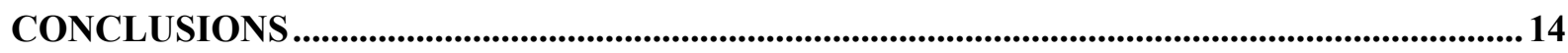

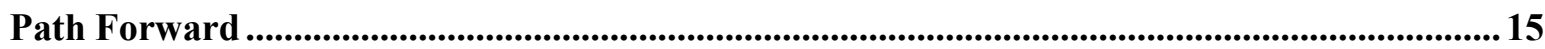

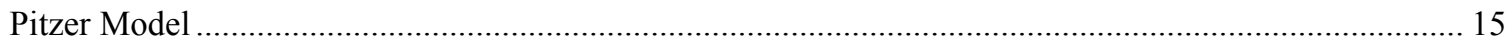

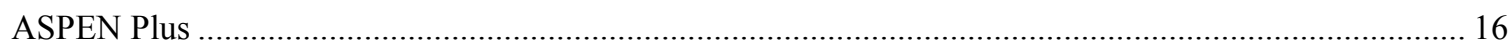

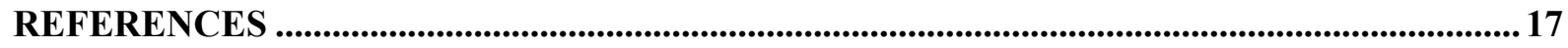

APPENDIX A: STEAM REFORMING PROCESS STREAMS WHERE ACTIVITY

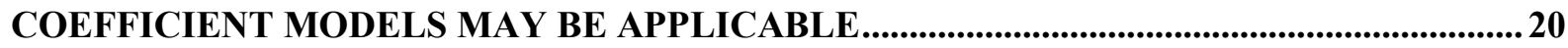

SBW Mixing Tank ...................................................................................................................................... 21

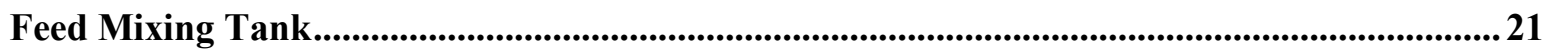

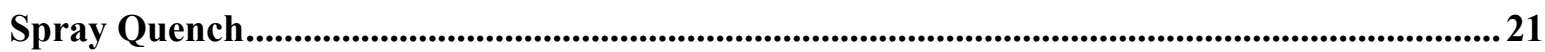

Submerged Bed /Packed Bed/CausticScrubber ......................................................................... 22

High Efficiency Mist Eliminator (HEME).................................................................................22

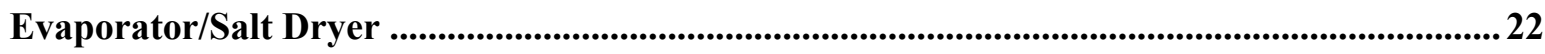

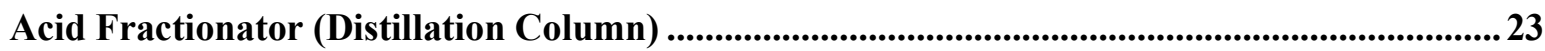




\begin{abstract}
APPENDIX B: VALUES OF PITZER PARAMETERS AND EQUILIBRIUM

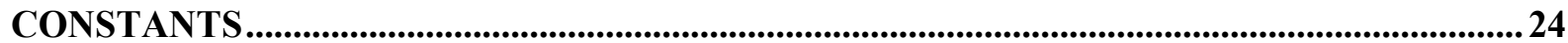

APPENDIX C: REGRESSION PROGRAM TO OBTAIN PITZER PARAMETERS................ 26

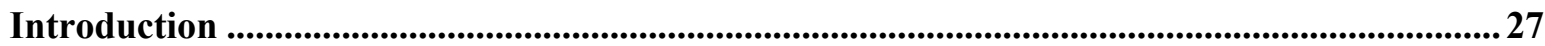

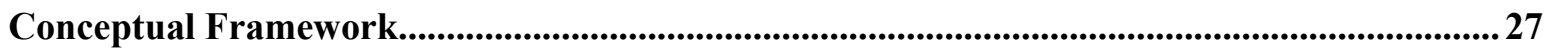

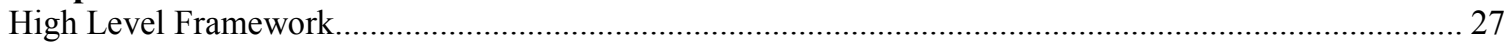

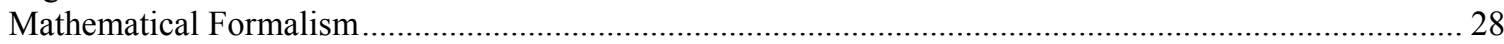

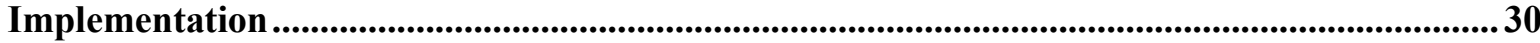

Programming Environment ………………………

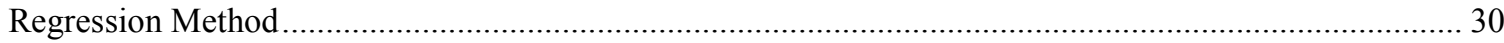

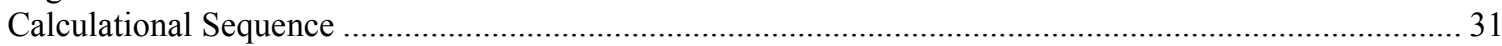

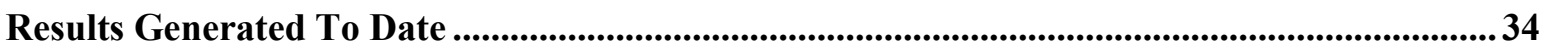

\title{
FIGURES
}

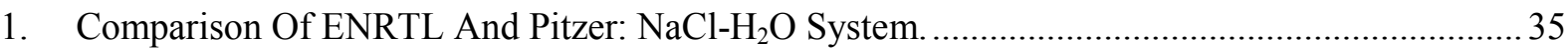

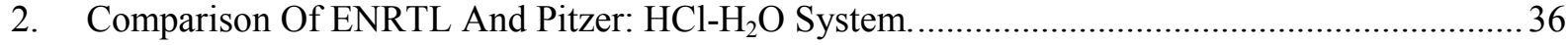

3. Comparison Of ENRTL And Pitzer: HCl-NaCl- $\mathrm{H}_{2} \mathrm{O}$ System..................................................... 37

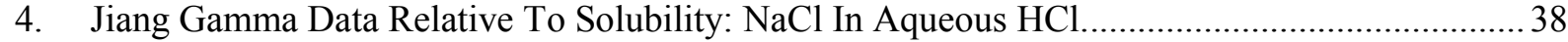

5. Comparison Of ENRTL And Pitzer: HCl-NaCl-KCl- $\mathrm{H}_{2} \mathrm{O}$ System. .............................................. 39

6. Comparison Of Pitzer Parameter Values: $\mathrm{HCl}-\mathrm{H}_{2} \mathrm{O}$ System. .....................................................40

7. Comparison Of Pitzer Parameter Values: $\mathrm{NaCl}-\mathrm{H}_{2} \mathrm{O}$ System/Solubility......................................41

8. Comparison Of Pitzer Parameter Values: $\mathrm{NaCl}-\mathrm{H}_{2} \mathrm{O}$ System/Gamma ........................................ 42

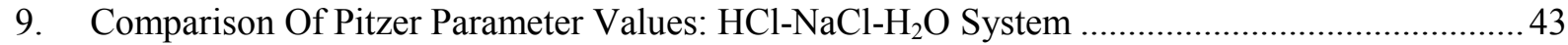

10. Comparison Of Pitzer Parameter Values: HCl-NaCl-KCl- $\mathrm{H}_{2} \mathrm{O}$ System....................................... 44

11. Difficulty Of Experimentally Determining Extent Of Dissociation: $\mathrm{HSO}_{4}{ }^{-} \mathrm{In}$ Water.................. 45

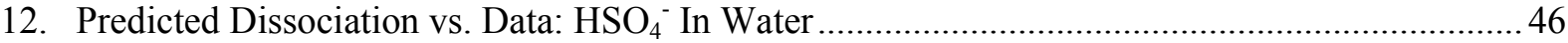

13. Predicted Activity Coefficient vs. Data: $\mathrm{H}_{2} \mathrm{SO}_{4}-\mathrm{H}_{2} \mathrm{O}$ System …............................................47

14. Comparison Of Predicted vs. Experimental Fraction Of Dissociation Data: $\mathrm{HNO}_{3}-\mathrm{H}_{2} \mathrm{O}$ System. 48

15. Comparison Of Predicted vs. Experimental Stoichiometric Activity Coefficient Data: $\mathrm{HNO}_{3}-\mathrm{H}_{2} \mathrm{O}$ System.

16. Comparison Of Predicted vs. Experimental Activity Coefficient Data Of Undissociated Species: $\mathrm{HNO}_{3}-\mathrm{H}_{2} \mathrm{O}$ System.

\section{TABLES}

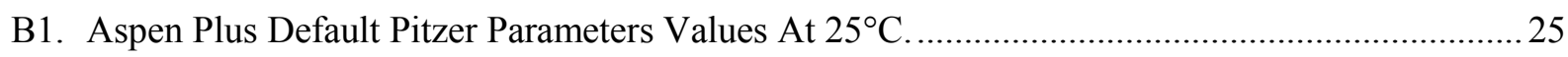

B2. Recommended Pitzer Parameter And Equilibrium Constant Values At $25^{\circ} \mathrm{C}$............................ 25

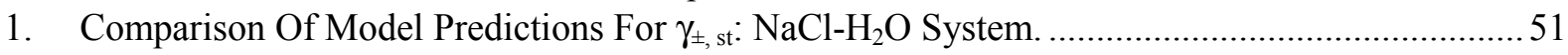

2. Comparison Of Model Predictions For $\gamma_{ \pm, \text {st }}: \mathrm{HCl}-\mathrm{H}_{2} \mathrm{O}$ System..............................................55

4. Comparison Of Pitzer Parameters For Solubility: $\mathrm{HCl}-\mathrm{NaCl}-\mathrm{H}_{2} \mathrm{O}$ System.................................54

5. Comparison Of Model Predictions For $\gamma_{ \pm, \text {st }}: \mathrm{HCl}-\mathrm{NaCl}-\mathrm{KCl}-\mathrm{H}_{2} \mathrm{O}$ System. .................................55

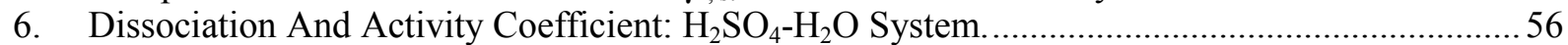

7. Regressed Dissociation And Activity Coefficient Data: $\mathrm{HNO}_{3}-\mathrm{H}_{2} \mathrm{O}$ System. ............................59

8. Comparison Of Our Pitzer Code With That Of ASPEN Plus: $\mathrm{H}_{2} \mathrm{SO}_{4}-\mathrm{H}_{2} \mathrm{O}$ System....................61

9. Validation Of Pitzer Subroutine Of Regression Program: $\mathrm{H}_{2} \mathrm{SO}_{4}-\mathrm{H}_{2} \mathrm{O}$ System.........................62

10. Comparision Of ASPEN Plus vs. Pitzer Subroutine In The Debye-Huckle Limit.......................63

11. Summary Of Results: Percent Absolute Residuals Between Predicted And Experimental Values 


\section{Physical Properties Models For Simulation Of Processes To Treat INEEL Tank Farm Waste: Thermodynamic Equilibrium}

\section{INTRODUCTION}

The purpose of this document is to provide a status of the development during FY2002 of a database for physical properties models for the simulation of the treatment of liquid Sodium-Bearing Waste (SBW) at Idaho National Engineering and Environmental Laboratory (INEEL). Waste management activities at the INEEL and throughout the DOE complex will entail waste retrieval, characterization, treatment, and packaging for disposal, interim storage, transportation, and final disposal. The immediate focus at the INEEL is retrieval, treatment, and packaging of the SBW inventory in the INTEC Tank Farm Facility (TFF). Consequently, the primary focus of model development during FY2002 has been on thermodynamic modeling of non-ideal aqueous solutions. Later, a similar needs assessment for solid calcine in binsets at INTEC is also being considered, as well as CERCLA closure activities for the TFF and associated remedial actions for contaminated soils in that facility. Depending on the methods selected for treating calcine and soils, the needs outlined here may also be relevant to those future activities.

Treatment of SBW stored in the TFF at INEEL is a priority for the Department of Energy under the 1995 Settlement Agreement with the State of Idaho. Several options to treat this waste for disposal have been considered. During FY2001 Bechtel BWXT Idaho was directed to develop a vitrification flowsheet for SBW. However, this direction was altered at the start of FY2002 and vitrification has been supplanted with other treatment options. One option currently under DOE consideration is stream reforming (SR) of the SBW followed by packaging of the solid product for disposal at the Waste Isolation Pilot Plant (WIPP) in New Mexico. Because steam reforming became a major contender for treating SBW, INEEL process development efforts funded by the Tank Focus Area (TFA) were re-directed in FY02 from vitrification to steam reforming.

\section{Process Design At INEEL}

An essential tool in developing any chemical process is a process flowsheet (FS) and its associated mass balance (MB). The FS/MB describes the expected process performance, based on the assumptions and known facts about the underlying phenomena which occur during the processing steps. Thus, the FS/MB provides the basis for design and operation of the actual processing facility whose design is under consideration.

The main objectives in generating the FS/MB are as follows:

(a) Identify all input and output streams for the process;

(b) Track the chemical components in the input streams through the process, partitioning them among the output streams;

(c) Describe the chemical form(s) of each input component in the output streams (e.g., how much of the $\mathrm{Hg}$ in the offgas will be elemental $\mathrm{Hg}$ vapor, $\mathrm{HgCl}_{2}$ vapor, and solid $\mathrm{HgO}$ [aerosol], etc.). 
(d) Determine flowrates and physical properties (temperature, density, corrosivity, etc.) of all process streams needed for equipment design.

The above information is used to generate equipment specifications for process unit operations (e.g., required throughputs, separation or reaction efficiencies, temperatures, etc.), and to assess the adequacy of the process relative to the process requirements (e.g., is the concentration of $\mathrm{Hg}$ in the stack gas below the regulatory limit). Both these uses of the MB assume that the information provided in items (a)-(d) above is credible. The resulting design will generally lead to a process fraught with problems - operational, regulatory, etc. - if the data are not credible.

\section{Role Of Modeling}

The reason for building a simulation model for steam reforming in a commercial process simulator is to provide mass balance accounting to support programmatic planning. Modeling of INEEL SBW treatment processes has been done in the past using linked EXCEL spreadsheets which lack a physical properties database. The objective for FY-2002 was to continue the transition away from the spreadsheet-based simulation toward a full-fledged commercial simulation software package with thermodynamic simulation capability based on a compatible physical properties database. This package will be used to perform basic mass and heat balances on individual unit operations and around the entire treatment train. Having an integrated model with a thermodynamic database will increase the ability of INEEL engineers to assess system-wide impacts of changes to individual unit operations.

ASPEN Plus has been tentatively chosen as the commercial process simulator to generate the MB for treatment of SBW (Nichols et al., 2001). Each unit operation will be represented in some fashion when modeling the overall process. Aspen Plus allows latitude in the choice of a method to represent the behavior of each unit operation in a process, (i.e., mechanistic models, empirical data, or correlations, may be used). ASPEN Plus contains well-developed thermodynamic approaches for mechanistic modeling of subprocesses whose performances are principally governed by thermodynamic limits. However, for subprocesses whose performance is governed principally by other considerations (e.g., transport rates, mixing, etc.) AspenPlus (without customized "add-ons") is a poor substitute for direct empirical data or empirically-based correlations. In light of this, the plan is to limit mechanistic modeling to unit operations (or subprocesses) where thermodynamic equilibrium is likely to be approached. Specifically, the capability of the ASPEN Plus simulator to calculate chemical and phase partitioning (vapor-liquid, liquid-solid, or vapor-liquid-solid) of a set of chemicals in a process stream will be used to characterize the performance of unit operations where equilibrium may be assumed. Elsewhere, empirically-determined performance parameters or correlations will be applied in a "black box" model for the respective unit operations.

\section{Thermodynamic Modeling of Non-Ideal Solutions}

The following design issues in SBW treatment are considered addressable by thermodynamic modeling: (1) concentrations of corrosive species in liquid and gas process streams; (2) concentrations of regulated pollutants in process effluents (gas and liquid) and their associated waste streams (filters, grouted scrub liquor, etc.); and (3) precipitation of insoluble solids from blending of feed streams of differing compositions. To simulate these entities using standard thermodynamic models requires that the activities of species in solution be calculable from the composition, temperature, and pressure of the solution. Due account should be taken of all species in solution which significantly impact the ionic strength and the activities of the species of concern. 
An activity coefficient model of reasonable fidelity is needed within a relatively short time. Conceptual Design of alternatives for treatment and disposal of SBW is scheduled to begin in FY03. By that time a design tool is needed that can provide reasonable first-order estimates of activity coefficients in the relevant media. Ideally, such estimates should be based on measurements that can be made without inordinate expenditures of time and money (e.g., thermodynamic measurements on solutions containing only one or two electrolytes). It is emphasized that incremental improvements to theoretical approaches which are not usable by practitioners simply will not do. Engineering is the art of approximation and what is now needed is a method to improve the state of that art.

Because the solutions of interest (i.e., blended liquids from the TFF and blowdown effluents from scrubbers) will contain many species at high concentrations (and generally at high ionic strengths), it is necessary that models be used that are capable of estimating activity coefficients (for both ionic and molecular species) in such solutions. The estimated ionic strength of post-evaporation SBW in the TFF is 10 molal, major contributors being nitrate ( $\sim 5$ molar), sodium, and hydrogen (both 1-2 molal). An overview of the unit operations and a preliminary process configuration for steam reforming treatment of SBW was previously published (Taylor et al., 2002). A subset of those unit operations consisting of those where thermodynamic modeling might be applied is included here (see Appendix A).

In the last 3-4 decades a number of activity coefficient models for thermodynamic modeling of aqueous chemical solutions have been proposed. The Electrolyte Non-Random Two-Liquid (ENRTL) model of Chen et al. (1982) is a local composition model for the excess Gibbs energy of electrolyte systems that accounts for two contributions, one resulting from long range electrostatic forces between ions and the other from short range forces between all the species. ENRTL is referred to by Kumar (1993) as the most used model for electrolyte solutions, and is recommended by Aspen Technology. In our own literature search, however, we have found far more researchers reporting parameter values for the Pitzer ion-interaction model (Pitzer, 1973) for electrolyte systems than those supporting ENRTL. There appears to be a considerable investment by DOE to generate a Pitzer model database (Weber (2000) and Weber et al. (2000) from ORNL, and Felmy and Rai (1999) and Felmy et al. (2000) from PNNL).

\section{Brief Overview Of Pitzer Ion-Interaction Model}

In simple form, the Pitzer model is a representation of the excess Gibbs free energy $\left(\mathrm{G}^{\mathrm{ex}}\right)$ in a solution which uses a virial equation as follows:

$$
\frac{G_{e x}}{w_{w} R T}=f(I)+\sum_{i} \sum_{j} m_{i} m_{j} \lambda_{i j}(i)+\sum_{i} \sum_{j} \sum_{k} m_{i} m_{j} m_{k} \mu_{i j k}+\ldots
$$

where:

$$
\begin{array}{lll}
\mathrm{w}_{\mathrm{w}} & = & \mathrm{kg} \text { of water in the solution } \\
\mathrm{I} & = & \text { ionic strength }=1 / 2 \sum_{i} m_{i} z_{i}^{2} \\
\mathrm{~m}_{\mathrm{i}} & =\quad \text { molality of solute specie } \mathrm{i} \\
\lambda, \mu & =\quad \text { virial coefficients }
\end{array}
$$

The first term on the right in Eq. (A) represents the empirically-extended form of the DebyeHuckel limiting law for the long range electrostatic forces between ions. The virial coefficient matrices, $\lambda_{\mathrm{ij}}$ and $\mu_{\mathrm{ijk}}$, are assumed symmetric. The second virial coefficients $\left(\lambda_{\mathrm{ij}}\right.$ 's) represent short- 
range interactions in the presence of the solvent between solute particles $i$ and $j$. The third virial coefficients $\left(\mu_{\mathrm{ijk}}\right.$ 's) represent similar three-particle interactions. In general, both the $\lambda$ 's and the $\mu$ 's are ionic-strength dependent, though in most cases the dependence is weak for the latter. Pitzer derives individual solute activity coefficients by differentiation of the expression for $\mathrm{G}^{\text {ex }}$ given by Eq. (A). Thus:

$$
\ln \gamma_{i}=\left[\frac{\partial\left(\frac{G^{e x}}{w_{w} R T}\right)}{\partial m_{i}}\right]_{n_{w}}=\left(z_{i}^{2} / 2\right) f^{\prime}+2 \sum_{j} \lambda_{i j} m_{j}+\left(z_{i}^{2} / 2\right) \sum_{j} \sum_{k} \lambda_{j k}^{\prime} m_{j} m_{k}+3 \sum_{j} \sum_{k} \mu_{i j k} m_{i} m_{j} m_{k}+\ldots
$$

An expression for the osmotic coefficient, $\phi$, is obtained similarly by differentiation of $\mathrm{G}^{\mathrm{ex}}$. In the Pitzer formalism the coefficient terms in the equations for $\mathrm{G}^{\mathrm{ex}}, \ln \gamma_{\mathrm{i}}$, and $\phi$ are transformed into a set of empirically-determinable coefficients, $\mathrm{B}_{\mathrm{ij}}, \mathrm{C}_{\mathrm{ij}}, \Phi_{\mathrm{ij}}$, and $\Psi_{\mathrm{ijk}}$ (one set for the $\mathrm{G}^{\mathrm{ex}}, \ln \gamma$, and $\phi$ equations, respectively). When these coefficients are substituted for $\lambda$ and $\mu$ the resulting activity coefficient equation for cation ' $\mathrm{M}$ ' is:

$$
\begin{aligned}
\ln \gamma_{M}= & z_{M}^{2} F+\sum_{a} m_{a}\left(2 B_{M a}+Z C_{M a}\right)+\sum_{c} m_{c}\left(2 \Phi_{M c}+\sum_{a} m_{a} \Psi_{M c a}\right) \\
& +\sum_{a<a^{\prime}} m_{a} m_{a^{\prime}} \Psi_{M a a^{\prime}}+z_{M}+\sum_{c} \sum_{a} m_{c} m_{a} C_{c a}+2 \sum_{n} m_{n} \lambda_{n M}+\ldots
\end{aligned}
$$

where $\mathrm{Z}=\sum \mathrm{m}_{\mathrm{i}}\left|\mathrm{z}_{\mathrm{i}}\right|$, and the indices and subscripts have the following meanings: $c$ refers to cationic terms, $a$ to anionic terms, $n$ to molecular solute terms, and $a<a^{\prime}$ refers to single counting of terms involving the same two anions.

An analogous equation applies for the activity coefficient of an anion. The coefficients $B_{\mathrm{ij}}$, $\mathrm{C}_{\mathrm{ij}}, \Phi_{\mathrm{ij}}, \Psi_{\mathrm{ijk}}$, and $\lambda_{\mathrm{ij}}$ in Eq. (C) are represented as explicit functions of the ionic strength and of the ionic charges. The $\mathrm{B}_{\mathrm{ij}}$ coefficients are typically expressed as explicit functions of ionic strength involving two (or more) adjustable ' $\beta$ ' constants $\left(\beta^{(0)}, \beta^{(1)}, \ldots\right.$ ), while the $C_{i j}$ and $\lambda_{i j}$ coefficients are treated as simple adjustable parameters. The $\Phi_{\mathrm{ij}}$ and $\Psi_{\mathrm{ijk}}$ coefficients are non-zero only when there are two or more different electrolytes present in the solution, and hence, are referred to as "mixing" terms. The $\Phi_{\mathrm{ij}}$ term is expressed as follows:

$$
\Phi_{i j}=\theta_{i j}+{ }^{E} \theta_{i j}(I)
$$

and

$$
\Phi_{i j}^{\prime}=I^{E} \theta_{i j}(I)^{\prime}
$$

where $\theta_{\mathrm{ij}}$ arises from short-range interactions and is treated as a constant, and ${ }^{\mathrm{E}} \theta_{\mathrm{ij}}(\mathrm{I})$ is assumed to vary with ionic strength and arises from long-range interactions between ions whose charges are of the same sign but of different magnitudes. The $F$ term of Eq. (C) involves the derivative of phi, and thus, the derivative of theta, as indicated in Eq. (E). ${ }^{\mathrm{E}} \theta_{\mathrm{ij}}(\mathrm{I})$ and $\mathrm{I}^{\mathrm{E}} \theta_{\mathrm{ij}}$ are the so-called "unsymmetrical mixing" terms referred to later in the text. 
Finally, the $\Psi_{\mathrm{ijk}}$ parameter is used as a "difference" term to account for differences between the empirically-measured activity coefficient values and those predicted from Eqs. (D) \& (E) obtained by assuming the $\Psi$ 's are zero.

This description of the Pitzer model is admittedly cursory, and is provided as an overview and as a contextual introduction of the terminology that is used later in this report. A more complete description of the Pitzer model can be found in Pitzer (1973; 1991).

\section{Electrolyte Nomenclature}

Additional nomenclature used in this report is briefly defined below. The mean ionic activity coefficient of an electrolyte is expressed by

$$
\gamma_{ \pm}^{v}=\gamma_{+}^{v+} \gamma_{-}^{v-}
$$

and the mean ionic molality is given by

$$
\mathrm{m}_{ \pm}{ }^{\mathrm{v}}=\mathrm{m}_{+}^{\mathrm{v+}} \mathrm{m}_{-}^{\mathrm{v}-}
$$

where the total number of ions is given by

$$
v=v_{+}+v_{-}
$$

If ionization is assumed to be complete, then

$$
\begin{aligned}
& \mathrm{m}_{+}=\mathrm{v}_{+} \mathrm{m}_{+}, \\
& \mathrm{m}_{-}=\mathrm{v}_{-} \mathrm{m}_{-},
\end{aligned}
$$

and

$$
\mathrm{m}_{ \pm, \mathrm{st}}^{\mathrm{v}}=\left(\mathrm{v}_{+}{ }^{\mathrm{v+}} \mathrm{v}_{-}^{v_{-}}\right) \mathrm{m}^{\mathrm{v}}
$$

where $\mathrm{m}$ is the total (or stoichiometric) molality of the electrolyte. The stoichiometric ionic molality $\left(\mathrm{m}_{ \pm, \mathrm{st}}\right)$ is the ionic molality of the electrolyte calculated assuming complete dissociation. Activity coefficients $\gamma_{ \pm}$calculated on the basis of stoichiometric ionic molalities $\left(\mathrm{m}_{ \pm, \mathrm{st}}\right)$ rather than mean ionic molalities $\left(\mathrm{m}_{ \pm}\right)$are referred to in this report as stoichiometric activity coefficients (Denbigh, 1981) and are represented by $\gamma_{ \pm, s t}$. If one aggregate (intermediate ion, neutral molecule or complex ion) is formed by the solute from its simple ions, the relationship between the stoichiometric and mean functions of the solute is (Robinson and Stokes, 1959, pp. 37-39)

$$
\gamma_{ \pm, \mathrm{st}} \mathrm{m}_{ \pm, \mathrm{st}}=\gamma_{ \pm} \mathrm{m}_{ \pm}
$$

Symmetrical mixing is used to refer to the case when ions $i$ and $j$ have the same charge (both sign and magnitude, i.e., $\mathrm{z}_{i}=\mathrm{z}_{j}$ ). For example, the ternary solution $\mathrm{HCl}-\mathrm{NaCl}-\mathrm{H}_{2} \mathrm{O}$ involves symmetrical mixing because both cations $\mathrm{H}^{+}$and $\mathrm{Na}^{+}$have a charge of magnitude one. The ternary solution $\mathrm{HCl}-\mathrm{CaCl}_{2}-\mathrm{H}_{2} \mathrm{O}$, on the other hand, has unsymmetrical mixing because the charges for the two cations $\mathrm{H}^{+}$and $\mathrm{Ca}^{+2}$ have different magnitudes, one and two, respectively. 


\section{COMPARISON OF ENRTL AND PITZER MODELS}

ASPEN Plus includes both the ENRTL and Pitzer models as property method options for aqueous electrolyte solutions. Since the preferred simulation approach is to find a practical activity coefficient model supported by the selected commercial simulator, ASPEN Plus, the first task was to compare the ENRTL and Pitzer models.

\section{Single-Salt Systems}

Figures 1 and 2 compare the ASPEN Plus predictions for ENRTL and Pitzer models for aqueous sodium chloride and hydrochloric acid, respectively, at 0-6 molal. Tables 1 and 2 show the quantitative data for the two systems. The Pitzer model using the ASPEN Plus default values for $\beta^{(0)}$, $\beta^{(1)}$, and $\mathrm{C}^{\phi}$ [designated by PITZER(AP)] is clearly superior in both cases, having residuals of $0.145 \%$ and $0.40 \%$ for $\mathrm{NaCl}$ and $\mathrm{HCl}$, respectively, compared to $1.41 \%$ and $19.71 \%$ residuals, respectively, with the ENRTL model. Residuals are calculated as the absolute value of the difference between the predicted and experimental values divided by the experimental. The relatively poor accuracy of the ENRTL model for aqueous $\mathrm{HCl}$ was surprising given the simplicity of the system - a single, strong acid. The "PITZER(R)" and "PITZER(W)" designations refer to using alternative sets of Pitzer parameters and will be discussed later, as will the data at higher molalities.

\section{Multiple-Salt Systems}

A comparison of the two electrolyte models simulated in ASPEN Plus vs. activity coefficient data for the multiple-salt mixture $\mathrm{HCl}-\mathrm{NaCl}-\mathrm{H}_{2} \mathrm{O}$ is presented graphically in Figure 3 and quantitatively in Table 3. The "PITZER(M)" designation in the table refers to an alternative set of Pitzer parameters discussed later. "I" refers to ionic strength on the molality scale. It is obvious that the Pitzer equation using the default binary parameters resident in ASPEN Plus' databank and no mixing parameters [PITZER(AP)] is far superior to the ENRTL model for predicting the stoichiometric molal activity coefficient of $\mathrm{HCl}$, with residuals of $1.96 \%$ compared to $26.80 \%$, respectively.

ASPEN Plus predicted salt precipitation of $\mathrm{NaCl}$ for all but two of the solutions with an ionic strength of $7.0 \mathrm{~mol} / \mathrm{kg}$. In order to ascertain whether or not the Pitzer equation was predicting the precipitation of $\mathrm{NaCl}$ prematurely, the solution composition corresponding to the activity coefficient data (Jiang, 1996a) were plotted in Figure 4 alongside the $\mathrm{HCl}-\mathrm{NaCl}$ solubility curve as reported in Linke and Seidell (1965). The solubility data is listed in the first nine columns of Table 4. It can be seen in Fig. 4 that the solutions of Jiang for $\mathrm{I}=6.0$ barely fall below the solubility curve and that all but two of the points for $\mathrm{I}=7.0$ are above the solubility curve. Thus, the Pitzer model accurately predicted $\mathrm{NaCl}$ precipitation and indicated that the corresponding experimental solutions of Jiang were apparently supersaturated.

Figure 5 and Table 5 show activity coefficient data (Jiang, 1996b) when $\mathrm{KCl}$ is added to the mixture. The last two columns of Table 5 show the predicted activities of $\mathrm{NaCl}$ and $\mathrm{KCl}$ using a superior set of Pitzer parameters (to be discussed later). The shaded cells indicate activities greater than the thermodynamic solubility product listed at the top of the column. It appears that again Jiang's experimental solutions at high ionic strength could have been at supersaturated conditions.

Consequently, only those data points predicted by the Pitzer model to be non-saturated were used in the accuracy comparison. Again, the Pitzer model using the default binary parameters from ASPEN Plus' databank without mixing parameters [PITZER(AP)] is superior to ENRTL for predicting the stoichiometric molal activity coefficient of $\mathrm{HCl}$, with residuals of $5.09 \%$ compared to $35.92 \%$, respectively. 


\section{ASSESSMENT OF THE PITZER ION-INTERACTION MODEL}

\section{Background}

In Pitzer's development of the above-described equations for electrolytes, he felt the most important result was the recognition of an ionic strength dependence of the effect of short-range forces in binary interactions. Pitzer modified the Debye-Huckel model to include this feature to produce a system of equations simpler than previously proposed rigorous models (such as Scatchard (1961) and Scatchard et al. (1970)) yet providing more physically meaningful parameters. The model appeared to yield comparable agreement with experimental results for mixed and single electrolytes. Silvester and Pitzer (1977) extended the original treatment to wide temperature ranges and for the enthalpy and heat capacity.

\section{Solubility}

Furst and Renon (1982) applied Pitzer's model to study the solubility isotherms of four ternary systems - NaCl-NaNO3- $\mathrm{H}_{2} \mathrm{O}, \mathrm{NaCl}-\mathrm{KCl}-\mathrm{H}_{2} \mathrm{O}, \mathrm{KCl}-\mathrm{KNO} 3-\mathrm{H}_{2} \mathrm{O}$, and NaNO2-NaNO $3-\mathrm{H}_{2} \mathrm{O}$. They showed that using the binary parameters only $\left(\beta^{(0)}, \beta^{(1)}\right.$, and $\mathrm{C}^{\phi}$ of each salt) introduced appreciable error into the predicted solubilities (around 20\% from graphical estimates). The mixing parameter $\psi$ was the key to obtaining improved accuracy. Weber (2000) specifically addressed the fact that Pitzer binary parameter values regressed from single-salt data many times do not extrapolate well for mixtures that involve ionic strengths that exceed saturation of the component single salts.

\section{Association}

Archer (1991) extended Pitzer's original model to include an ionic strength-dependent third virial coefficient (adding a $\mathrm{C}^{\phi(1)}$ parameter) to better represent the $\mathrm{NaBr}-\mathrm{H}_{2} \mathrm{O}$ system. Clegg, Rard, and Pitzer (1994) generalized Archer's extension to self-associating electrolytes and applied it to the study of the $\mathrm{H}_{2} \mathrm{SO}_{4}-\mathrm{H}_{2} \mathrm{O}$ system. Pitzer, Wang, Rard, and Clegg (1999) then showed that the thermodynamic representation of highly soluble, self-associating salts is greatly improved at molalities greater than 2.5 by the inclusion of ionic-strength dependency in higher-order virial coefficients. They generalized Archer's (1991) extension by proposing equations for including ionic-strength dependence in third, fourth, and higher virial coefficients. The authors found their extended model to be effective in representing the complex behavior of aqueous $\mathrm{CaCl}_{2}$ and $\mathrm{MgCl}_{2}$ solutions at $25^{\circ} \mathrm{C}$ without the use of association constants for concentrations to 11.0 and $5.9 \mathrm{~mol} / \mathrm{kg}$, respectively. The equation for $\mathrm{CaCl}_{2}$ requires nine parameters and the inclusion of ionic-strength dependence up to the fifth virial coefficient to adequately account for the interactions of the chloride complexes $\mathrm{CaCl}_{3}{ }^{-}, \mathrm{CaCl}_{4}{ }^{-2}$, and $\mathrm{Ca}_{2} \mathrm{Cl}_{3}{ }^{+}$. The equation for $\mathrm{MgCl}_{2}$ requires six parameters and the inclusion of ionic-strength dependence up to the fourth virial coefficient to adequately account for the interactions of the $\mathrm{MgCl}_{3}{ }^{-}$ complex.

\section{Potential Benefits}

There may be several benefits of the Pitzer ion-interaction model that are important to the practitioner: 1) it provides a consistent thermodynamic framework - a consistent set of equations for activity coefficient, enthalpy, heat capacity, and density; 2) parameter values for many systems are available in the public literature - obtaining parameter values for a variety of species and systems is currently receiving much attention from researchers; 3 ) it has a rigorous theoretical underpinning such that the shape of the $\gamma_{ \pm}$vs. molality curve can usually be made to fit that of experimental data despite the error with actual values, so the framework may be robust enough to provide predictions within engineering design accuracy despite an incomplete set of interaction parameter values; 4) all required 
interaction parameters can be obtained from single-salt and binary-salt solutions, reducing the experimental overhead required to model a complex solution; and 5) it describes the thermodynamics of individual ions rather than just neutral ion pairs, so it offers the potential to model chemical equilibria (association/complexation/ionization).

\section{Concerns}

There are, however, several concerns with the Pitzer model from a practitioner's point of view: 1) the error that may be acceptable for a few-salt solution may be compounded and produce unacceptable error for a many-salt solution such as SBW; 2) the model was originally applied to the 0 $6 \mathrm{~m}$ concentration range, so many of the Pitzer parameter values in the literature are not applicable to high ionic-strength, complex mixtures, such as $10 \mathrm{~m} \mathrm{SBW} ; 3)$ the work of researchers like Archer (1991), Clegg et al. (1994), and Pitzer et al. (1999) suggest that an inordinate amount of association data needs to be experimentally determined, and then corresponding activity coefficient data need to be regressed to obtain association-based Pitzer parameters if one desires to model chemical and phase equilibria of complex mixtures; and 4) accurate predictions of $\gamma_{ \pm}$do not ensure accurate predictions of ionic activity coefficients (the activity coefficient of individual ions cannot be measured) and specie concentrations, so the Pitzer model may not be accurate for predicting chemical equilibrium for complex solutions.

\section{Preliminary Conclusion}

These concerns appear to be receiving attention from researchers. Perez-Villasenor et al. (2002) claim to be able to represent strong 1:1 and 1:2 electrolytes at molalities as high as 25 . Borkowski et al. (2001) are using Pitzer's treatment to develop a geochemical model describing the solubility of actinides in underground water at the Waste Isolation Pilot Plant (WIPP) Project. Even though the application involves hundreds of species, the authors have concluded that mixing terms can be ignored and $\beta^{(1)}$ can have universal values for groups of species, such as the actinide oxalate complexes. One must remember that inaccurate values of activity coefficients or extents of dissociation that follow the proper trends are more desirable for key speices during design than assuming ideality (activity coefficients $=1$ ) and complete dissociation. On the strength of these kinds of applications where simplifying assumptions reduce the number of adjustable parameters, we believe there is reason to expect that a useful, simplified implementation of the Pitzer model to SBW treatment can be achieved.

\section{Validation}

The focus of the effort in FY2002 to assess the applicability of the Pitzer model addressed the concerns regarding ionic strength higher than 6 molal, the prediction of precipitation, and the calculation of chemical equilibrium.

\section{High Concentration}

Activity Coefficient data (Robinson and Stokes, 1959; Cerquetti et al., 1968; Hamer and Wu, 1972) and predictions for the $\mathrm{HCl}-\mathrm{H}_{2} \mathrm{O}$ system up to 16 molal are displayed in Figure 6. One can see that the usual values for the binary parameters, designated by "PITZER(AP)", used by ASPEN Plus and given by Pitzer (1991) provide accurate predictions up to 6 molal, after which the accuracy rapidly diminishes. At high molalities, the ENRTL model is superior to Pitzer if the default binary parameter

values are used. However, it is possible to obtain a set of Pitzer binary parameters that has acceptable accuracy over the entire concentration range. The "PITZER(R)" line represents binary parameters regressed in ASPEN Plus using all the data up to 16 molal. It is shown in Table 2 that one can reduce 
the error in the Pitzer equation over the entire concentration range from $\pm 14.21 \%$ to $\pm 1.55 \%$ if one is willing to slightly increase the error in the dilute range from $\pm 0.40 \%$ to $\pm 1.39 \%$. This exercise suggests that the Pitzer equation may be robust enough to simulate, for strongly dissociated electrolytes at least, concentrations much higher than the traditionally imposed limit of 6 molal, agreeing with the findings of Perez-Villasenor et al. (2002).

\section{Solid-Liquid Equilibrium}

Solubility data (Linke and Seidell, 1965) and predictions for the symmetrical system HCl$\mathrm{NaCl}-\mathrm{H}_{2} \mathrm{O}$ up to 12 molal are displayed in Figure 7, and the quantitative information is listed in Table 4 for up to 19 molal. The "B," "B2," and "B3" series involve different sets of binary parameters, but they have similar accuracy. Adding mixing terms (the "M" series), however, appreciably improves the prediction of the saturation concentration, reducing the error from $\pm 14 \%$ to $\pm 4 \%$. The ENRTL model is also shown for comparison. The binary parameters and solubility constant from Weber (2000) that was used in the " $\mathrm{M}$ " predictions were used to predict $\gamma_{ \pm, \text {st }}$ for $\mathrm{NaCl}$ under single-salt conditions, which is shown in Figure 8 and Table 1 . One can see that using the binary and $\mathrm{K}_{\mathrm{sp}}$ values that optimize the solubility predictions perform more poorly for the single salt than the default ASPEN Plus binaries, $\pm 0.72 \%$ error compared to $\pm 0.15 \%$, respectively. However, both sets of binaries provide reasonable accuracy for $\gamma_{ \pm, \mathrm{st}}$.

Figures 9 and 10 graphically display, and Tables 3 and 5 quantify, the impact of using mixing parameters in the symmetrical systems $\mathrm{HCl}-\mathrm{NaCl}-\mathrm{H}_{2} \mathrm{O}$ and $\mathrm{HCl}-\mathrm{NaCl}-\mathrm{KCl}-\mathrm{H}_{2} \mathrm{O}$, respectively. The " $\mathrm{M}$ " series was generated using the mixing terms, $\mathrm{NaCl}$ binaries, and $\mathrm{NaCl} \mathrm{K}_{\mathrm{sp}}$ from Weber (2000), as well as the $\mathrm{HCl}$ binaries generated from regressing data up to 16 molal. It is clear that the mixing parameters help, but only moderately, going from $\pm 1.96 \%$ error to $\pm 1.87 \%$ in the case of the ternary solution and from $\pm 5.09 \%$ to $\pm 2.53 \%$ in the quarternary case.

The difference in the impact of the mixing parameters between predicting solubility and the stoichiometric activity coefficient suggest that phase equilibria data is a better test of predicted specie (individual ions and molecular solutes) activity coefficients than is stoichiometric activity coefficient data.

\section{Chemical Equilibrium - Association}

\section{$\mathrm{H}_{2} \mathrm{SO}_{4}$}

Assuming the first dissociation step of sulfuric acid to be complete, the one intermediate aggregate formed is the $\mathrm{HSO}_{4}{ }^{-}$ion, and Eq. (F) reduces to

$$
\gamma_{ \pm, \mathrm{st}(\mathrm{H} 2 \mathrm{SO} 4)}=\gamma_{ \pm(\mathrm{H} 2 \mathrm{SO} 4)} \mathrm{m}_{ \pm(\mathrm{H} 2 \mathrm{SO} 4)} / \mathrm{m}_{ \pm, \mathrm{st}(\mathrm{H} 2 \mathrm{SO} 4)}=\left[\left(\gamma_{\mathrm{H}+}^{2} \gamma_{\mathrm{SO} 4-2} \mathrm{~m}_{\mathrm{H}^{+}}^{2} \mathrm{~m}_{\mathrm{SO} 4-2}\right) / 4 \mathrm{~m}^{3}\right]^{1 / 3},
$$

and the equilibrium for the second dissociation step is expressed by

$$
\mathrm{K}_{\mathrm{D} 2, \mathrm{HSO} 4-}=\left(\gamma_{\mathrm{H}^{+}} \gamma_{\mathrm{SO} 4-2} \mathrm{~m}_{\mathrm{H}^{+}} \mathrm{m}_{\mathrm{SO} 4-2}\right) /\left(\gamma_{\mathrm{HSO} 4-} \mathrm{m}_{\mathrm{HSO} 4-}\right)
$$

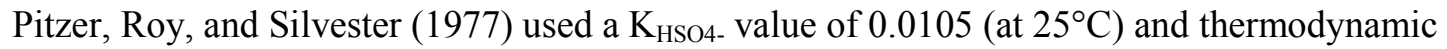
experimental data to perform a least-squares optimization to predict the traditional, binary, Pitzer parameters $\left(\beta^{(0)}, \beta^{(1)}\right.$, and $\left.C^{\phi}\right)$ for sulfuric acid. Extents of dissociation data were not included in the regression. Clegg, Rard, and Pitzer (1994) performed a more extensive optimization on the $\mathrm{H}_{2} \mathrm{SO}_{4}{ }^{-}$ $\mathrm{H}_{2} \mathrm{O}$ system that included dissociation data and an extended Pitzer parameter set that included an ionic-strength dependent, third-order, virial term. The predicted fractions of dissociation of the two studies are compared in Figure 11 with just two of the many dissociation data sources used by the later study (Clegg et al., 1994). Two assessments are quickly made from this graph. First, one can see that 
the discrepancy between the two experimental sets decreases as the concentration increases. Clegg et al. (1994) discuss the difficulty of determining extents of dissociation at dilute concentrations and explain their rationale for giving more credibility to the data of Chen and Irish (1971) in the dilute range. Second, one can see that the dissociation predictions of the two optimization studies become appreciably different above a molality of 2.5 even though the activity coefficient and osmotic coefficient predictions listed in their respective articles remain very close. In other words, leastsquares optimization of Pitzer parameters for associating electrolytes need the additional constraint of dissociation data if predicting chemical equilibria is a main objective.

Stoichiometric activity coefficient and fraction of dissociation data were used, along with $\mathrm{K}_{\mathrm{HSO}-\mathrm{S}}=0.0105$, to regress the traditional binary Pitzer parameters $\left(\beta^{(0)}, \beta^{(1)}\right.$, and $C^{\phi}$ only) for the $\mathrm{H}_{2} \mathrm{SO}_{4}-\mathrm{H}_{2} \mathrm{O}$ system at higher concentrations than performed by Clegg et al. (1994). The optimization procedure used to regress the parameters is explained in Appendix C. Figures 12 and 13 and Table 6 display the results graphically and quantitatively. The ENRTL model poorly predicts both $\alpha$ (fraction of dissociation) and $\gamma_{ \pm, s t}$. The default Pitzer parameters in ASPEN Plus for the aqueous sulfuric acid system all have values of zero, so the poor predictive capability of the PITZER(AP) curve for the activity coefficient is expected, but its dissociation curve is surprisingly close to the data.

There appears to be an error in ASPEN Plus which is discussed in the "Validation of ASPEN Plus" section. The differences in the PITZER(RAP) - regressed parameters used in ASPEN Plus - and PITZER(RP) - predictions straight from the regression program - curves are due to the error and quantifies the need to resolve the error. The regressed, association-based, binary, Pitzer parameters permit the representation of the sulfuric acid system to $\pm 4.2 \%$ for the stoichiometric activity coefficient up to $20 \mathrm{~m}$ and to $\pm 8.3 \%$ for the fraction of dissociation up to $42 \mathrm{~m}$. Alternate sets of Pitzer parameter values (including mixing terms, for example) were not studied because of the error in ASPEN Plus. The values of the regressed, binary, Pitzer parameters are shown in Table B2.

\section{$\mathrm{HNO}_{3}$}

If the aggregate formed is electrically neutral, as in the case of nitric acid, Eq. (F) simplifies to

$$
\gamma_{ \pm, \mathrm{st}}=\alpha \gamma_{ \pm}
$$

where $\alpha$ represents the fraction of dissociation. The equilibrium is expressed by

$$
\mathrm{K}_{\mathrm{D}, \mathrm{HNO}}=\left(\gamma_{\mathrm{H}^{+}} \gamma_{\mathrm{NO}_{-}-} \mathrm{m}_{\mathrm{H}^{+}} \mathrm{m}_{\mathrm{NO3}-}\right) /\left(\gamma_{\mathrm{HNO} 3} \mathrm{~m}_{\mathrm{HNO} 3}\right)
$$

Davis and de Bruin (1964) discuss the difficulty of experimentally determining a consistent set of activity and fraction of dissociation data, and they concluded that relative uncertainties in the values of activities, dissociation, and $\mathrm{K}_{\mathrm{D} \text {, HNO3 }}$ were in the range $10-20 \%$. The authors analyzed several sets of activity and dissociation data to generate a recommended set of consistent data. Figure 14 displays three sets of experimental dissociation data and two model predictions. Only the recommended values of Davis and de Bruin were used to regress the Pitzer parameters, and a line is drawn through those points for comparison sake. If the regression of the Pitzer parameters is constrained only by $\mathrm{K}_{\mathrm{D}, \mathrm{HNO} 3}=$ 18.8 (recommended by Davis and de Bruin) and the $\gamma_{ \pm, s t}$ data, the predicted fractions of dissociation are appreciably higher (represented by the PITZER(RS) curve). As expected, when the parameter regression is constrained by the specified $\mathrm{K}_{\mathrm{D}, \mathrm{HNO}}$ value and both the $\gamma_{ \pm, \mathrm{st}}$ and $\alpha$ data, the predicted fractions of dissociation are closer to the recommended experimental values (shown by the PITZER(RSD) curve).

Figure 15 displays results for $\gamma_{ \pm, s t}$. Naturally, the predictions not constrained by dissociation data (RS) fit the data better. The data of Hamer and $\mathrm{Wu}(1972)$ is displayed for comparison, and it reinforces the assertion of Davis and de Bruin of the uncertainty involved with experimental data. The 
predicted activity coefficient of undissociated, molecular $\mathrm{HNO}_{3}$ is compared with experimental values in Figure 16. There is a large difference in the predicted values depending upon whether or not dissociation data was used in the regression of the Pitzer parameters. Table 7 provides a more quantitative assessment and shows that the average error in the predicted $\gamma_{\mathrm{HNO} 3}$ values is an appreciable $\pm 25.4 \%$ even when the dissociation data was used in the regression of the Pitzer parameters.

The change in slope at the high-molality end of the RSD curves for the stoichiometric and molecular activity coefficients shown in Figures 15 and 16, respectively, are indicative of the high ionic-strength dependence of the thermodynamics of the system. Several attempts to include data at higher concentrations in the parameter regression were unable to obtain reasonable fits. This is consistent with the experience of Archer (1991), Clegg et al. (1994), and Pitzer et al. (1999). 


\section{VALIDATION OF ASPEN PLUS}

\section{Binary Interaction Terms For Ions Of Unlike Sign $\left(\beta^{(0)}, \beta^{(1)}, C^{\phi}\right)$}

There appears to be a problem with the implementation of the Pitzer electrolyte model in the ASPEN Plus software. The issue was first identified when we attempted to reproduce the values of ionic activity coefficients predicted by ASPEN Plus for the $\mathrm{H}_{2} \mathrm{SO}_{4}-\mathrm{H}_{2} \mathrm{O}$ system. The Furst and Renon (1982) form of the Pitzer equation for ionic activity coefficients is used by ASPEN Plus, and the equation as given in the Aspen Tech reference manual (Aspen Technology, 2001 - equation (5)) was used in the Pitzer subroutine of our Visual Basic regression program (see Appendix C). The Pitzer parameter values given by Pitzer, Roy, and Silvester (1977) were added to ASPEN Plus in the Properties|Parameters forms. The ionic activity coefficients predicted for $\mathrm{H}^{+}, \mathrm{HSO}_{4}{ }^{-}$, and $\mathrm{SO}_{4}{ }^{-2}$ by ASPEN Plus and those calculated by our Pitzer subroutine using the equilibrium molalities determined by ASPEN Plus did not agree. The difference in the values went as high as $29 \%$ in the case of $\mathrm{SO}_{4}{ }^{-2}$. The average deviation in the predicted values of the stoichiometric activity coefficient was $5.25 \%$ (see Table 8).

The Pitzer subroutine of our regression program had previously been validated by comparing its predicted stoichiometric activity coefficients with those of Pitzer, Roy, and Silvester (1977). The agreement was excellent; most values agreeing to the third significant digit or higher, and the average deviation was $0.42 \%$ (see Table 9). Consequently, the lack of agreement between the values predicted by the subroutine and those of ASPEN Plus is disconcerting and suggest that errors exist in the ASPEN Plus implementation of the Pitzer model.

To further investigate the implementation of the Pitzer model in ASPEN Plus, a simple test of the Debye-Huckel limiting value was performed with our Pitzer subroutine and ASPEN Plus. The limiting ionic activity coefficient in the Pitzer formalism in this case reduces to the Debye-Huckel term

$$
\ln \gamma_{i}=z_{i}^{2^{*}} f^{\prime} / 2
$$

if all the short-range, ion-ion interaction terms are set to zero (Furst and Renon, 1982; Aspen Technology, 2001). The activity coefficient of an ionic species then depends only on the total ionic strength of the solution (the $f^{\prime}$ term) and is independent of its concentration. The only speciedependency of the activity coefficient is through the specie's absolute charge, $\left|z_{i}\right|$. Species of the same absolute charge will, therefore, have the same predicted activity coefficients in any solution having a fixed ionic strength regardless of their concentrations.

The ratio of the natural logarithm of the activity coefficient of two ions in this reduced state is

$$
\ln \gamma_{\mathrm{i}} / \ln \gamma_{\mathrm{j}}=\left(\mathrm{z}_{\mathrm{i}}^{2^{*}} f^{\prime} / 2\right) /\left(\mathrm{z}_{\mathrm{j}}^{2 *} f^{\prime} / 2\right)=\mathrm{z}_{\mathrm{i}}^{2} / \mathrm{z}_{\mathrm{j}}^{2}
$$

so the ratio for a singly-charged ion over that of a doubly-charged ion is simply

$$
\ln \gamma_{|z|=1} / \ln \gamma_{|z|=2}=z_{i}^{2} / z_{j}^{2}=(1)^{2} /(2)^{2}=1 / 4=0.250
$$

The default Pitzer parameters for $\mathrm{H}_{2} \mathrm{SO}_{4}$ in Aspen Plus are all equal to zero according to the Tools|Retrieve Parameter Results form (see Table B1), implying that the Debye-Huckel limit expressed by Eq. (G) should be used. Table 10 compares the results of ASPEN Plus and the Pitzer subroutine of our Visual Basic regression program for given ionic molalities with $\beta^{(0)}=\beta^{(1)}=C^{\phi}=0$. 
Evidently, for the case of $\mathrm{H}_{2} \mathrm{SO}_{4}$, ASPEN Plus predicts neither the same ionic activity coefficients for the $\mathrm{H}^{+}$and $\mathrm{HSO}_{4}{ }^{-}$species nor the value of 0.250 required by Eq. $(\mathrm{H})$ for the ratio $\ln \gamma_{\mathrm{i}} / \ln \gamma_{\mathrm{SO} 4-2}$, while the Pitzer subroutine predicts both. To be sure that the default value of zero for the Pitzer parameters, as indicated by the Toos|Retrieve Parameter Results form, were indeed being used by ASPEN, zero values were manually entered on the Properties/Parameters form. The results were the same. Although ASPEN Plus does not satisfy the Debye-Huckel limit test with $\mathrm{H}_{2} \mathrm{SO}_{4}$, its predictions for uni-valent (1:1) salts shown in Table 10 do appear to satisfy the Debye-Huckel limit test. This suggests that ASPEN Plus does not consistently implement the Pitzer formalism. We have informed Aspen Technology of this problem, but they have not yet confirmed the problem nor proposed a solution.

\section{Mixing Terms $(\Phi, \psi)$}

$\Phi_{\mathrm{ij}}$ and $\psi_{\mathrm{ijk}}$ account for interactions between ions of like sign and are, therefore, relevant only

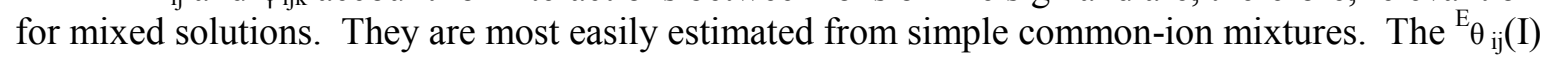
and $\mathrm{I}^{\mathrm{E}} \theta_{\mathrm{ij}}{ }^{\prime}(\mathrm{I})$ terms of $\Phi_{\mathrm{ij}}$ and its derivative (Eqs. (D) \& (E)) account for long-range electrical forces that occur from unsymmetrical mixing effects. For symmetrical mixing, the ${ }^{{ }^{E}} \theta_{i j}$ term (and thus its derivative, $\left.{ }^{\mathrm{E}} \theta_{\mathrm{ij}}{ }^{\prime}\right)$ dissappears. With respect to the mixing term between two ions of like charge, $\Phi_{\mathrm{ij}}$, the ASPEN Plus user's manual (Aspen Technology, 2001) only mentions the $\theta_{\mathrm{ij}}$ and $\theta_{\mathrm{ij}}$ ' terms and states that $\theta_{\mathrm{ij}}{ }^{\prime}$ is assumed to be zero. This suggests that ASPEN Plus only uses the ionic-strength independent parameter $\theta_{\mathrm{ij}}$, and therefore, cannot account for the ionic-strength dependency of $\Phi_{\mathrm{ij}}{ }^{\phi}$ that is required to accurately represent the thermodynamic effects of unsymmetrical mixing. This possible shortcoming of Pitzer's implementation in ASPEN Plus has not been confirmed with Aspen Technologies, nor have we estimated its potential impact on the accuracy of thermodynamic modeling of SBW solutions. 


\section{CONCLUSIONS}

There are four broad conclusions that result from the physical properties database/model development during FY2002. First, the Pitzer model is superior to ENRTL. Second, for the practitioner, the Pitzer formalism is robust enough to deal with ionic strengths much higher than the traditionally imposed limit of 4-6 molal, and it can deal with simple mixtures having ionic strengths comparable to that of SBW $(\approx 10 \mathrm{~m})$ at an accuracy level that is acceptable for design work. Third, it is not yet clear whether or not the Pitzer model can handle in a practical manner the complex chemical and phase equilibria occurring in SBW mixtures. Although the analysis of the $\mathrm{HCl}-\mathrm{NaCl}-\mathrm{H}_{2} \mathrm{O}, \mathrm{HCl}-$ $\mathrm{NaCl}-\mathrm{KCl}-\mathrm{H}_{2} \mathrm{O}, \mathrm{H}_{2} \mathrm{SO}_{4}-\mathrm{H}_{2} \mathrm{O}$, and $\mathrm{HNO}_{3}-\mathrm{H}_{2} \mathrm{O}$ systems suggests that the Pitzer model is satisfactory for the practitioner for few-salt systems, the accuracy of a practical implementation of the Pitzer model for a many-salt mixture of SBW's thermodynamic complexity has yet to be determined. It is recommended that future efforts be focused on completing this assessment. And fourth, the issues of the error and apparent lack of accounting for unsymmetrical mixing in the implementation of the Pitzer model in ASPEN Plus need to be resolved before the software can continue to be used to simulate electrolyte solutions in efforts to further assess the Pitzer model.

Additional details and minor conclusions are presented below:

- Use of the ENRTL should be phased out as a properties model for the simulation of SBW treatment as Pitzer parameter data become available to support full use of the Pitzer model.

A summary of the comparison between the Pitzer and ENRTL models is presented in Table 11. The molality-based Pitzer model with only binary parameters $\left(\beta^{(0)}, \beta^{(1)}\right.$, and $\left.C^{\phi}\right)$ performed appreciably better than the ENRTL model for all systems studied, leading us to conclude that the Pitzer formalism provides greater opportunity to improve the accuracy of thermodynamic calculations for complex electrolyte solutions than does ENRTL.

The Pitzer model without mixing terms was 7-13 times more accurate than ENRTL for predicting stoichiometric molal activity coefficients of strong electrolytes in the few aqueous systems studied up to 7.0 molal. Deviation from experimental data ranged from $\pm 0.145 \%$ for single-salt solutions to $\pm 5.09 \%$ for a uni-valent, quarternary, common-ion mixture in the case of the Pitzer model, compared to $\pm 1.41 \%$ and $\pm 35.92 \%$, respectively, for the ENRTL model.

The Pitzer model was superior to ENRTL at predicting solubility for the $\mathrm{HCl}-\mathrm{NaCl}-\mathrm{H}_{2} \mathrm{O}$ system, with $\pm 4 \%$ error compared to $\pm 34 \%$, respectively.

The Pitzer model was superior to ENRTL at predicting dissociation of $\mathrm{HSO}_{4}{ }^{-}$, with $\pm 8.3 \%$ error compared to $\pm 64.3 \%$, respectively.

- For the practitioner, the Pitzer formalism is robust enough to deal with strongly dissociated electrolytes at concentrations much higher than the traditionally imposed limit of 4-6 molal.

The analyses with $\mathrm{HCl}, \mathrm{H}_{2} \mathrm{SO}_{4}$, and $\mathrm{HNO}_{3}$ suggest that the Pitzer model can adequately deal with solutions having SBW's ionic strength of $\approx 10 \mathrm{~m}$. The $\mathrm{HCl}-\mathrm{H}_{2} \mathrm{O}$ system can accurately be represented $\left( \pm 1.55 \%\right.$ error for $\left.\gamma_{ \pm, \text {st }}\right)$ up to 16 molal acid, the $\mathrm{H}_{2} \mathrm{SO}_{4}-\mathrm{H}_{2} \mathrm{O}$ system $\left( \pm 4.2 \%\right.$ for $\gamma_{ \pm \text {, st }}$ and $\pm 8.3 \%$ for $\alpha)$ up to $20 \mathrm{~m}$ acid, and the $\mathrm{HNO}_{3}-\mathrm{H}_{2} \mathrm{O}$ system $\left( \pm 1.2 \%\right.$ for $\gamma_{ \pm \text {, st }}$ and $\pm 2.0 \%$ for $\left.\alpha\right)$ up to $12 \mathrm{~m}$ acid.

- Phase equilibria data is a better test of predicted specie (individual ions and molecular solutes) activity coefficients than is stoichiometric activity coefficient data. 
The activity coefficient of $\mathrm{HCl}$ can be predicted to within $\pm 2 \%$ in $\mathrm{HCl}-\mathrm{NaCl}-\mathrm{H}_{2} \mathrm{O}$ when $\mathrm{I} \leq 6$ and to within $\pm 5.1 \%$ in $\mathrm{HCl}-\mathrm{NaCl}-\mathrm{KCl}-\mathrm{H}_{2} \mathrm{O}$ when $\mathrm{I} \leq 5$, without mixing parameters. Although mixing parameters do moderately increase the accuracy of predicted $\gamma_{ \pm, s t}$ values, their impact appears to be minimal. Thus, the implication from mean activity coefficient data is that mixing parameters are not required to achieve reasonable accuracy for symmetrical mixing.

However, the solubility data imply the opposite. Mixing parameters can reduce the error in predicted solubility 3- to 4-fold under conditions of symmetrical mixing in the ionic strength range of SBW. Adding mixing terms reduced the predicted solubility limit of $\mathrm{NaCl}$ in $\mathrm{HCl}-\mathrm{NaCl}-\mathrm{H}_{2} \mathrm{O}$ from $\pm 14 \%$ to $\pm 4 \%$ for $\mathrm{I} \leq 12$.

- Mixing parameters improve accuracy, but may not be required, at high ionic strengths under conditions of symmetrical mixing.

The solubility limit of $\mathrm{NaCl}$ in $\mathrm{HCl}-\mathrm{NaCl}-\mathrm{H}_{2} \mathrm{O}$ was predicted to within $\pm 14 \%$ when $\mathrm{I} \leq 12$, without using mixing terms. Fourteen percent error for those species where data is unavailable may be tolerable for a practitioner.

- Least-squares optimization of Pitzer parameters for associating electrolytes needs the additional constraint of equilibrium constant and dissociation data if predicting chemical equilibria is a main objective.

As shown in the case of the $\mathrm{H}_{2} \mathrm{SO}_{4}-\mathrm{H}_{2} \mathrm{O}$ system, regression of parameters without dissociation data may suffice in the dilute range, but accuracy in the predicted speciation can be appreciably improved at $\mathrm{m}>2.5$ if dissociation data is incorporated in the regression.

This fact is more evident in the $\mathrm{HNO}_{3}-\mathrm{H}_{2} \mathrm{O}$ system, where inclusion of dissociation data in the regression reduced the error in the predicted $\alpha$ from $\pm 9 \%$ to $\pm 2 \%$ and in the predicted $\gamma_{\mathrm{HNO} 3}$ from $127 \%$ to $\pm 25 \%$.

- Reasonable accuracy in the prediction of chemical equilibria (speciation in liquid mixtures) will be hard to achieve with any thermodynamic model because of the experimental uncertainties in equilibrium constants and concentrations of individual species.

The discrepancies in fraction of dissociation data and equilibrium constant values for various studies of aqueous $\mathrm{H}_{2} \mathrm{SO}_{4}$ and $\mathrm{HNO}_{3}$ attest to this reality.

\section{Path Forward}

It is recommended that near-term efforts be focused on the following activities:

\section{Pitzer Model}

- Determine binary parameters for other acids pertinent to SBW, such as HF, and chlorides and nitrates.

- Assess practicality of using the model to predict chemical and solid-liquid equilibria of SBW by comparing the predictions of association-based parameters arrived at via regression of single-salt data with experimental dissociation and solubility data in the literature for pertinent mixtures, such as $\mathrm{H}_{2} \mathrm{SO}_{4}-\mathrm{NaOH}-\mathrm{H}_{2} \mathrm{O}$ (Chen and Irish, 1971), $\mathrm{H}_{2} \mathrm{SO}_{4}-\mathrm{HNO}_{3}-\mathrm{H}_{2} \mathrm{O}$ (Deno et al., 1961; Sampoli, et al.,1985; Carslaw et al., 1995), and $\mathrm{HCl}-\mathrm{H}_{2} \mathrm{SO}_{4}-\mathrm{H}_{2} \mathrm{O}$ (Carslaw et al., 1995). Linke and Seidell $(1958,1965)$ have solubility 
data for several pertinent multicomponent mixtures involving nitrate, sulfate, chloride, flouride, aluminum, and mercury. Tagirov and Schott (2001) give equilibrium constants for many aluminum flouride and aluminum sulfate ionic complexes over the temperature range $25^{\circ} \mathrm{C}-350^{\circ} \mathrm{C}$. These equilibrium constants could be used with the solubility data from Linke and Seidell, for example, to estimate association-based, Pitzer parameters for critical aluminum flouride species.

- Use the Pitzer model to estimate activity coefficients to regress Henry law constants from vapor pressure data of single-salt solutions, such as $\mathrm{HCl}$ and $\mathrm{HNO}_{3}$, which can be found in common sources such as Perry's Chemical Engineers' Handbook (Perry and Green, 1997). Then validate the Henry law constants with vapor/liquid equilibrium data for mixtures, such as $\mathrm{H}_{2} \mathrm{SO}_{4}-\mathrm{HNO}_{3}-\mathrm{H}_{2} \mathrm{O}$ and $\mathrm{H}_{2} \mathrm{SO}_{4}-\mathrm{HCl}-\mathrm{H}_{2} \mathrm{O}$ (Zhang et al., 1993; Carslaw et al., 1995).

- Assess ability to model molecular solutes, such as hydrocarbons, in electrolyte mixtures.

- Determine the need for mixing terms under conditions of unsymmetrical mixing, especially at near-saturation conditions. The introduced error may be intolerable, even for practitioners.

- Increase the capability of the Visual Basic regression program to include solubility, vaporliquid equilibrium, and temperature-dependency data. Include the ability to regress mixing parameters also. This is needed because ASPEN Plus can only perform regression for strongly dissociated electrolytes while many of the key species in SBW involve appreciable association.

\section{ASPEN Plus}

- Determine the extent of the apparent error in the implementation of the Pitzer model evidenced by the failure for the $\mathrm{H}_{2} \mathrm{SO}_{4}-\mathrm{H}_{2} \mathrm{O}$ system to reproduce the Debye-Huckel limit and to predict activity coefficients consistent with the Furst/Renon equations. The error needs to be resolved before ASPEN Plus can continue to be used to simulate multielectrolyte mixtures to validate Pitzer parameters regressed from single-salt aqueous data in our Visual Basic regression program.

- Assess the impact of ignoring the ionic-strength dependency in the $\Phi_{\mathrm{ij}}$ mixing terms in ASPEN Plus for unsymmetrical mixing. 


\section{REFERENCES}

Archer, Donald G. (1991), “Thermodynamic Properties Of The NaBr + H2O System”, Journal of Physical and Chemical Reference Data, Vol. 20, No. 3, pp. 509-555.

Aspen Technology (2001), Aspen Physical Property System: Physical Property Methods and Models 11.1, Appendix C: Pitzer Activity Coefficient Model, September, Aspen Technology, Inc.: Cambridge, MA.

Borkowski, M., Robert C. Moore, M.B. Bronikowski, Jianfeng Chen, O.S. Pokrovsky, Yuanxian Xia, and Gregory R. Choppin (2001), "Thermodynamic Modeling of Actinide Complexation With Oxalate at High Ionic Strength", Journal of Radioanalytical and Nuclear Chemistry, Vol. 248, No. 2, May, pp. 467-471.

Carslaw, Kenneth S., Simon L. Clegg, and Peter Brimblecombe (1995), "A Thermodynamic Model of the System HCl-HNO3-H2SO4-H2O, Including Solubilities of $\mathrm{HBr}$, from $<200$ to $328 \mathrm{~K}$ ", Journal of Physical Chemistry, Vol. 99, No. 29, pp. 11557-11574.

Cerquetti, Alessandro, Paolo Longhi, and Torquato Mussini (1968), "Thermodynamics of Aqueous Hydrochloric Acid from E.M.F.'s of Hydrogen-Chlorine Cells", Journal of Chemical and Engineering Data, Vol. 13, No. 4, October, pp. 458-461.

Chen, Chau-Chyun, H.I. Britt, J.F. Boston, and L.B. Evans (1982), "Local Composition Model for Excess Gibbs Energy of Electrolyte Systems, Part I: Single Solvent, Single Completely Dissociated Electrolyte Systems", AIChE Journal, Vol. 28, No. 4, July, 1982, pp. 588-596.

Chen, H. and D.E. Irish (1971), “A Raman Spectral Study of Bisulfate-Sulfate Systems. II. Constitution, Equilibria, and Ultrafast Proton Transfer in Sulfuric Acid”, Journal of Physical Chemistry, Vol. 75, No. 17, pp. 2672-2680.

Clegg, Simon L., Joseph A. Rard, and Kenneth S. Pitzer (1994), “Thermodynamic Properties Of 0-6 mol kg-1 Aqueous Sulfuric Acid From 273.15 to 328.15 K”, Journal of the Chemical Society, Faraday Transactions: Physical Chemistry \& Chemical Physics, Vol. 90, No. 13, pp. 18751894.

Davis, W., Jr. and H.J. de Bruin (1964), "New Activity Coefficients Of 0-100 Per Cent Aqueous Nitric Acid", Journal of Inorganic Nuclear Chemistry, Vol. 26, pp. 1069-1083.

Denbigh, Kenneth (1981), The Principles of Chemical Equilibrium, $4^{\text {th }}$ Edition, Cambridge University Press: New York.

Deno, N.C., Henry J. Peterson, and Edward Sacher (1961), "Nitric Acid Equilibria In Water-Sulfuric Acid", Journal of Physical Chemistry, Vol. 65, No. 2, February, pp. 199-201.

Felmy, Andrew R., and Dhanpat Rai (1999), “Application of Pitzer's Equations for Modeling the Aqueous Thermodynamics of Actinide Species in Natural Waters: A Review", Journal of Solution Chemistry, Vol. 28, No. 5, May, pp. 533-553.

Felmy, Andrew R., Lisa M. Onishi, Nancy S. Foster, James R. Rustad, Dhanpat Rai, and Marvin J. Mason (2000), "An Aqueous Thermodynamic Model For The $\mathrm{Pb}+2-\mathrm{Na}+-\mathrm{K}+-\mathrm{Ca}+2-\mathrm{Mg}+2$ $\mathrm{H}+$-Cl- - SO4-2 -H2O System To High Concentration: Application To WIPP Brines", Geochim. Cosmochim. Acta, Vol. 64, No. 21, pp. 3615-3628. 
Furst, Walter and Henri Renon (1982), "Effect of the Various Parameters in the Application of Pitzer's Model to Solid-Liquid Equilibrium. Preliminary Study for Strong 1-1 Electrolytes", Industrial \& Engineering Chemistry Process Design and Development, Vol. 21, No. 3, July, pp. 396400.

Hamer, Walter J., and Yung-Chi Wu (1972), "Osmotic Coefficients and Mean Activity Coefficients of Uni-univalent Electrolytes in Water at 25 C", Journal of Physical and Chemical Reference Data, Vol. 1, No. 4, pp. 1047-1099.

Jiang, Chengfa (1996a), "Activity Coefficients of Hydrochloric Acid in Concentrated Electrolyte Solutions. 1. $\mathrm{HCl}+\mathrm{NaCl}+\mathrm{H} 2 \mathrm{O}, \mathrm{HCl}+\mathrm{LiCl}+\mathrm{H} 2 \mathrm{O}$, and $\mathrm{HCl}+\mathrm{BaCl} 2+\mathrm{H} 2 \mathrm{O}$ at $298.15 \mathrm{~K}$ ", Journal of Chemical and Engineering Data, Vol. 41, No. 1, pp. 113-116.

Jiang, Chengfa (1996b), "Activity Coefficients of Hydrochloric Acid in Concentrated Electrolyte Solutions. 2. $\mathrm{HCl}+\mathrm{BaCl} 2+\mathrm{KCl}+\mathrm{H} 2 \mathrm{O}, \mathrm{HCl}+\mathrm{LiCl}+\mathrm{KCl}+\mathrm{H} 2 \mathrm{O}$, and $\mathrm{HCl}+\mathrm{NaCl}+\mathrm{KCl}$ + H2O at 298.15 K", Journal of Chemical and Engineering Data, Vol. 41, No. 1, pp. 117-120.

Kumar, Anil (1993), "Salt Effect on Vapor-Liquid Equilibria: A Review of Correlations and Predictive Models", Separation Science and Technology, Vol. 28, No. 10, pp. 1799-1818.

Linke, W.F. and A. Seidell (1958), Solubilities of Inorganic and Metal-Organic Compounds, $4^{\text {th }}$ Edition, Vol. I, Van Nostrand: New York.

Linke, W.F. and A. Seidell (1965), Solubilities of Inorganic and Metal-Organic Compounds, $4^{\text {th }}$ Edition, Vol. II, American Chemical Society: Washington, D.C.

Nichols, Todd T., Charles M. Barnes, Lance Lauerhass, and Dean D. Taylor (2001), Selection of Steady-State Process Simulation Software to Optimize Treatment of Radioactive and Hazardous Waste, INEEL/EXT-01-00485, May.

Perez-Villasenor, Fernando, Gustavo A. Iglesias-Silva, and Kenneth R. Hall (2002), "Osmotic And Activity Coefficients Using A Modified Pitzer Equation For Strong Electrolytes 1:1 and 1:2 at 298.15 K", Industrial \& Engineering Chemistry Research, Vol. 41, No. 5, March 6, pp. 10311037.

Perry, Robert H. and Don W. Green (1997), Perry's Chemical Engineers' Handbook, 7th Edition, McGraw-Hill: San Francisco.

Pitzer, Kenneth S. (1973), "Thermodynamics of Electrolytes. I. Theoretical Basis and General Equations", Journal of Physical Chemistry, Vol. 77, No. 2, January 18, pp. 268-277.

Pitzer, Kenneth S., Editor (1991), Activity Coefficients in Electrolyte Solutions, CRC Press, 2nd Edition, Ann Arbor.

Pitzer, Kenneth S., Rabindra N. Roy, and Leonard F. Silvester (1977), "Thermodynamics of Electrolytes. 7. Sulfuric Acid", Journal of the American Chemical Society, Vol. 99, No. 15, July 20, pp. 4930-4936.

Pitzer, Kenneth S., Peiming Wang, Joseph A. Rard, and Simon L. Clegg (1999), "Thermodynamics of Electrolytes. 13. Ionic Strength Dependence of Higher-Order Terms; Equations for $\mathrm{CaCl} 2$ and MgCl2", Journal of Solution Chemistry, Vol. 28, No. 4, pp. 265-282.

Press, W.H., Brian P. Flannery, Saul A. Teukolsky, and William T. Vetterling (1986), Numerical Recipes, Cambridge University Press: Cambridge, UK. 
Robinson, R.A. and R.H. Stokes (1959), Electrolyte Solutions: The Measurement and Interpretation of Conductance, Chemical Potential and Diffusion in Solutions of Simple Electrolytes, $2^{\text {nd }}$ Edition, Academic Press, Inc.: New York.

Sampoli, M., A. De Santis, Nunziata C. Marziano, and A. Zingales (1985), "Equilibria of Nitric Acid in Sulfuric and Perchloric Acid at $25 \mathrm{C}$ by Raman and UV Spectroscopy", Journal of Physical Chemistry, Vol. 89, No. 13, pp. 2864-2869.

Scatchard, George (1961), "Osmotic Coefficients and Activity Coefficients in Mixed Electrolyte Solutions", Journal of the American Chemical Society, Vol. 83, No. 12, pp. 2636-2642.

Scatchard, George, R.M. Rush, and J.S. Johnson (1970), "Osmotic and Activity Coefficients for Binary Mixtures of Sodium Chloride, Sodium Sulfate, Magnesium Sulfate, and Magnesium Chloride in Water at 25 C. III. Treatment with the Ions as Components", Journal of Physical Chemistry, Vol. 74, No. 21, pp. 3786-3796.

Silvester, Leonard F. and Kenneth S. Pitzer (1977), "Thermodynamics of Electrolytes. 8. HighTemperature Properties, Including Enthalpy and Heat Capacity, with Application to Sodium Chloride", Journal of Physical Chemistry, Vol. 81, No. 19, September 22, pp. 1822-1828.

Tagirov, Boris and Jacques Schott (2001), "Aluminum Speciation In Crustal Fluids Revisited", Geochimica et Cosmochimica Acta, Vol. 65, No. 21, pp. 3965-3992

Taylor, Dean D., Charles M. Barnes, and Todd T. Nichols (2002), Process Options Description for Steam Reforming Flowsheet Model of INEEL Tank Farm Waste, INEEL/EXT-02-00545, Rev. 0 , May.

Weber, Charles F. (2000), "Calculation Of Pitzer Parameters At High Ionic Strengths", Industrial \& Engineering Chemistry Research, Vol. 39, No. 11, November, pp. 4422-4426.

Weber, Charles F., Edward C. Beahm, Douglas D. Lee, and Jack S. Watson, (2000), “A Solubility Model For Aqueous Solutions Containing Sodium, Fluoride, And Phosphate Ions", Industrial \& Engineering Chemistry Research, Vol. 39, No. 2, February, pp. 518-526.

Zhang, Renyi, Paul J. Wooldridge, and Mario J. Molina (1993), "Vapor Pressure Measurements for the $\mathrm{H} 2 \mathrm{SO} 4 / \mathrm{HNO} 3 / \mathrm{H} 2 \mathrm{O}$ and $\mathrm{H} 2 \mathrm{SO} 4 / \mathrm{HCl} / \mathrm{H} 2 \mathrm{O}$ Systems: Incorporation of Stratospheric Acids into Background Sulfate Aerosols", Journal of Physical Chemistry, Vol. 97, pp. 8541-8548. 
APPENDIX A: STEAM REFORMING PROCESS STREAMS WHERE ACTIVITY COEFFICIENT MODELS MAY BE APPLICABLE 
The process design effort for steam reforming of SBW could benefit from an activity coefficient model (and supporting data) for the following solutions:

\section{SBW Mixing Tank}

Description:SBW from the TFF (1-3 tank wastes, including UDS) will be blended at $10-33^{\circ} \mathrm{C}$, ambient pressure. Precipitation may occur as a result of the instability of the resultant mixtures. Salts may form from combinations of species of interest (and minor species in feed). In addition soluble complexes of $\mathrm{F}^{-}, \mathrm{Cl}^{-}$are likely to form with specific cations (Al, $\mathrm{Zr}$ ).

Needed Information:Average concentrations of $\mathrm{H}^{+}, \mathrm{Cl}^{-}$and $\mathrm{HF}$ in tank for corrosion estimates. Also, identities and quantities of solids likely to precipitate (these may include $\mathrm{Al}, \mathrm{As}, \mathrm{Fe}, \mathrm{F}, \mathrm{Mo}, \mathrm{Na}, \mathrm{NO}_{3}$, $\mathrm{P}, \mathrm{PO}_{4}, \mathrm{SO}_{4}, \mathrm{SiO}_{2}, \mathrm{Zr}$ ) for assessment of blending scenarios and required equipment/piping sizing (blending equipment needed?)

Species of Interest:HF, $\mathrm{H}, \mathrm{Cl}, \mathrm{Al}, \mathrm{Fe}, \mathrm{F}, \mathrm{Mo}, \mathrm{Na}, \mathrm{K}, \mathrm{NO}_{3}, \mathrm{P}, \mathrm{PO}_{4}, \mathrm{SO}_{4}, \mathrm{Zr}$

\section{Feed Mixing Tank}

Description:Mix SBW and scrub purge with sugar/carbon/other reductant at $25-100^{\circ} \mathrm{C}$, ambient pressure. Vapor/liquid chemical equilibrium assumed. $\mathrm{N}_{2}, \mathrm{NO}, \mathrm{NO}_{2}, \mathrm{HNO}_{3}, \mathrm{O}_{2}, \mathrm{H}_{2} \mathrm{O}$ equilibrate chemically and phasically (gas/liquid). Gas phase chemical equilibration of $\mathrm{H}_{2}, \mathrm{CO}$, reductant with temperature dependence of equilibrium limits. Sulfate reduction to volatile forms $\left(\mathrm{H}_{2} \mathrm{SO}_{4} / \mathrm{SO}_{2} / \mathrm{SO}_{3} / \mathrm{H}_{2} \mathrm{~S}\right)$.

Needed Information:(1) Composition and temperature of gas exiting, (2) Composition and temperature of liquid exiting

Species of Interest: $\mathrm{N}_{2}, \mathrm{NO}, \mathrm{NO}_{2}, \mathrm{HNO}_{3}, \mathrm{O}_{2}, \mathrm{H}_{2} \mathrm{O}, \mathrm{H}_{2} ; \mathrm{CO}$, organic reductant; $\mathrm{H}_{2} \mathrm{SO}_{4} / \mathrm{SO}_{2} / \mathrm{SO}_{3} / \mathrm{H}_{2} \mathrm{~S}$

\section{Spray Quench}

Description: Rapidly cool a gas stream and remove a portion of entrained particulates at $100-700^{\circ} \mathrm{C}$, 5-12 psia. Vapor-liquid equilibrium and thermodynamically-limited aqueous speciation of $\mathrm{Hg}\left(\mathrm{Hg}^{\mathrm{o}}\right.$, $\mathrm{HgCl}_{2}, \mathrm{Hg}_{2} \mathrm{Cl}_{2}, \mathrm{HgCO}_{3}$ ) are assumed. Aqueous dissolution of solids from steam reformer. Acid gas capture and dissociation $\left(\mathrm{HNO}_{3}, \mathrm{H}_{2} \mathrm{SO}_{4}, \mathrm{HF}\right.$, and $\left.\mathrm{HCl}\right)$. Partitioning of $\mathrm{NO}_{2}, \mathrm{HNO}_{3}, \mathrm{CO}_{2}, \mathrm{CO}, \mathrm{Hg}$, $\mathrm{HgCl}_{2}, \mathrm{HgCl}, \mathrm{HgCO}_{3}, \mathrm{H}_{2} \mathrm{O}, \mathrm{HCl}, \mathrm{HF}, \mathrm{H}_{2} \mathrm{SO}_{4}, \mathrm{SO}_{2}, \mathrm{SO}_{3}$ between gas and aqueous phases.

Needed Information:(1) Composition and temperature of gas exiting (including mass of entrained liquid), (2) Composition and temperature of liquid exiting, (3) Composition of solids exiting in gas and liquid streams

Species of Interest: Gas $\left(\mathrm{N}_{2}, \mathrm{NO}, \mathrm{NO}_{2}, \mathrm{O}_{2}, \mathrm{CO}_{2}, \mathrm{CO}, \mathrm{H}_{2}, \mathrm{Hg}, \mathrm{H}_{2} \mathrm{~S}\right)$, near-neutral $\mathrm{pH}$ aqueous $\left(\mathrm{NO}_{3}^{-}, \mathrm{Cl}^{-}\right.$, $\mathrm{F}^{-}, \mathrm{H}^{+}, \mathrm{H}_{2} \mathrm{O}, \mathrm{SO}_{4}{ }^{-2}, \mathrm{H}_{2} \mathrm{SO}_{4}$, solids from steam reformer (alkali oxides, aluminosilicates). 


\section{Submerged Bed/Packed Bed/CausticScrubber}

Description:Cooling and/or scrubbing of gas with liquid, and separation of solids from gas at 70$100^{\circ} \mathrm{C}, 5-12$ psia. Vapor/liquid equilibrium assumed. Acid dissociation $\left(\mathrm{HNO}_{3}, \mathrm{H}_{2} \mathrm{SO}_{4}, \mathrm{HF}\right.$, and $\left.\mathrm{HCl}\right)$. Aqueous $\mathrm{Hg}$ speciation $\left(\mathrm{Hg}^{\mathrm{o}}, \mathrm{HgCl}_{2}, \mathrm{Hg}_{2} \mathrm{Cl}_{2}, \mathrm{HgCO}_{3}\right)$. Partitioning of $\mathrm{NO}_{2}, \mathrm{HNO}_{3}, \mathrm{CO}_{2}, \mathrm{CO}, \mathrm{Hg}$, $\mathrm{HgCl}_{2}, \mathrm{HgCl}, \mathrm{H}_{2} \mathrm{O}, \mathrm{HCl}, \mathrm{HF}, \mathrm{H}_{2} \mathrm{SO}_{4}, \mathrm{SO}_{2}, \mathrm{SO}_{3}$ between gas and aqueous phases. Vaporization/condensation of water.

Needed Information:(1) Composition and temperature of gas exiting, (2) Composition and temperature of liquid exiting, (3) Composition of solids exiting in liquid stream

Species of Interest:Effluent gas from upstream scrubber (could contain $\mathrm{N}_{2}, \mathrm{NO}, \mathrm{NO}_{2}, \mathrm{O}_{2}, \mathrm{CO}_{2}, \mathrm{CO}, \mathrm{H}_{2}$, $\left.\mathrm{H}_{2} \mathrm{O}, \mathrm{HCs}, \mathrm{Cl}_{2}, \mathrm{SO}_{2}, \mathrm{SO}_{3}, \mathrm{HF}, \mathrm{HCl}, \mathrm{HNO}_{3}\right)$, alkaline aqueous $\left(\mathrm{Na}^{+}, \mathrm{NO}^{-}, \mathrm{Cl}^{-}, \mathrm{F}^{-}, \mathrm{OH}^{-}, \mathrm{CO}_{3}^{-2}, \mathrm{HCO}_{3}^{-}\right.$, $\mathrm{H}_{2} \mathrm{O}, \mathrm{SO}_{3}^{-2}, \mathrm{SO}_{4}^{-2}, \mathrm{HgCl}_{2}, \mathrm{HgCl}, \mathrm{Hg}^{+2}, \mathrm{HgCO}_{3}$, cations from dissolved solids--Na, $\mathrm{K}, \mathrm{Fe}, \mathrm{Al}, \mathrm{Si}$ )

\section{High Efficiency Mist Eliminator (HEME)}

Description:Collect liquid scrub droplets remaining in offgas prior to final HEPA filtration and $\mathrm{Hg}$ removal in GAC columns. Collect some remaining solid particles from offgas at $50-175^{\circ} \mathrm{C}, 5-12$ psia. Vapor/liquid equilibrium assumed. Acid dissociation $\left(\mathrm{HNO}_{3}, \mathrm{H}_{2} \mathrm{SO}_{4}, \mathrm{HF}\right.$, and $\left.\mathrm{HCl}\right)$. Aqueous $\mathrm{Hg}$ speciation $\left(\mathrm{Hg}^{\mathrm{o}}, \mathrm{HgCl}_{2}, \mathrm{HgCl}, \mathrm{HgCO}_{3}\right)$. Partitioning of $\mathrm{NO}_{2}, \mathrm{HNO}_{3}, \mathrm{CO}_{2}, \mathrm{CO}, \mathrm{Hg}, \mathrm{HgCl}_{2}, \mathrm{HgCl}, \mathrm{H}_{2} \mathrm{O}$, $\mathrm{HCl}, \mathrm{HF}, \mathrm{H}_{2} \mathrm{SO}_{4}, \mathrm{SO}_{2}, \mathrm{SO}_{3}$ between gas and aqueous phases. Vaporization/condensation of water

Needed Information:(1) Composition of gas exiting (including entrained liquid and solids),

(2) Composition of liquid exiting, (3) Composition of solids exiting liquid stream

Species of Interest:(see 'Submerged Bed/Packed Bed/CausticScrubber', above)

\section{Evaporator/Salt Dryer}

Description:Remove part or all $\mathrm{H} 2 \mathrm{O}$ from SBW feed or scrubber blowdown by evaporation to gas phase at $25-150^{\circ} \mathrm{C}, 10-12 \mathrm{psia}$. Gas/liquid/solid equilibrium assumed. Evaporation of water from evaporator feed. Partitioning of $\mathrm{NO}_{2}, \mathrm{CO}_{2}, \mathrm{Hg}, \mathrm{HNO}_{3}, \mathrm{HCl}, \mathrm{HF}, \mathrm{H}_{2} \mathrm{O}, \mathrm{H}_{2} \mathrm{SO}_{4}, \mathrm{Hg}, \mathrm{HgCl}_{2}, \mathrm{H}_{2} \mathrm{BO}_{3}$, and acid salts between evaporator bottoms and overheads. Precipitation of nitrate, sulfate, chloride, fluoride, phosphate salts. Scaling deposits of $\mathrm{CaCO}_{3}, \mathrm{SiO}_{2}$. Soluble complexes of $\mathrm{F}^{-}$and $\mathrm{Cl}^{-}$with $\mathrm{Al}^{+3}, \mathrm{Cr}^{+3}, \mathrm{Fe}^{+3}, \mathrm{Zr}^{+4}, \mathrm{H}_{2} \mathrm{BO}_{3}$.

Needed Information:(1) Gas (overheads) exit composition, flow rate, and temperature, (2) Bottoms (liquid or solid) exit composition, flow rate, and temperature, (3) Presence or absence of solid precipitates (including scaling deposits), (4) Composition of solids leaving with bottoms.

Species of Interest: $\mathrm{Gas}\left(\mathrm{N}_{2}, \mathrm{NO}, \mathrm{NO}_{2}, \mathrm{O}_{2}, \mathrm{CO}_{2}, \mathrm{CO}, \mathrm{H}_{2}, \mathrm{Hg}, \mathrm{HgCl}_{2}, \mathrm{HCl}, \mathrm{H}_{2} \mathrm{SO}_{4}, \mathrm{HF}, \mathrm{NO}_{\mathrm{x}}\right)$, aqueous $\left(\mathrm{NO}_{3}^{-}, \mathrm{NO}_{2}^{-}, \mathrm{Cl}^{-}, \mathrm{F}^{-}, \mathrm{H}^{+}, \mathrm{H}_{2} \mathrm{O}, \mathrm{SO}_{4}^{-2}, \mathrm{Hg}^{\mathrm{o}}, \mathrm{Hg}^{+2}, \mathrm{HgCl}_{2}\right.$, cations from dissolved solids in feed), solid (UDS in feed, scaling deposits $\left[\mathrm{CaCO}_{3}, \mathrm{SiO}_{2}\right]$, precipitates formed by over concentration of the feed), solids (UDS in entering liquid) 


\section{Acid Fractionator (Distillation Column)}

Description: Recover $\mathrm{HNO}_{3}$ from evaporator overheads at $90-115^{\circ} \mathrm{C}, 10-12$ psia. Assume vapor/liquid equilibrium.

Needed Information:(1) Gas composition after extraction of $\mathrm{HNO}_{3}$ and other acid gases, (2) Liquid composition after extraction.

Species of Interest: $\mathrm{HNO}_{3}, \mathrm{HCl}, \mathrm{HF}, \mathrm{H}_{2} \mathrm{O}, \mathrm{Hg}, \mathrm{HgCl}_{2}, \mathrm{HgCO}_{3}, \mathrm{H}_{2} \mathrm{SO}_{4}, \mathrm{SO}_{2}, \mathrm{SO}_{3}$ 
APPENDIX B: VALUES OF PITZER PARAMETERS AND EQUILIBRIUM CONSTANTS 
Table B1. ASPEN Plus Default Pitzer Parameter Values At $25^{\circ} \mathrm{C}$.

\begin{tabular}{|l|l|l|l|}
\hline Aqueous Electrolyte & $\beta^{(0)}$ & $\beta^{(1)}$ & $\mathrm{C}^{\phi}$ \\
\hline $\mathrm{HCl}$ & 0.1775 & 0.2945 & 0.0008 \\
\hline $\mathrm{NaCl}$ & 0.0765 & 0.2664 & 0.00127 \\
\hline $\mathrm{KCl}$ & 0.04835 & 0.2122 & -0.00084 \\
\hline $\mathrm{NaOH}$ & 0.0864 & 0.253 & 0.0044 \\
\hline $\mathrm{KOH}$ & 0.1298 & 0.32 & 0.0041 \\
\hline $\mathrm{HF}$ & 0.045861 & -7.41684 & -0.00294 \\
\hline $\mathrm{HNO} 3$ & 0.1119 & 0.3206 & 0.001 \\
\hline $\mathrm{H} 2 \mathrm{SO} 4(\mathrm{H}+, \mathrm{SO} 4-2)$ & 0 & 0 & 0 \\
$\mathrm{H} 2 \mathrm{SO} 4(\mathrm{H}+, \mathrm{HSO} 4-)$ & 0 & 0 & 0 \\
\hline
\end{tabular}

ASPEN Plus v. 11.1 does not have $\theta$ and $\psi$ values in its databank - they are set to zero by default (Aspen Technology, 2001). The default parameter values for $\beta^{(0)}, \beta^{(1)}$, and $C^{\phi}$ are obtained from the Tools|Retrieve Parameter Results menu item.

Table B2. Recommended Pitzer Parameter and Equilibrium Constant Values At $25^{\circ} \mathrm{C}$.

\begin{tabular}{|c|c|c|c|c|c|}
\hline & \multicolumn{2}{|c|}{ Binaries } & $\theta$ & $\psi$ & $\operatorname{Ln}(\mathrm{K})$ \\
\hline $\begin{array}{l}\text { ASPEN Plus Defaults } \\
\text { (See Table B1) }\end{array}$ & \multicolumn{2}{|l|}{$\mathrm{HCl}(\mathrm{m} \leq 6)$} & & & \\
\hline Pitzer et al. (1977) & & & & & $\mathrm{H}_{2} \mathrm{SO}_{4}\left(\mathrm{~K}_{\mathrm{D} 2}\right):-4.55638$ \\
\hline Pitzer (1991, Ch. 3) & & $\begin{array}{l}\mathrm{H}, \mathrm{Na}=0.036 \\
\mathrm{~K}, \mathrm{Na}=-0.012 \\
\mathrm{~K}, \mathrm{H}=0.005 \\
\mathrm{Cl}, \mathrm{OH}=-0.050 \\
\mathrm{NO}, \mathrm{Cl}=0.016\end{array}$ & $\begin{array}{l}\mathrm{H}, \mathrm{Na}, \mathrm{Cl}=-0.004 \\
\mathrm{~K}, \mathrm{Na}, \mathrm{Cl}=-0.0018 \\
\mathrm{Cl}, \mathrm{OH}, \mathrm{Na}=-0.006 \\
\mathrm{NO} 3, \mathrm{Cl}, \mathrm{Na}=-0.006\end{array}$ & \\
\hline Weber (2000) & $\begin{array}{l}\frac{\mathrm{NaCl}}{\beta^{(0)}=0.06743} \\
\beta^{(1)}=0.3301 \\
C^{\phi}=0.00263\end{array}$ & $\begin{array}{l}\frac{\mathrm{KCl}}{\beta^{(0)}}=0.05957 \\
\beta^{(1)}=0.1782 \\
C^{\phi}=-0.00433\end{array}$ & & $\begin{array}{l}\mathrm{K}, \mathrm{H}, \mathrm{Cl}=-0.01099 \\
\mathrm{Cl}, \mathrm{OH}, \mathrm{K}=-0.00317\end{array}$ & $\begin{array}{l}\mathrm{NaCl}\left(\mathrm{K}_{\text {sp }}\right): 3.6155 \\
\mathrm{KCl}\left(\mathrm{K}_{\mathrm{sp}}\right): 2.0148\end{array}$ \\
\hline Davis \& de Bruin (1964) & & & & & $\mathrm{HNO}_{3}\left(\mathrm{~K}_{\mathrm{D}}\right): 2.93386$ \\
\hline \multirow{5}{*}{ This Work } & \multicolumn{2}{|l|}{$\begin{array}{l}\frac{\mathrm{HCl}(6<\mathrm{m} \leq 16)}{\beta^{(0)}=0.203486} \\
\beta^{(1)}=0.1516 \\
\mathrm{C}^{\phi}=-0.003646\end{array}$} & & & \\
\hline & \multicolumn{2}{|c|}{$\mathrm{H}_{2} \mathrm{SO}_{4}(\mathrm{~m} \leq 20)$} & & & \\
\hline & $\begin{array}{l}\mathrm{H}^{+}, \mathrm{HSO}_{4}^{-} \\
\beta^{(0)}=0.233741 \\
\beta^{(1)}=0.57387 \\
\mathrm{C}^{\phi}=-0.004693\end{array}$ & $\begin{array}{l}\mathrm{H}^{+}, \mathrm{SO}_{4}{ }^{-2} \\
\beta^{(0)}=0.075952 \\
\beta^{(1)}=0.102569 \\
C^{\phi}=0.003188\end{array}$ & & & \\
\hline & \multicolumn{2}{|c|}{$\mathrm{HNO}_{3}(\mathrm{~m} \leq 12)$} & & & \\
\hline & $\begin{array}{l}\mathrm{H}^{+}, \mathrm{NO}_{3} \\
\beta^{(0)}=0.146672 \\
\beta^{(1)}=0.199341 \\
\mathrm{C}^{\phi}=-0.003046\end{array}$ & $\begin{array}{l}\mathrm{HNO}_{3}, \mathrm{H}^{+} \\
\beta^{(1)}=0.186837 \\
\underline{\mathrm{HNO}}_{3}, \mathrm{NO}_{3}{ }^{-} \\
\beta^{(0)}=0.119983\end{array}$ & & & \\
\hline
\end{tabular}


APPENDIX C: REGRESSION PROGRAM TO OBTAIN PITZER PARAMETERS 


\section{Introduction}

Application of Pitzer's model to calculate activity coefficients of species in an aqueous solution requires input of adjustable interaction parameters between the species in the solution. Typically these parameters are obtained by regressing model predictions against corresponding measured quantities. AspenPlus includes a regression capability for this purpose; however, as currently configured this capability assumes that all electrolyte species are fully dissociated and does not allow for species partitioning into both associated and dissociated species. In addition to this limitation, errors have been identified in the AspenPlus implementation of the Pitzer model (see discussion in the main text of this report). For these reasons a different regression program was needed to continue the current effort to improve models used at the INEEL for design of SBW treatment processes. Hence, the regression program described herein was developed.

At the time the idea for an in-house regression program was conceived the authors were engaged in finding suitable parameters for the Pitzer model to predict the degree of dissociation during the second ionization of $\mathrm{H}_{2} \mathrm{SO}_{4}$ and during the single dissociation of $\mathrm{HNO}_{3}$, both in aqueous solution. Therefore, initial development of the tool was focused on this immediate need. The first version of the program was therefore intended as a proof-of-principle exercise, tailored to obtaining Pitzer parameters for the two acids. However, the program has been designed on a conceptual framework that is amenable to generalization so that regression of Pitzer parameters for multiple species against a variety of empirical data can also be handled after appropriate modifications to the program.

\section{Conceptual Framework}

\section{High Level Framework}

All aqueous solutions incorporate the potential to drive the component species toward a condition of minimal Gibbs free energy. Thus, species in solution react with one another in such a way as to generate those chemical species and concentrations whose aggregate free energy is minimal, given the set of all species and concentrations which could be produced from those initially present. In design of chemical processes it is therefore helpful to be able to predict the composition target toward which the solution progresses in time. Free energies of any mixture can be calculated using well-established thermodynamic methods if the identities and activities of the mixture components are known. The activity of a chemical specie, $i$, is usually expressed as the product of its activity coefficient $\left(\gamma_{i}\right)$ and its concentration $\left(\mathrm{m}_{\mathrm{i}}\right)$ in the mixture. (While the choice of a method for expressing specie concentration is arbitrary, current conventions generally use either mole fraction (dimensionless) or molality (moles/kg solvent). Since most published data use the latter convention, it is assumed here.) If the activity coefficients of all possible species are known (or can be calculated from the mixture composition) then the free energy can be calculated for an arbitrary mixture composition. Thus, a calculational model can be devised to predict, apriori, the equilibrium composition of the mixture, if the initial composition is specified. This is the principal objective of aqueous thermodynamic modeling in the current development effort. The Pitzer model offers the capability of calculating the activity coefficients of all species in a solution and thus provides the key step mentioned above for this modeling.

However, the Pitzer model cannot be applied until a set of empirically-determined species interaction parameters have been specified. Descriptions of these parameters and details of the Pitzer model are discussed in a variety of sources (see, for example Pitzer $(1973,1991))$. Details of the model are not provided here, since the objective is simply to describe the regression program developed to obtain the parameters. It suffices here to note that the activity coefficients of species in solution are primary determinants in the partitioning of the species among the possible products of reaction. In addition, 
they also determine the species partitioning between phases (liquid, gas, and solid). Therefore, knowledge of the activity coefficients allows one to predict the direction and final destination of all chemical species in a given mixture.

If the activity coefficients are not known, but measurements are available which describe the partitioning of the chemical species in solution, then the activity coefficients can (in principle) be determined by inverse reasoning. Alternatively, the parameters in the Pitzer model can be estimated by fitting the partitioning behavior predicted by the model to what is observed. This is the task that the regression program described here is designed to accomplish. Experimental partitioning measurements (or mathematical entities derived from such measurements) which are typically reported in the literature, include mean stoichiometric activity coefficients, phase equilibrium data (liquid/liquid, solid/liquid, vapor/liquid), chemical equilibrium data, salt solubilities, freezing point depression, osmotic coefficients, and electrochemical potentials. All these types of information can be used to estimate Pitzer parameters. The current version of the regression program, however, uses only stoichiometric activity coefficients and/or chemical equilibrium data (i.e., extent of dissociation of an electrolyte).

While the program is directed primarily at obtaining values for the adjustable parameters in Pitzer's model for activity coefficients the program framework will also handle regression of other parameters, notably equilibrium constants for the reactions involved. Therefore, in the discussion which follows the term "Pitzer parameters" can include other parameters in addition to interaction parameters for Pitzer's model.

\section{Mathematical Formalism}

In the discussion which follows the following notation is used (bold face indicates vector quantities):

$\mathbf{Y}=$ Vector of empirically determinable variables which depend on activity coefficients and for which values are available for use in regressing Pitzer parameters (e.g., stoichiometric activity coefficient $\left[\gamma_{ \pm, s t}\right]$ of an electolyte in aqueous solution)

$\mathbf{X}=$ Vector of independent variables corresponding to the measured variables in $\mathbf{Y}$ (e.g., initial stoichiometric concentration of the electrolyte in the solution)

$\mathbf{P}=$ Vector of Pitzer parameters for the species in solution (some or all of which are to be determined by regression; e.g., $\left.\beta^{(0)}{ }_{\mathrm{ij}}, \beta^{(1)}{ }_{\mathrm{ij}}, \mathrm{C}^{\varphi}\right)$

$\gamma=$ Vector of activity coefficients for the chemical species in solution

$\mathbf{m}=$ Vector of concentrations (molalities $\equiv$ mols $/ \mathrm{kg}$ solvent) of the chemical species in the solution.

$\gamma_{ \pm, \text {st }}=$ Stoichiometric activity coefficient of an electrolyte in solution, molality basis

$\varphi(\mathbf{P})=$ Objective function minimized in regression of Pitzer parameters

$v \quad=$ Stoichiometric coefficient of a specie participating in a reaction

I $=$ Ionic strength of solution, molality basis

The Pitzer model provides an explicit function $\mathrm{f}$ that can be used to calculate the activity coefficients of the components of an aqueous mixture if their concentrations (m) are known:

$\gamma=f(\mathbf{P}, \mathbf{m})$

As noted above, thermodynamic equilibrium dictates which chemical species will be present and their concentrations in the final solution based on minimization of the Gibbs free energy $(\mathrm{G})$ of the solution. 
Minimization of $\mathrm{G}$ can be represented mathematically in a variety of ways. Here, it is represented by a set of reaction equations with corresponding equilibrium constants determined from the change in free energy between reactants and products in their standard states. These constants impose constraints on the final species concentrations of the form:

$g\left(\mathbf{m}, \gamma, \mathbf{K}, \mathbf{m}_{\mathbf{0}}\right)=\mathbf{0}$

where $\mathbf{K}$ is the vector of equilibrium constants representing all the reactions that can occur in the solution and $\mathbf{m}_{\mathrm{o}}$ is the vector of initial species concentrations in the mixture. This equation implicitly implies a relation of the form:

$\mathbf{m}=\boldsymbol{h}\left(\boldsymbol{\gamma}, \mathbf{K}, \mathbf{m}_{\mathbf{0}}\right)$

Substituting this in Eq. 1) above yields:

$\gamma=f\left(\mathbf{P}, \boldsymbol{h}\left(\boldsymbol{\gamma}, \mathbf{K}, \mathbf{m}_{\mathbf{o}}\right)\right)$

which, in turn, implicitly implies the functional relation:

$\gamma=f f\left(\mathbf{P}, \mathbf{K}, \mathbf{m}_{\mathbf{0}}\right)$

With the above functional relation between $\boldsymbol{\gamma}$ and $\left(\mathbf{P}, \mathbf{K}\right.$, and $\left.\mathbf{m}_{\mathbf{0}}\right)$ theoretical predictions can be made for the variables represented by $\mathbf{Y}$ based on the corresponding known values of the independent variable(s) in $\mathbf{X}$. Mathematically, we represent these theoretical values as follows:

$\mathbf{Y}_{\text {calc }}=\boldsymbol{F}(\boldsymbol{\gamma}, \mathbf{X})=\boldsymbol{F F}(\mathbf{P}, \mathbf{K}, \mathbf{X})$

Here we have assumed that $\mathbf{m}_{\mathbf{0}}$ is included in $\mathbf{X}$. Finally the values in $\mathbf{Y}_{\text {calc }}$ can be compared with the measured values of the corresponding variables, and a least-squares objective function can be defined as follows:

$\varphi=\sum_{i=1}^{N p t s}\left[w_{i}\left(Y_{i, \text { calc }}-Y_{i, \text { meas }}\right)^{2}\right]$

where:

Npts $=$ number of data points used in regressing the Pitzer parameters

$\mathrm{w}_{\mathrm{i}}=$ positive weight factors for the $\mathrm{i}^{\text {th }}$ data point such that

$\sum_{i=1}^{N p t s} w_{i}=1.0$

From Eq. 6), $\mathbf{Y}_{\text {calc }}$ may be regarded in the regression as a function of $\mathbf{P}$ only, since $\mathbf{X}$ and $\mathbf{K}$ both contain only data values and equilibrium constants which do not change during the regression (any equilibrium constants that are to be regressed are included in $\mathbf{P}$ ). Since the $Y_{i, \text { meas }}$ are also constant data values the objective function, $\varphi$, can also be regarded as a function of $\mathbf{P}$ only. Estimates for the Pitzer parameters, $\mathbf{P}$, are now obtained bu minimizing $\varphi$. The resulting parameters are then considered acceptable for use in the Pitzer model to predict activity coefficients for the relevant species in arbitrary aqueous solutions. 


\section{Implementation}

\section{Programming Environment}

To implement the above formalism, Visual Basic (VB) for Applications contained within Microsoft Excel was selected. The reasons for this choice are as follows:

(1) Excel spreadsheets provide a convenient means of tabulating, documenting, storing, and retrieving data. In addition, the spreadsheet utilities provide powerful tools for pre- and post-processing of numerical data.

(2) Excel's VB interactive development environment (IDE) provides a seamless interface between Excel spreadsheets and VB code.

(3) The VB implementation in Excel provides high-level functions and a programming environment which facilitate rapid development and debugging of usable code.

One drawback of using Excel VB is that the execution speed is lower than with a fully compiled language such as $\mathrm{C}++$ or Fortran. However, the advantages listed above outweigh this drawback for the present time.

\section{Regression Method}

As previously noted, the first version of the regression program is not fully general; rather, it was designed as a "proof of principle" exercise which targets regression of Pitzer parameters for $\mathrm{H}_{2} \mathrm{SO}_{4}$, assuming dissociation of $\mathrm{H}_{2} \mathrm{SO}_{4}$ to $\mathrm{H}^{+}$and $\mathrm{HSO}_{4}^{-}$, and partial dissociation of $\mathrm{HSO}_{4}^{-}$to $\mathrm{H}^{+}$and $\mathrm{SO}_{4}{ }^{-2}$. Thus, the current code allows only two types of experimental variables in $\mathbf{Y}$, namely, stoichiometric activity coefficient data and degree of dissociation data, corresponding to the types of data that were used to regress Pitzer coefficients for $\mathrm{H}_{2} \mathrm{SO}_{4}$. In addition, in the first code version only one reaction among the species in solution was considered (again corresponding to the $\mathrm{H}_{2} \mathrm{SO}_{4}$ case, where it is assumed that $\mathrm{H}^{+}, \mathrm{SO}_{4}{ }^{-2}$, and $\mathrm{HSO}_{4}{ }^{-}$are the initial [and only] reactants in the aqueous mixture. Dissociation of the water solvent was neglected, as it contributes very little to the $\mathrm{H}^{+}$concentration in strong acid solutions). However, generalization to an arbitrary number of reactions among the initial species will easily fit into the structure created for a single reaction.

Given the focus on single dissociation of an acid electrolyte, the regression of the Pitzer parameters proceeds as follows. First, the user provides the following inputs in a single spreadsheet:

(1) The dissociation reaction, specifying the identities of the species, their ionic charges (0 for molecular or neutral aggregates), and their stoichiometric coefficients;

(2) Initial values for all required parameters in the Pitzer model (including the equilibrium constant for the dissociation reaction). In the current program the Pitzer equations are truncated after the second virial terms, so only $\beta^{(0)}{ }_{\mathrm{ij}}, \beta^{(1)}{ }_{\mathrm{ij}}$, and $\mathrm{C}^{\varphi}$ are required;

(3) Specification of which of the input parameters are to be considered known (and therefore fixed during the regression) and which are to be regressed against the data;

(4) Tabulations of the $\mathbf{X}$ and $\mathbf{Y}$ vectors (components of $\mathbf{X}$ are presently assumed to be stoichiometric molalities of the dissociating electrolyte and components of $\mathbf{Y}$ are the measured stoichiometric activity coefficients and/or degrees of dissocation corresponding to the $\mathbf{X}$ values);

(5) Program control parameters (e.g., convergence criterion and maximum number of iterations for the regression, etc.). 
The program reads the input data and then gives the user the option to perform a "coarse search" for starting values of the regression parameters (this is further discussed below). Following this an optimized search is performed for values of the regression parameters which minimize the objective function, $\varphi$. The searching algorithm is based on Powell's quadratically convergent direction set method described in Press et al. (1986, pg. 297). The method searches for a relative minimum of a single-valued function ( $\mathrm{f}$ ) of $\mathrm{N}$ variables $\left(\mathrm{x}_{1}, \ldots, \mathrm{x}_{\mathrm{N}}\right)$. For the regression the function $\mathrm{f}$ is replaced by $\varphi$ and the independent variables $\mathrm{x}_{1}, \ldots, \mathrm{x}_{\mathrm{N}}$ become the Pitzer parameters to be regressed. Thus, the searching algorithm searches for a point $\mathbf{P}$ in $\mathrm{N}$-space which is a local minimum for $\varphi$.

The search begins at the point $\mathbf{P}_{0}$ corresponding to the beginning guesses, $\left(\mathrm{P}_{10}, \ldots, \mathrm{P}_{\mathrm{N} 0}\right)$ for the Pitzer parameters. A complete set of basis vectors in $\mathrm{N}$-space is selected and successive one-dimensional (1D) searches for minima of $\varphi$ are performed in the directions specified by these vectors. After each 1D search the point $\mathbf{P}$ is moved in the search direction to the point corresponding to the $1 \mathrm{D}$ minimum. Brent's method (Press et al., 1986, pg. 284) is used to perform these 1D searches. The basis vectors are altered after each search iteration so as to achieve quadratic convergence to the local minimum. In addition they are periodically reset to ensure linear independence is maintained. In essence, the search "walks downhill" toward a minimum for $\varphi$ and terminates when the change in each of the $\mathrm{N}$ variables is below a specified convergence value.

\section{Calculational Sequence}

The sequence of calculations is as follows:

Input processing. The required user inputs described in the preceding section are read from an Excel spreadsheet and stored in appropriate arrays. Flags are set to indicate which of the input Pitzer parameters are to be considered constant and which are to be regressed (i.e., numbered among the $\mathrm{N}$ independent variables of $\varphi$, described above). Iteration counters are initialized.

Coarse search. Next the option of performing a coarse search is offered. If the user opts for this the program reads user-supplied information describing a region of $\mathrm{N}$-space to be searched. This region is geometrically centered on the point $\mathbf{P}_{0}$, described by the user's initial guesses for the regression parameters. An N-dimensional geometrical mesh is then set up. The values of the $\mathrm{N}$ parameters at each point in the mesh differ from those at $\mathbf{P}_{0}$ by a geometric factor specified by the user. For example, for each regression parameter, $\mathrm{P}_{\mathrm{i}}$, the user provides a geometric factor, $\mathrm{c}_{\mathrm{i}}$, and specifies the number of points, $n_{i}$, to be searched on both sides of $\mathbf{P}_{0}$. If $P_{i 0}$ is the initial guess for $P_{i}$ then $2 n_{i}+1$ values of $\mathrm{P}_{\mathrm{i}}$ are included in the search mesh as follows:

$$
\begin{aligned}
& \mathrm{P}_{i 0} \cdot\left(\mathrm{c}_{\mathrm{i}}\right)^{-\mathrm{ni}} \\
& \mathrm{P}_{\mathrm{i} 0} \cdot\left(\mathrm{c}_{\mathrm{i}}\right)^{-(\mathrm{ni}-1)} \\
& \ldots \\
& \mathrm{P}_{\mathrm{i} 0} \cdot\left(\mathrm{c}_{\mathrm{i}}\right)^{-1} \\
& \mathrm{P}_{\mathrm{i} 0} \\
& \mathrm{P}_{\mathrm{i} 0} \cdot\left(\mathrm{c}_{\mathrm{i}}\right)^{+1} \\
& \ldots \\
& \mathrm{P}_{\mathrm{i} 0} \cdot\left(\mathrm{c}_{\mathrm{i}}\right)^{+(\mathrm{ni}-1)} \\
& \mathrm{P}_{\mathrm{i} 0} \cdot\left(\mathrm{c}_{\mathrm{i}}\right)^{+\mathrm{ni}}
\end{aligned}
$$

For example, if $\mathrm{c}_{\mathrm{i}}=10$ and $\mathrm{n}_{\mathrm{i}}=3$ the search mesh would include $0.01 \mathrm{x}\left(\mathrm{P}_{\mathrm{i} 0}\right), 0.1 \mathrm{x}\left(\mathrm{P}_{\mathrm{i} 0}\right), 1 \mathrm{x}\left(\mathrm{P}_{\mathrm{i} 0}\right), 10 \mathrm{x}\left(\mathrm{P}_{\mathrm{i} 0}\right)$, and $100 \mathrm{x}\left(\mathrm{P}_{\mathrm{i} 0}\right)$.

Similar values of the other N-1 regression parameters are also determined from user inputs. Thus, in all the mesh will contain $\left(2 \mathrm{n}_{1}+1\right)\left(2 \mathrm{n}_{2}+1\right) \ldots\left(2 \mathrm{n}_{\mathrm{N}}+1\right)$ points in $\mathrm{N}$-space that will be searched. At each of these points the value of $\varphi$ is calculated and the point in the mesh which gives the smallest $\varphi$ is 
retained as the starting point for the formal regression procedure described above. This coarse search is often necessary since the regression procedure only isolates relative minima. The nature of the function $\varphi$ is such that there are many local minima and the coarse search is useful in locating the region in $\mathrm{N}$-space where the absolute minimum for $\varphi$ will likely be found. The coarse search may be repeated in case the minimum point turns out to be on one of the boundaries of the search region, suggesting that further minimization of $\varphi$ may result by shifting the region.

Regression. Once a suitable starting point is defined the user then bypasses the coarse search and the Powell's method regression is performed, as described above. The method typically requires many evaluations of the function $\varphi$ enroute to finding a local minimum. The manner in which $\varphi$ is calculated is described next.

Objective function evaluation $(\varphi)$. As noted above, $\varphi$ is a weighted sum-of-squares of differences between the theoretical calculations (contained in $\mathbf{Y}_{\text {calc }}$ and based on the current values in $\mathbf{P}$ ) and experimental measurements (contained in $\mathbf{Y}_{\text {meas }}$ ). The sum-of-squares calculation is straightforward once the vector $\mathbf{Y}_{\text {calc }}$ has been obtained. In the current version of the program, only two types of $Y$ variables are calculated, namely $\gamma_{ \pm \text {st }}$ and $\varepsilon=$ (extent of dissociation of electrolyte). The calculation sequence used to obtain these is as follows:

Step 1: Initialize $\boldsymbol{\gamma}$ to $\mathbf{1}$ and $\mathbf{m}$ to $\mathbf{0}$. Then set $\mathrm{m}_{1}=\mathrm{m}_{10}\left(\mathrm{~m}_{1}=\right.$ concentration of the dissociating electrolyte, $\mathrm{m}_{10}=$ initial stoichiometric concentration), and set $\mathrm{m}_{\mathrm{H}+}=\mathrm{p} \cdot \mathrm{m}_{10}$, where $\mathrm{p}$ is the protonicity (number of hydrogen atoms) in the undissociated electrolyte. In the first version of the program (p-1) of these hydrogens are presumed to dissociate completely. The final dissociation is assumed to be partial. (For example, for $\mathrm{H}_{2} \mathrm{SO}_{4}, \mathrm{p}=2$ and $\mathrm{H}_{2} \mathrm{SO}_{4}$ is presumed to dissociate completely to $\mathrm{HSO}_{4}{ }^{-}$and $\mathrm{H}^{+}$giving a pre-equilibration concentration of $\mathrm{HSO}_{4}{ }^{-}$ and $\mathrm{H}^{+}$equal to the initial stoichiometric concentration of $\mathrm{H}_{2} \mathrm{SO}_{4}$. The second dissociation of $\mathrm{HSO}_{4}^{-}$to $\mathrm{H}^{+}$and $\mathrm{SO}_{4}^{-2}$ is partial and is the reaction of interest for the regression.)

Calculate the ionic strength, I, and the ionic strength-dependent coefficients in the Furst/Renon version of the Pitzer model equation for activity coefficients (See Equation 5 of Aspen Technology (2001)). For the first version of the program only the Debye-Huckel term and the B, B', and $\mathrm{C}$ terms in the equation were considered. The $\theta$ and $\psi$ terms may be added later):

$$
\begin{aligned}
& B_{i j}=\beta_{i j}^{(0)}+\frac{2 \beta_{i j}^{(0)}}{\alpha_{1}^{2} I}\left[1-\left(1+\alpha_{1} I^{1 / 2}\right) e^{-\alpha_{1} I^{1 / 2}}\right] \\
& B_{i j}^{\prime}=\frac{2 \beta_{i j}^{(1)}}{4 I^{2}}\left[-1+\left(1+2 I^{1 / 2}+2 I\right) e^{-2 I^{1 / 2}}\right] \\
& C_{i j}=\frac{C_{i j}^{\varphi}}{2\left|z_{i} z_{j}\right|^{1 / 2}}
\end{aligned}
$$

where:

$$
\begin{aligned}
\beta^{(0)}, \beta^{(1)}= & \text { Pitzer parameters for the } 2^{\text {nd }} \text { virial coefficients in the equation for excess Gibbs } \\
& \text { free energy, } \mathrm{G}^{\text {ex }} \\
C^{\varphi}= & \text { Pitzer parameter for the } 3^{\text {rd }} \text { virial coefficient } \\
\mathrm{Z}_{\mathrm{i}}= & \text { ionic charge on the } \mathrm{i}^{\text {th }} \text { specie } \\
\alpha_{1}= & 2(\mathrm{~kg} / \mathrm{mol})^{1 / 2}
\end{aligned}
$$


Step 2: Store the current estimates for $\boldsymbol{\gamma}$ and $\mathbf{m}$ for use in determining convergence of the iterative calculation in Steps 2-5. Calculate the extent of reaction, $x$, by solving the non-linear equilibrium equation:

$$
\ln (K)=\ln \left[\prod_{i=1}^{N \text { spec }}\left(\gamma_{i} m_{i}\right)^{v_{i}}\right]=\sum_{i=1}^{N \text { spec }} v_{i} \ln \left[\gamma_{i}\left(m_{i 0}+v_{i} x\right)\right]
$$

where:

$$
\begin{aligned}
\mathrm{x}= & \begin{array}{l}
\text { moles of electrolyte which react (i.e., dissociate) as reaction proceeds to } \\
\text { equilibrium }
\end{array} \\
v_{\mathrm{i}}= & \text { stoichiometric coefficient of specie } \mathrm{i} \text { in the reaction (positive for products, } \\
& \text { negative for reactants) } \\
= & \text { moles of specie produced/consumed per mole of electrolyte which reacts } \\
\mathrm{m}_{\mathrm{i}}= & \text { final concentration of specie } \mathrm{i} \text { at equilibrium } \\
\mathrm{m}_{\mathrm{i} 0}= & \text { initial concentration of specie } \mathrm{i} \\
\text { Nspec }= & \text { total number of solute species (ionic and molecular) in the solution }
\end{aligned}
$$

In solving for $\mathrm{x}$ the current estimated values for the $\gamma_{\mathrm{i}}$ are used. Once the value of $\mathrm{x}$ is known, the current estimates for the $m_{i}$ are updated to $\left(m_{i 0}+v_{i} x\right)$, and the dimensionless extent of dissociation, $\varepsilon$, is calculated from:

$$
\varepsilon=\frac{x}{m_{10}}
$$

Step 3: Recalculate I and the B, B', and C coefficients in the Furst/Renon equation using the updated estimate for $\mathbf{m}$.

Step 4: Recalculate the activity coefficients, $\gamma$, using the updated estimate for $\mathbf{m}$ in the Furst/Renon equation:

$$
\begin{aligned}
& \ln \left(\gamma_{i}\right)=\frac{1}{2} z_{i}^{2} f^{\prime}+2 \sum_{j} m_{j} B_{i j}+\frac{1}{2} z_{i}^{2} \sum_{j} \sum_{k} B_{j k}^{\prime} m_{j} m_{k}+\frac{1}{2}\left|z_{i}\right| \sum_{j} \sum_{k} C_{j k} m_{j} m_{k} \\
& +\left(\sum_{k} m_{k}\left|z_{k}\right|\right) \sum_{j} C_{i j} m_{j}
\end{aligned}
$$

where:

$\mathrm{f}^{\prime}(\mathrm{I}) \quad=$ Debye-Huckel term, given by

$$
f^{\prime}(I)=\frac{d f}{d I}=-2 A_{\varphi}\left[\frac{I^{1 / 2}}{\left(1+b I^{1 / 2}\right)}+\frac{2}{b} \ln \left(1+b I^{1 / 2}\right)\right]
$$

where:

$$
\begin{array}{ll}
\mathrm{A}_{\varphi} & =\text { Debye-Huckel constant }\left[0.391(\mathrm{~kg} / \mathrm{mol})^{1 / 2}\right] \\
\mathrm{b} & =1.2(\mathrm{~kg} / \mathrm{mol})^{1 / 2}
\end{array}
$$


Step 5: Calculate fractional changes in $\gamma$ and $\mathbf{m}$ that have occurred since the start of Step 2 and compare these with the user-input convergence criterion to determine whether the iterative determination of $\varepsilon, \gamma$, and $\mathbf{m}$ has converged.

Step 6: If $\varepsilon, \boldsymbol{\gamma}$, and $\mathbf{m}$ are not converged then go to Step 2. Otherwise go to Step 7 .

Step 7: Repeat Steps 1-6 for each data point input by the user. Then, using $\boldsymbol{\gamma}$ and $\varepsilon$ determined from each point, calculate the entries in the $\mathbf{Y}$ vector. In the first version of the program these entries are either the $\varepsilon$ which was calculated in Step 2, or the stoichiometric activity coefficient, calculated as follows:

$$
\begin{array}{ll}
\gamma_{ \pm, s t}=\left[\frac{\gamma_{2} m_{2} \gamma_{3} m_{3}}{m_{10}^{2}}\right]^{1 / 2} \quad(\text { for } \mathrm{p}=1) \\
\gamma_{ \pm, s t}=\left[\frac{\gamma_{2}^{2} m_{2}^{2} \gamma_{3} m_{3}}{4 m_{10}^{3}}\right]^{1 / 3} \quad(\text { for } \mathrm{p}=2)
\end{array}
$$

where:

()$_{1}=$ value for neutral electrolyte prior to all dissociations

()$_{2} \quad=$ value for $\mathrm{H}^{+}$

()$_{3}=$ value for the anion from the final dissociation of the electrolyte

Step 8: Calculate the weighted sum-of-squares function, $\varphi$, using $\mathbf{Y}_{\text {calc }}$ from the prior step and the user input values for $\mathbf{w}$ and $\mathbf{Y}_{\text {meas. }}$.

\section{Results Generated To Date}

As of this writing the regression program has been used successfully to obtain Pitzer parameters for $\mathrm{H}_{2} \mathrm{SO}_{4}$ and $\mathrm{HNO}_{3}$. These results are discussed within the main text of this report. As noted above, the computational and conceptual framework that have been established can now be expanded to allow

(a) Regression of the Pitzer parameters for multiple species undergoing multiple reactions in aqueous solution, and

(b) Regression against other types of experimental data (e.g., any or all of the following: phase equilibrium data (liquid/liquid, solid/liquid, vapor/liquid), chemical equilibrium data, salt solubilities, freezing point depression, osmotic coefficients, and electrochemical cell potentials).

Tentative planning for follow-on work during FY03 includes modifying the program to provide this expanded functionality. 
Figure 1. Comparison of ENRTL and Pitzer: $\mathrm{NaCl}-\mathrm{H}_{2} \mathrm{O}$ System.

\section{$\mathrm{NaCl}-\mathrm{H} 2 \mathrm{O}$ System}

- Robinson \& Stokes (1959) - - - PITZER (AP) - . - . - ENRTL

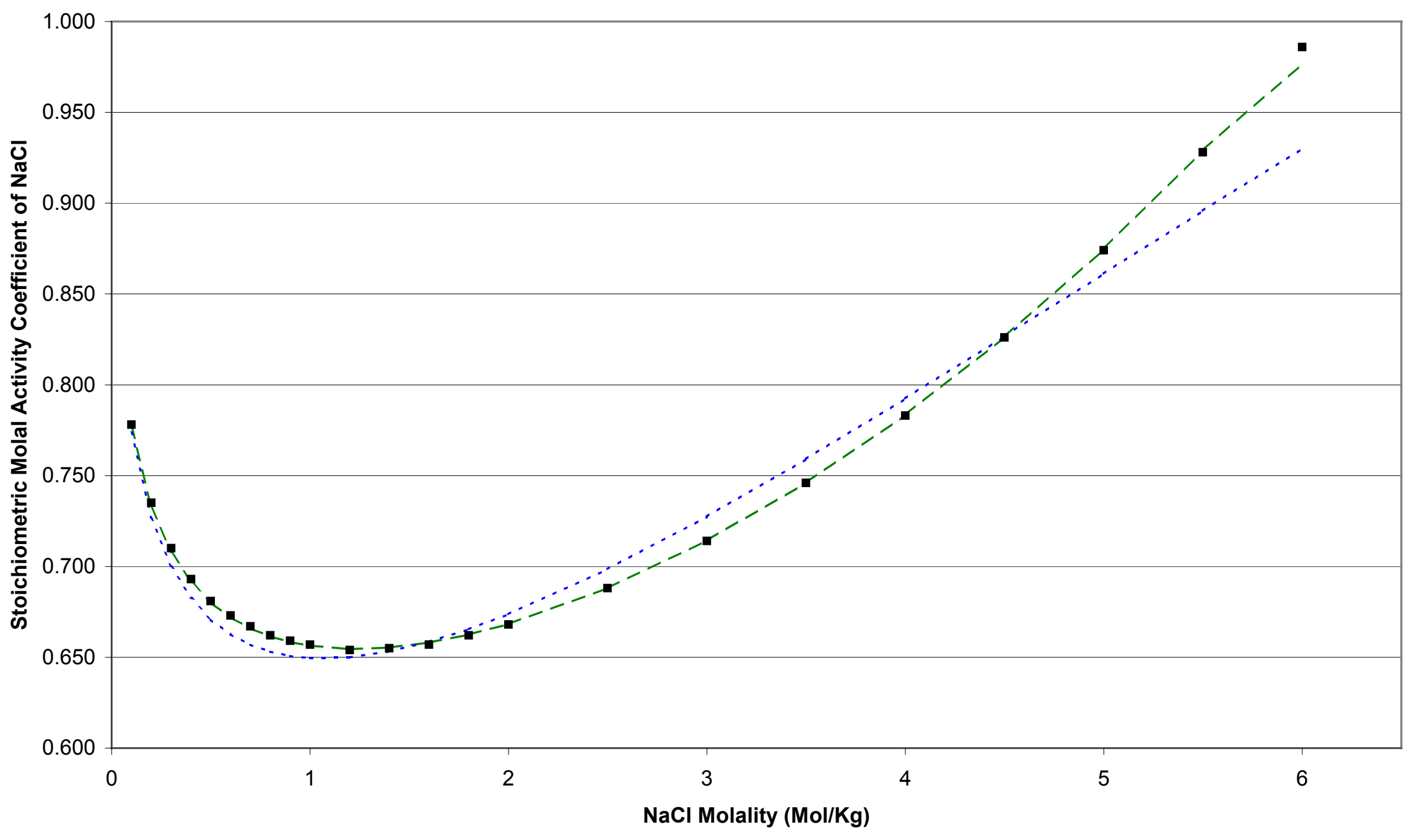


Figure 2. Comparison of ENRTL and Pitzer: $\mathrm{HCl}-\mathrm{H}_{2} \mathrm{O}$ System.

$\mathrm{HCl}-\mathrm{H} 2 \mathrm{O}$ System: 0-6 m

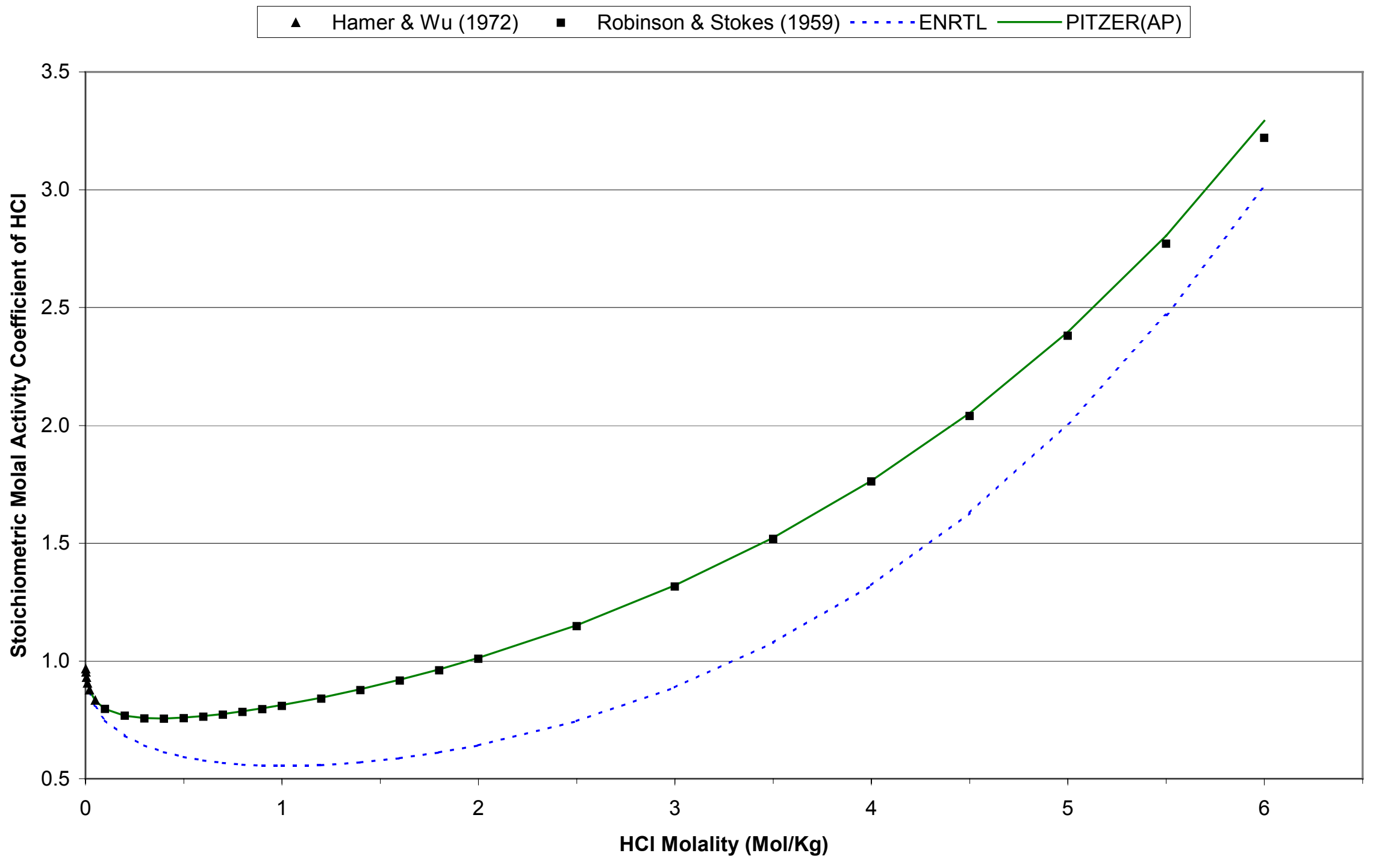


Figure 3. Comparison of ENRTL and Pitzer: $\mathrm{HCl}-\mathrm{NaCl}-\mathrm{H}_{2} \mathrm{O}$ System.

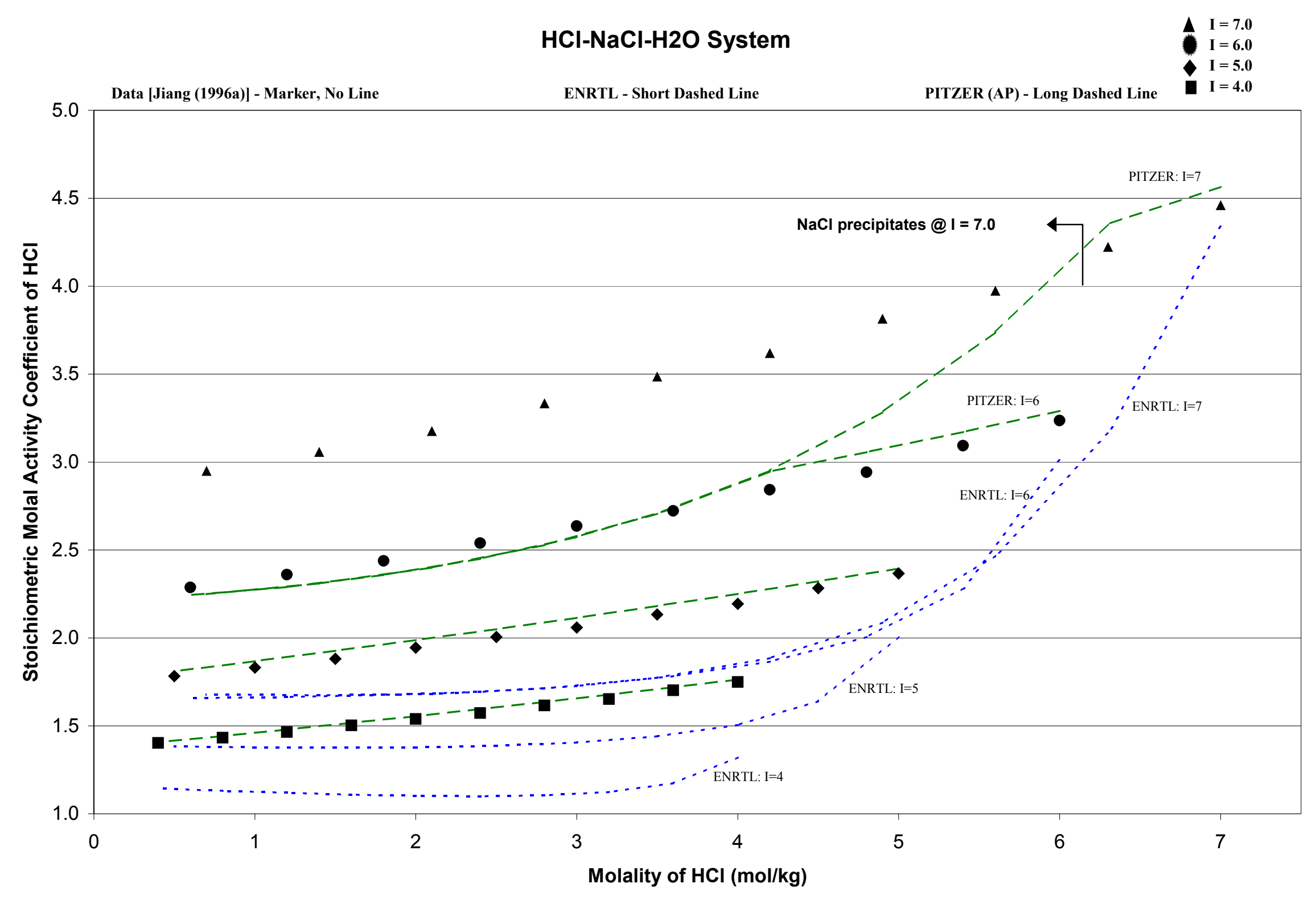


Figure 4. Jiang Gamma Data Relative To Solubility: $\mathrm{NaCl}$ in Aqueous $\mathrm{HCl}$.

\section{$\mathrm{NaCl}$ in Aqueous $\mathrm{HCl}$ Solution}

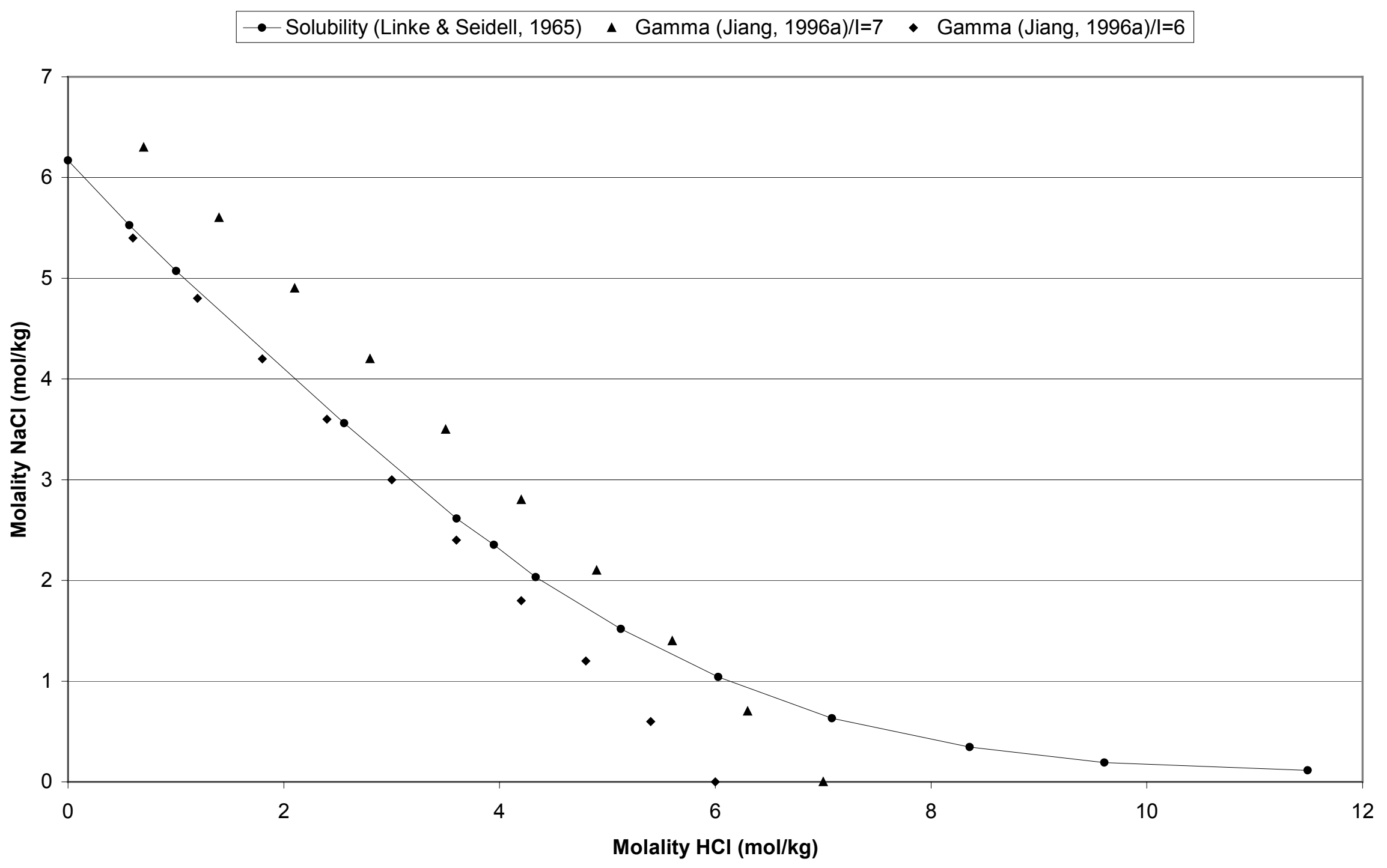


Figure 5. Comparison of ENRTL and Pitzer: HCl-NaCl-KCl- $\mathrm{H}_{2} \mathrm{O}$ System.

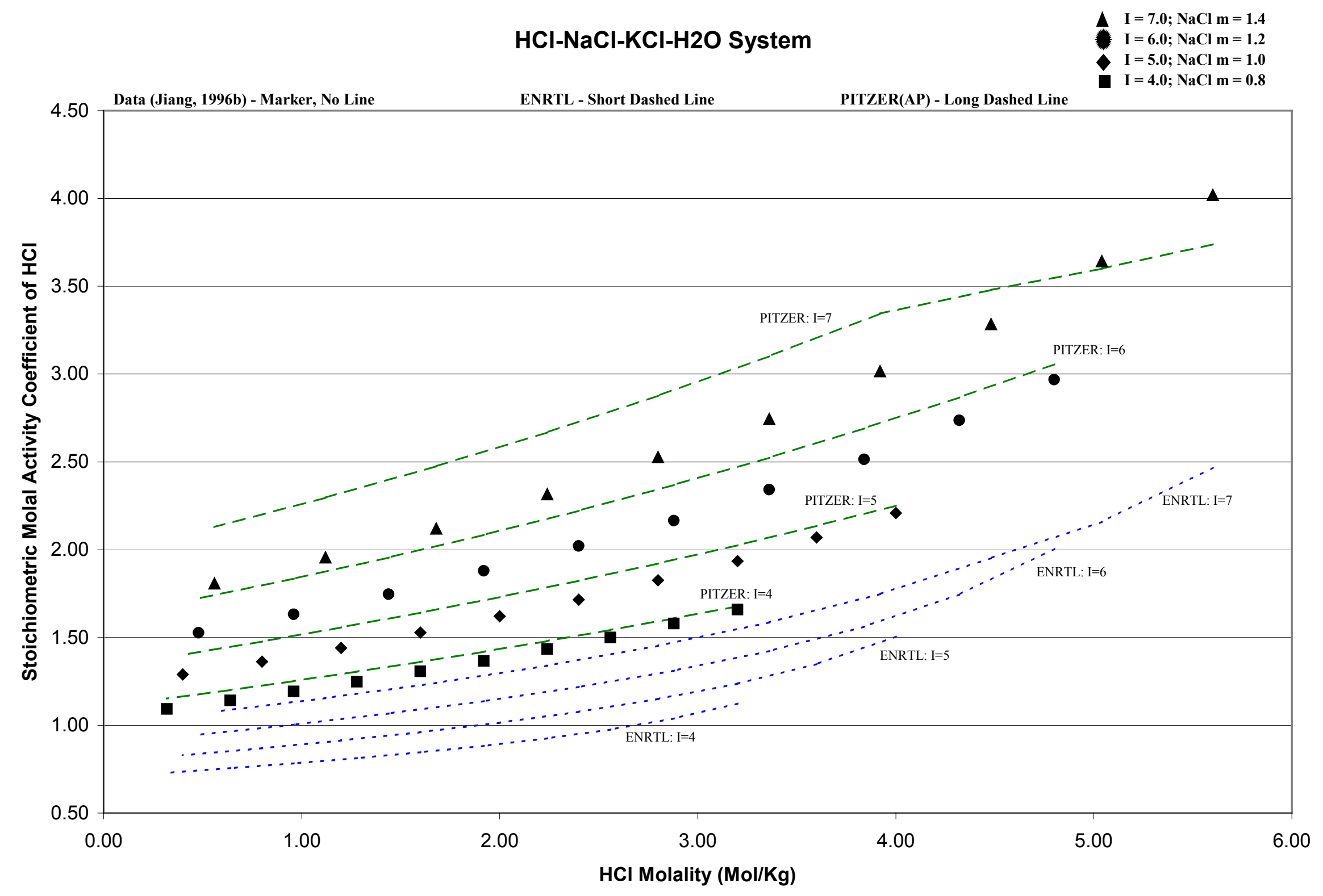


Figure 6. Comparison of Pitzer Parameter Values: $\mathrm{HCl}-\mathrm{H}_{2} \mathrm{O}$ System.

\section{HCl-H2O System: 0-16 m}

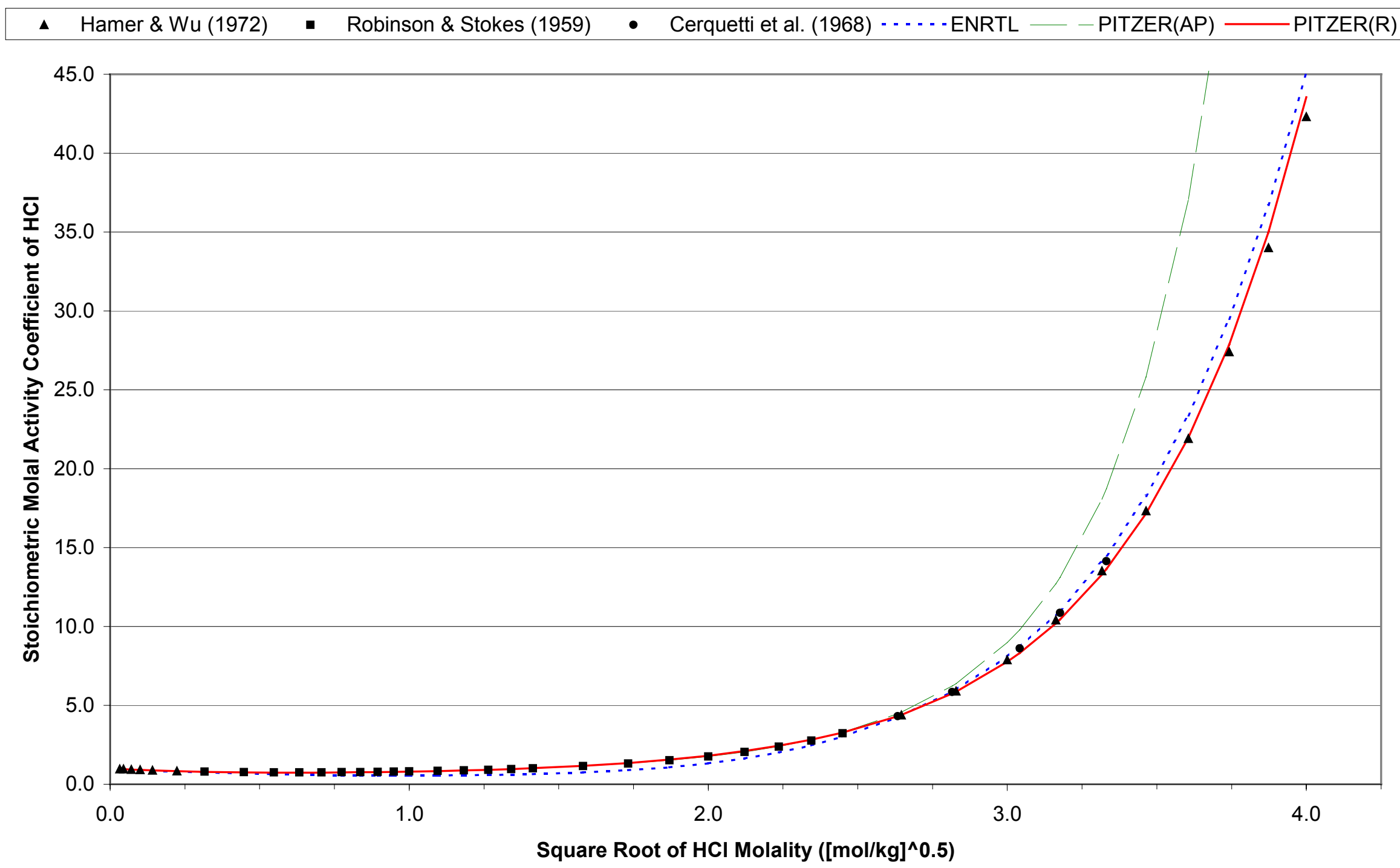


Figure 7. Comparison of Pitzer Parameter Values: $\mathrm{NaCl}-\mathrm{H}_{2} \mathrm{O}$ System/Solubility.

\section{$\mathrm{NaCl}$ Solubility in Aqueous $\mathrm{HCl}$ Solution}

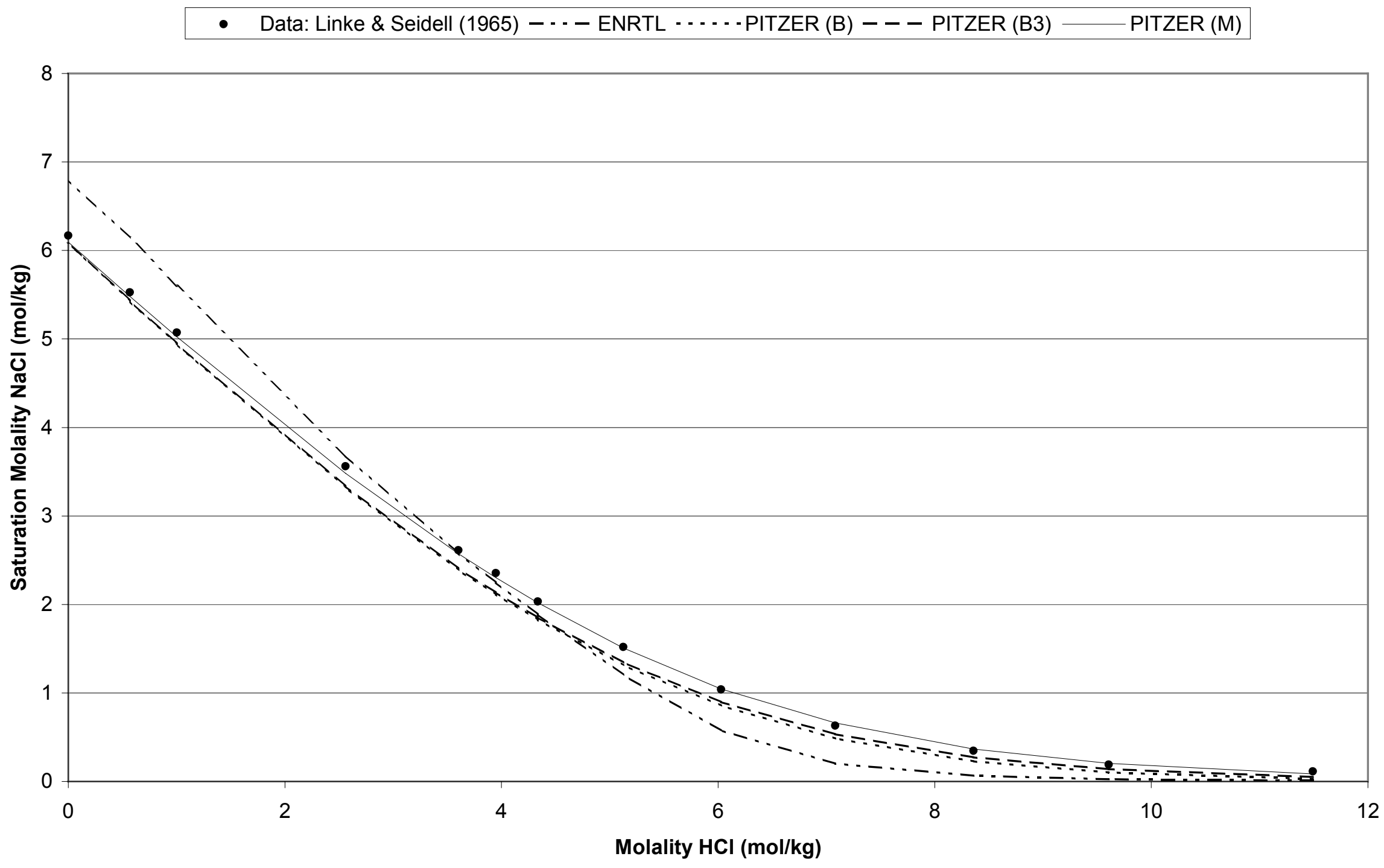


Figure 8. Comparison of Pitzer Parameter Values: $\mathrm{NaCl}-\mathrm{H}_{2} \mathrm{O}$ System/Gamma

\section{$\mathrm{NaCl}-\mathrm{H} 2 \mathrm{O}$ System}

- Robinson \& Stokes (1959) - - - PITZER (AP) —PITZER(M)

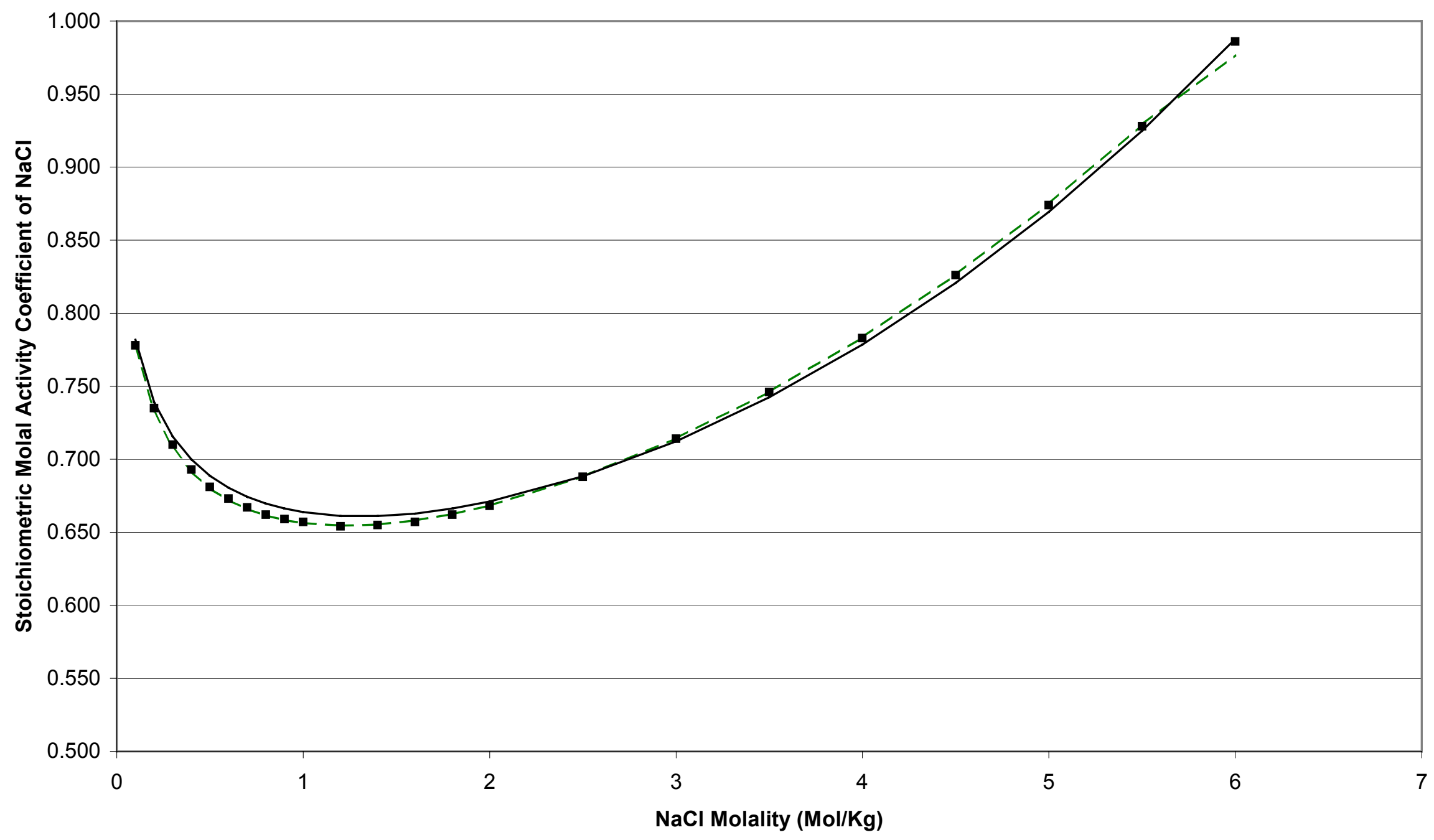


Figure 9. Comparison of Pitzer Parameter Values: HCl-NaCl- $\mathrm{H}_{2} \mathrm{O}$ System.

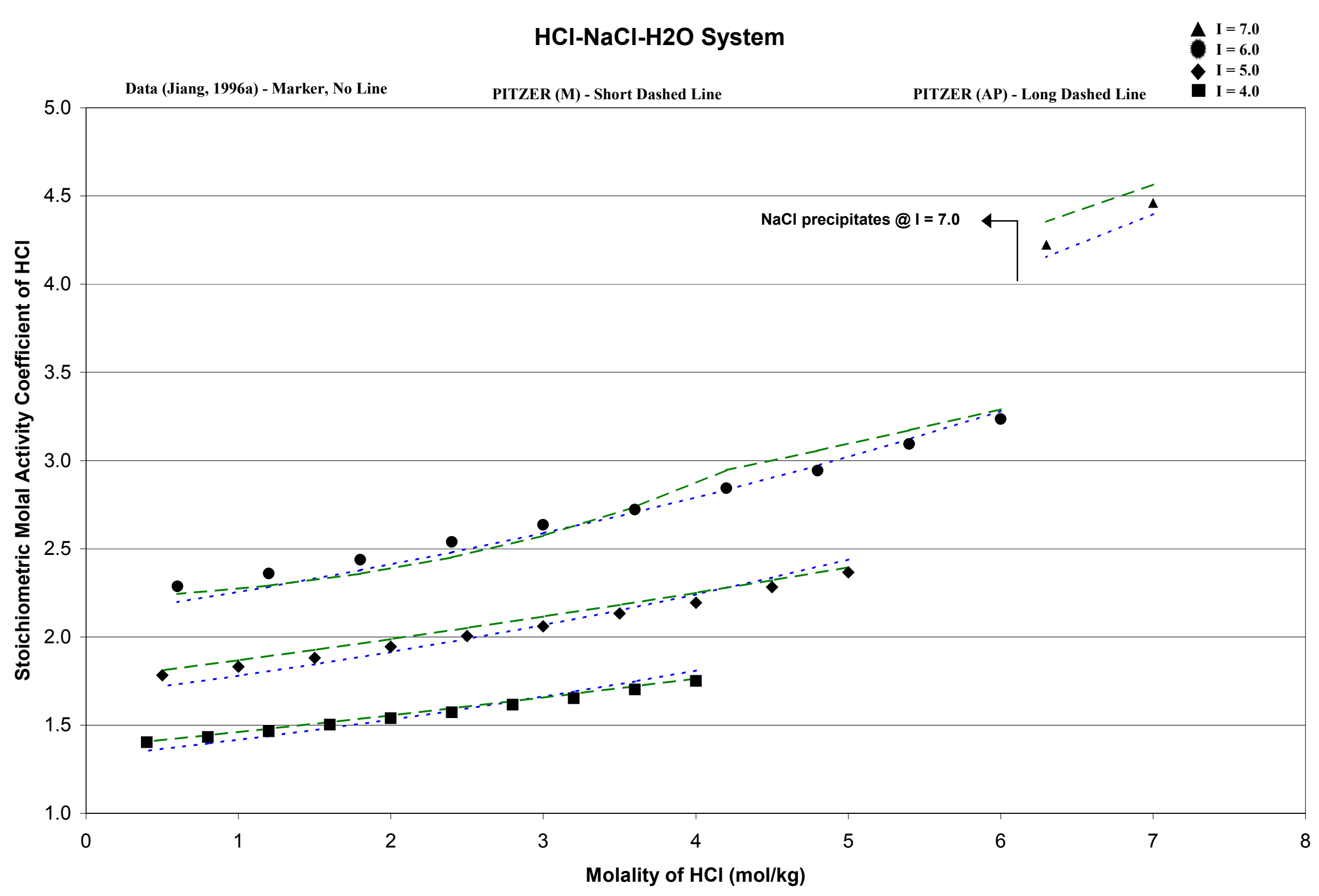


Figure 10. Comparison of Pitzer Parameter Values: HCl-NaCl-KCl- $\mathrm{H}_{2} \mathrm{O}$ System.

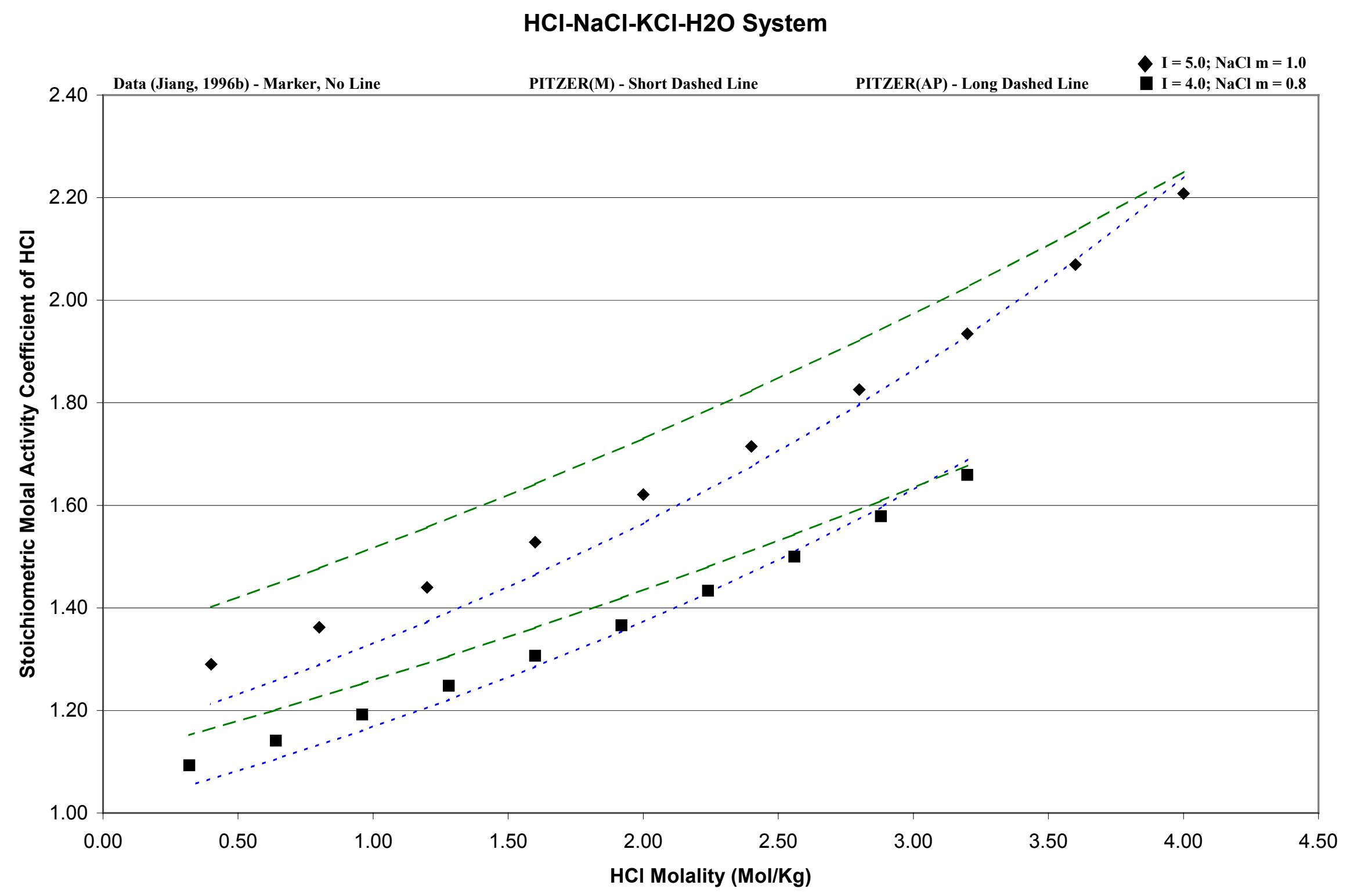


Figure 11. Difficulty of Experimentally Determining Extent of Dissociation: HSO4- in Water.

\section{Dissociation of HSO4- In Water}

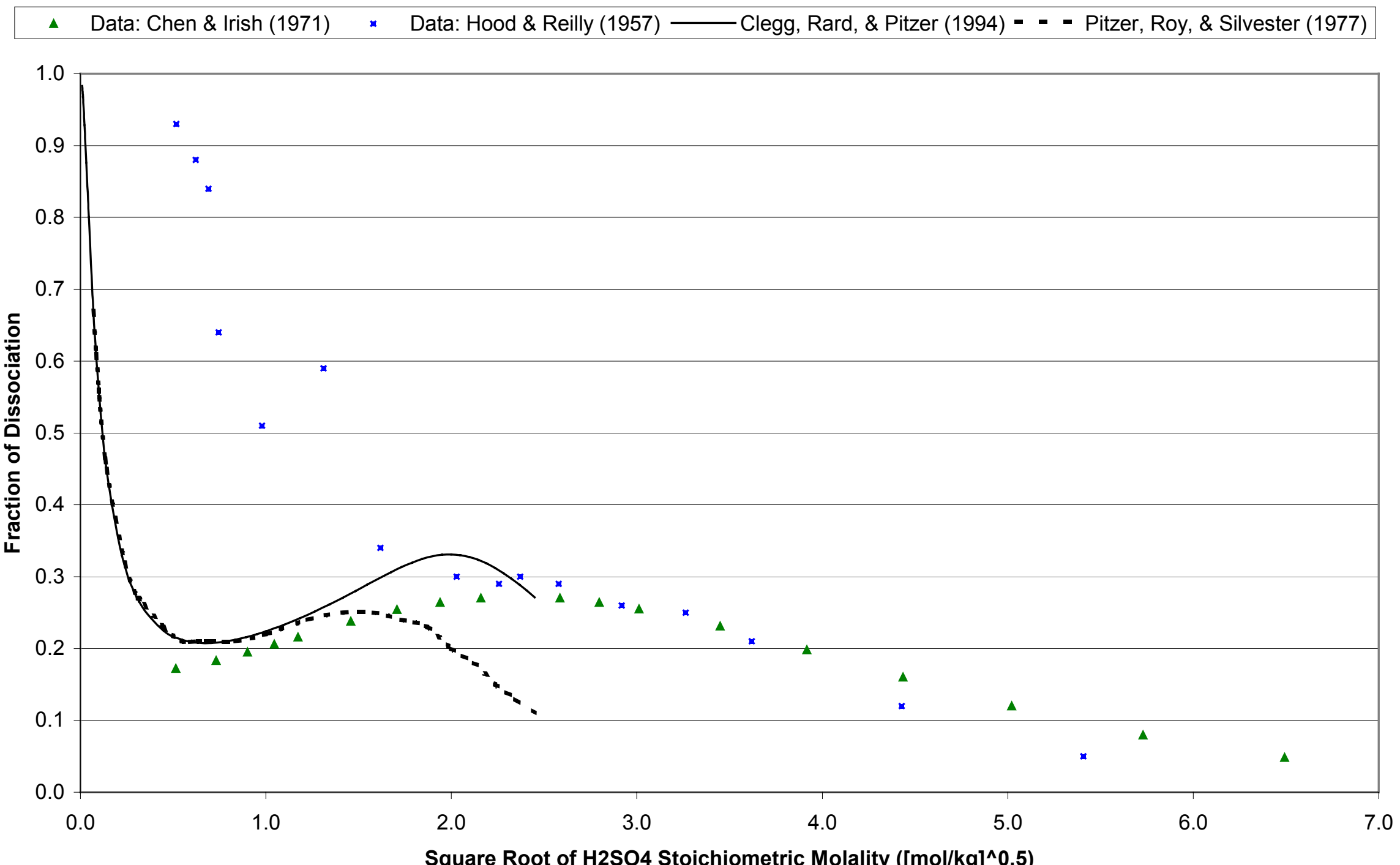


Figure 12. Predicted Dissociation vs. Data: HSO4- In Water

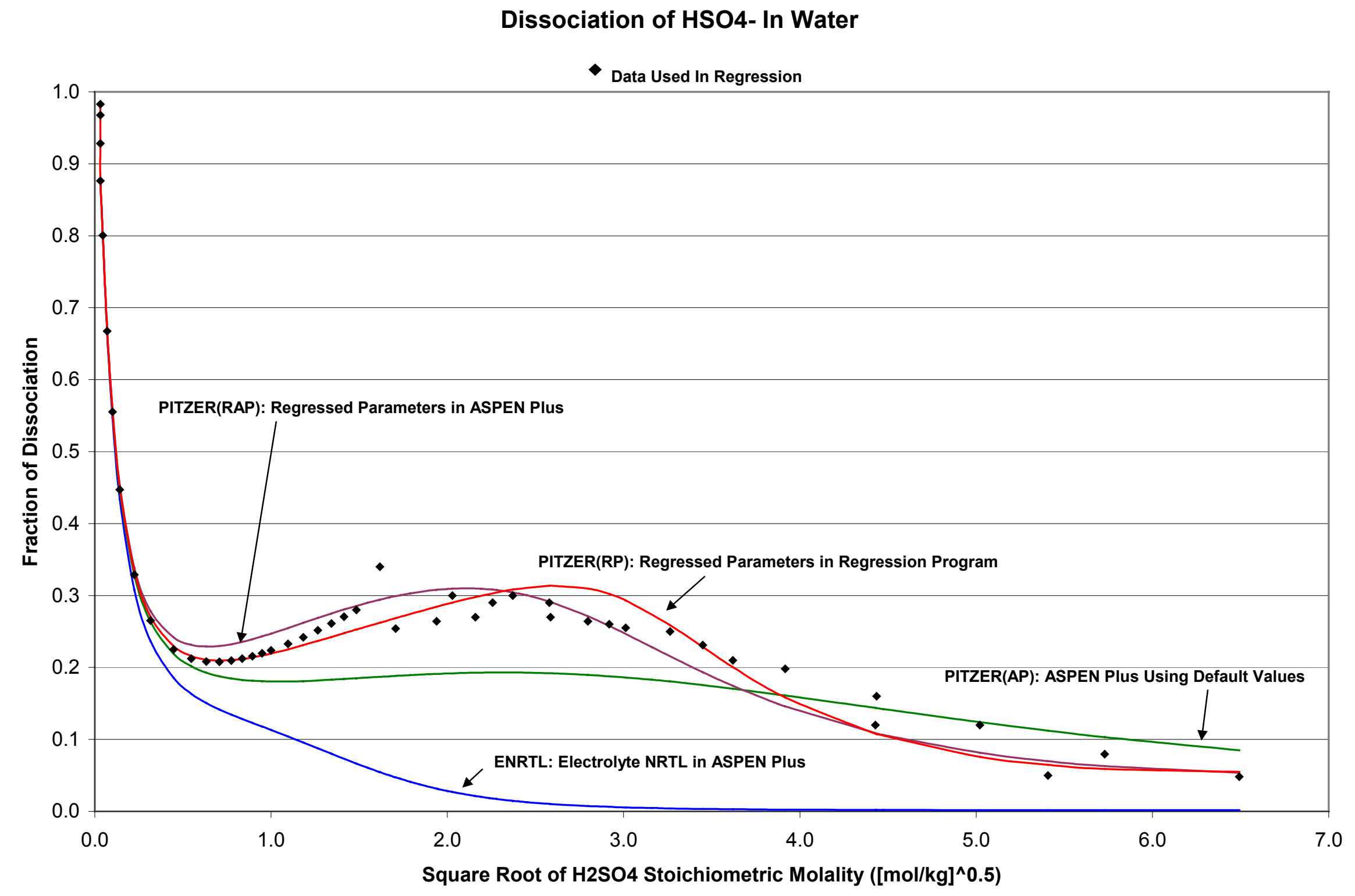




\section{Activity Coefficient of $\mathrm{H} 2 \mathrm{SO} 4$ in Water}

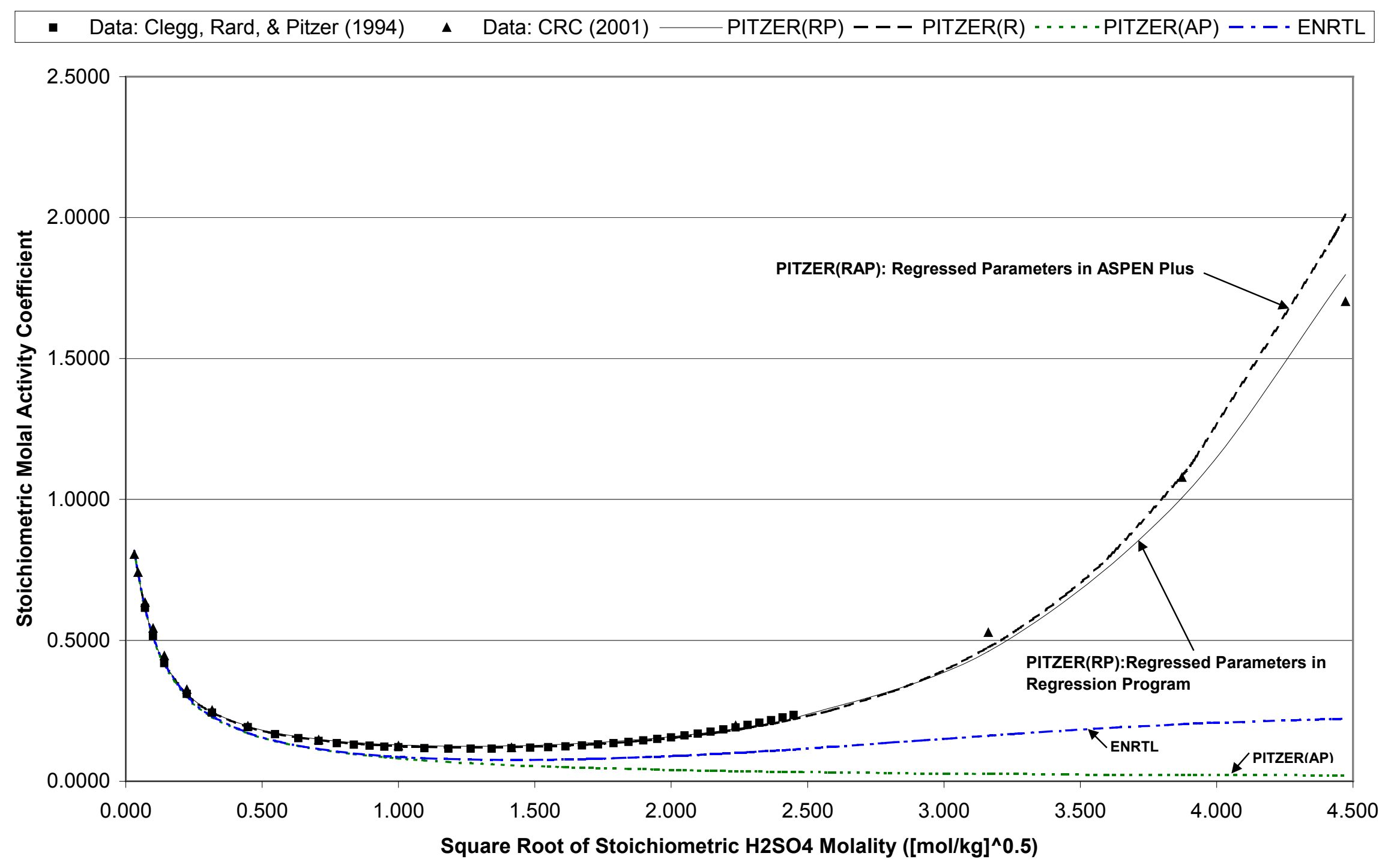


Figure 14. Comparison of Predicted vs. Experimental Fraction of Dissociation Data: $\mathrm{HNO}_{3}-\mathrm{H}_{2} \mathrm{O}$ System.

\section{HNO3 Dissociation in Water}

\begin{tabular}{|c|c|c|}
\hline$\longrightarrow$ Regression Data: Davis \& de Bruin (1964) & - - - PITZER(RS) & - - PITZER(RSD) \\
\hline
\end{tabular}

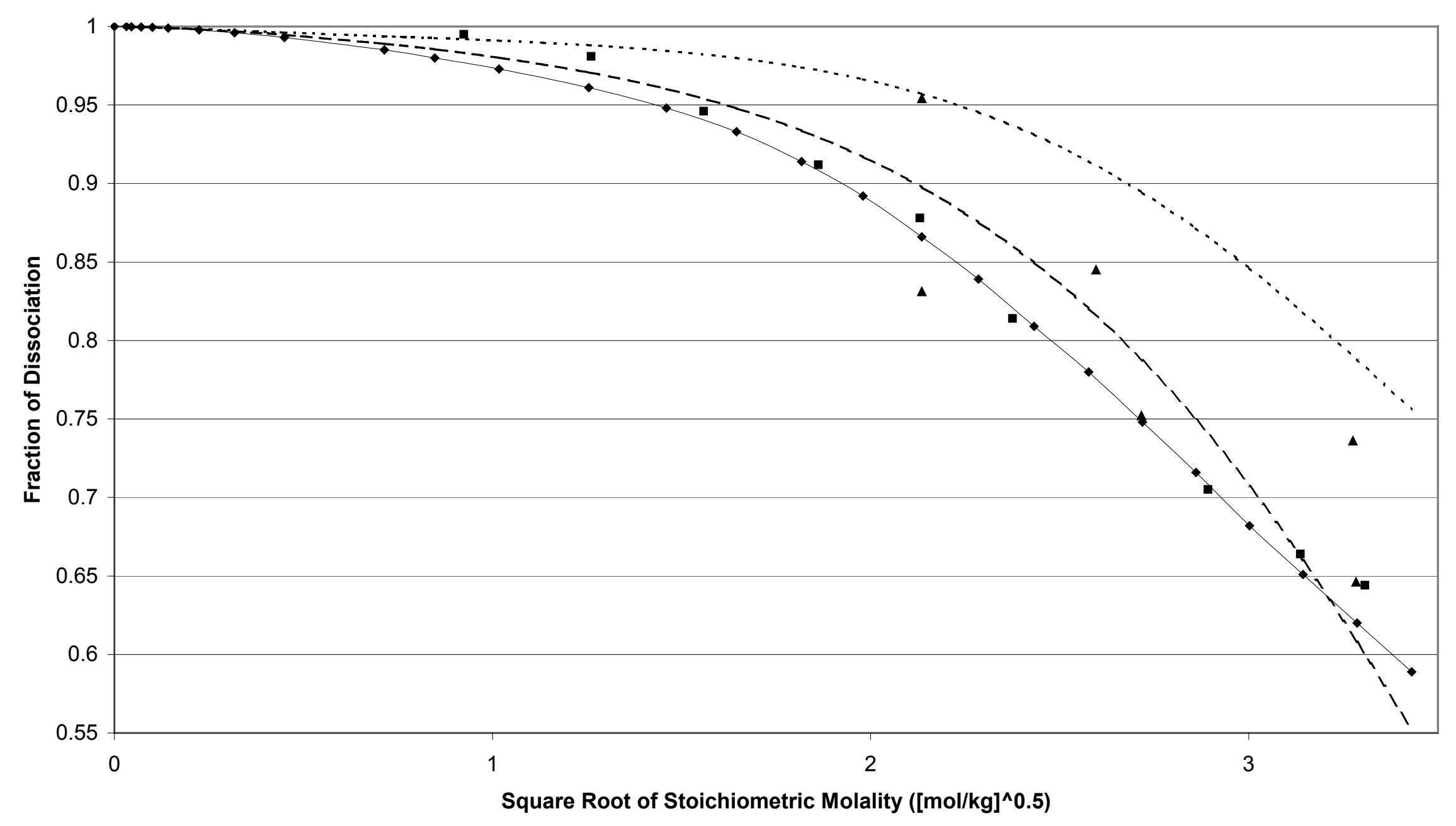


Figure 15. Comparison of Predicted vs. Experimental Stoichiometric Activity Coefficient Data: $\mathrm{HNO}_{3}-\mathrm{H}_{2} \mathrm{O}$ System.

\section{Activity Coefficient of $\mathrm{HNO} 3$ in Water}

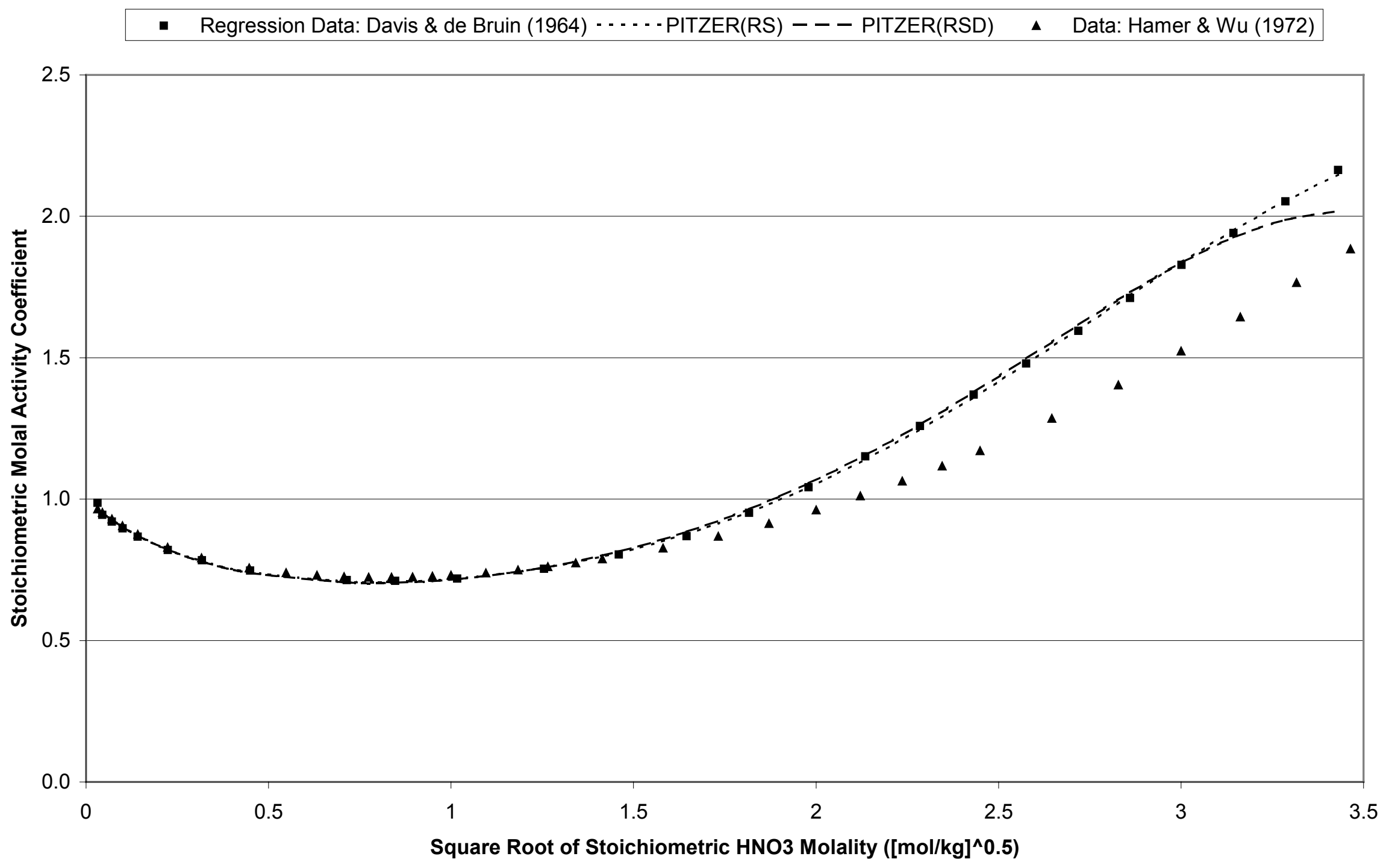




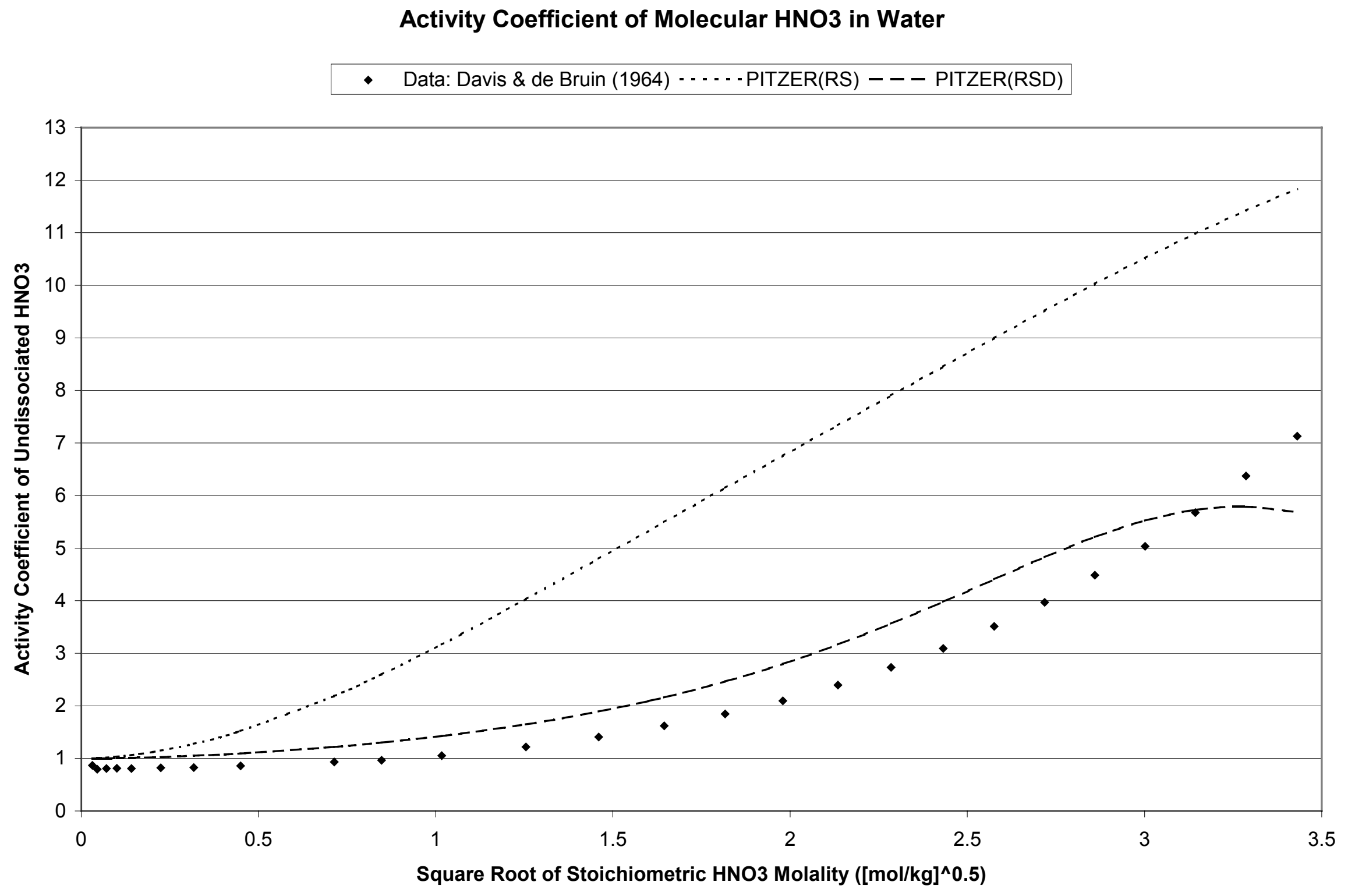


Table 1. Comparison Of Model Predictions For $\gamma_{ \pm, \text {st }}: \mathrm{NaCl}-\mathrm{H}_{2} \mathrm{O}$ System.

\begin{tabular}{|c|c|c|c|c|c|c|c|}
\hline \multirow{3}{*}{$\begin{array}{l}\mathrm{m} \mathrm{NaCl} \\
(\mathrm{mol} / \mathrm{kg})\end{array}$} & \multicolumn{7}{|c|}{$\gamma_{ \pm, \mathrm{st}(\mathrm{NaCl})}$} \\
\hline & \multirow{2}{*}{ Data $^{a}$} & \multicolumn{3}{|c|}{ Predictions } & \multicolumn{3}{|c|}{ Percent Absolute Deviation } \\
\hline & & ENRTL & PITZER(AP) & PITZER(M) ${ }^{\mathrm{c}}$ & ENRTL & PITZER(AP) & ${\text { PITZER }(M)^{c}}^{c}$ \\
\hline 0.1 & 0.778 & 0.774 & 0.777 & 0.782 & 0.537 & 0.096 & 0.487 \\
\hline 0.2 & 0.735 & 0.726 & 0.733 & 0.739 & 1.163 & 0.318 & 0.567 \\
\hline 0.3 & 0.710 & 0.700 & 0.708 & 0.715 & 1.424 & 0.305 & 0.764 \\
\hline 0.4 & 0.693 & 0.683 & 0.692 & 0.700 & 1.487 & 0.200 & 0.980 \\
\hline 0.5 & 0.681 & 0.671 & 0.680 & 0.689 & 1.483 & 0.111 & 1.129 \\
\hline 0.6 & 0.673 & 0.663 & 0.672 & 0.681 & 1.536 & 0.148 & 1.115 \\
\hline 0.7 & 0.667 & 0.657 & 0.666 & 0.674 & 1.508 & 0.157 & 1.103 \\
\hline 0.8 & 0.662 & 0.653 & 0.662 & 0.670 & 1.343 & 0.069 & 1.169 \\
\hline 0.9 & 0.659 & 0.651 & 0.658 & 0.666 & 1.251 & 0.090 & 1.110 \\
\hline 1.0 & 0.657 & 0.650 & 0.656 & 0.664 & 1.129 & 0.106 & 1.043 \\
\hline 1.2 & 0.654 & 0.650 & 0.655 & 0.661 & 0.612 & 0.082 & 1.108 \\
\hline 1.4 & 0.655 & 0.653 & 0.655 & 0.661 & 0.272 & 0.048 & 0.928 \\
\hline 1.6 & 0.657 & 0.659 & 0.658 & 0.663 & 0.235 & 0.164 & 0.889 \\
\hline 1.8 & 0.662 & 0.665 & 0.662 & 0.666 & 0.528 & 0.074 & 0.639 \\
\hline 2.0 & 0.668 & 0.674 & 0.668 & 0.671 & 0.859 & 0.047 & 0.453 \\
\hline 2.5 & 0.688 & 0.699 & 0.688 & 0.688 & 1.537 & 0.011 & 0.049 \\
\hline 3.0 & 0.714 & 0.728 & 0.714 & 0.712 & 1.901 & 0.034 & 0.234 \\
\hline 3.5 & 0.746 & 0.759 & 0.746 & 0.742 & 1.772 & 0.017 & 0.476 \\
\hline 4.0 & 0.783 & 0.793 & 0.783 & 0.779 & 1.214 & 0.063 & 0.568 \\
\hline 4.5 & 0.826 & 0.827 & 0.826 & 0.821 & 0.087 & 0.039 & 0.634 \\
\hline 5.0 & 0.874 & 0.861 & 0.875 & 0.869 & 1.452 & 0.090 & 0.529 \\
\hline 5.5 & 0.928 & 0.896 & 0.929 & 0.925 & 3.461 & 0.126 & 0.339 \\
\hline 6.0 & 0.986 & 0.930 & 0.977 & 0.988 & 5.670 & 0.931 & 0.182 \\
\hline & & & & Average & 1.411 & 0.145 & 0.717 \\
\hline
\end{tabular}

${ }^{a}$ Robinson and Stokes (1959). ${ }^{\mathrm{b}}$ ASPEN Plus default values for Pitzer NaCl binary values (see Table B1.). ${ }^{\mathrm{c}}$ Used NaCl binary and $\mathrm{K}_{\mathrm{sp}}$ values from Weber $(2000)$ in Table $\mathrm{B} 2: \beta^{(0)}=0.06743, \beta^{(1)}=0.3301, \mathrm{C}^{\phi}=0.00263, \mathrm{~K}_{\mathrm{sp}}=37.170$. 
Table 2. Comparison Of Model Predictions For $\gamma_{ \pm, \text {st }}: \mathrm{HCl}-\mathrm{H}_{2} \mathrm{O}$ System.

\begin{tabular}{|c|c|c|c|c|c|c|c|c|c|}
\hline \multirow{3}{*}{$\begin{array}{c}\mathrm{m} \mathrm{HCl} \\
(\mathrm{mol} / \mathrm{kg})\end{array}$} & \multicolumn{9}{|c|}{$\gamma_{ \pm, \text {st }(\mathrm{HCl})}$} \\
\hline & \multicolumn{3}{|c|}{ Data } & \multicolumn{3}{|c|}{ Predictions } & \multicolumn{3}{|c|}{ Percent Absolute Deviation } \\
\hline & $\mathrm{RS}^{\mathrm{a}}$ & $\mathrm{HW}^{\mathrm{b}}$ & CALM $^{\mathrm{C}}$ & ENRTL & PITZER(AP) $^{d}$ & PITZER(R) $^{\mathrm{e}}$ & ENRTL & PITZER(AP) ${ }^{\mathrm{d}}$ & PITZER(R) \\
\hline 0.001 & & 0.965 & & 0.965 & 0.965 & 0.965 & 0.02 & 0.04 & 0.02 \\
\hline 0.002 & & 0.952 & & 0.951 & 0.952 & 0.952 & 0.08 & 0.04 & 0.01 \\
\hline 0.005 & & 0.929 & & 0.926 & 0.929 & 0.928 & 0.35 & 0.05 & 0.15 \\
\hline 0.010 & & 0.905 & & 0.899 & 0.905 & 0.903 & 0.65 & 0.03 & 0.22 \\
\hline 0.020 & & 0.876 & & 0.865 & 0.876 & 0.873 & 1.30 & 0.05 & 0.40 \\
\hline 0.050 & & 0.832 & & 0.805 & 0.831 & 0.825 & 3.25 & 0.16 & 0.89 \\
\hline 0.1 & 0.796 & & & 0.748 & 0.796 & 0.786 & 6.01 & 0.02 & 1.21 \\
\hline 0.2 & 0.767 & & & 0.682 & 0.767 & 0.754 & 11.05 & 0.01 & 1.74 \\
\hline 0.3 & 0.756 & & & 0.641 & 0.757 & 0.742 & 15.18 & 0.19 & 1.87 \\
\hline 0.4 & 0.755 & & & 0.613 & 0.756 & 0.739 & 18.84 & 0.14 & 2.06 \\
\hline 0.5 & 0.757 & & & 0.592 & 0.760 & 0.743 & 21.78 & 0.33 & 1.91 \\
\hline 0.6 & 0.763 & & & 0.577 & 0.766 & 0.749 & 24.35 & 0.42 & 1.79 \\
\hline 0.7 & 0.772 & & & 0.567 & 0.775 & 0.759 & 26.60 & 0.42 & 1.70 \\
\hline 0.8 & 0.783 & & & 0.560 & 0.786 & 0.771 & 28.52 & 0.41 & 1.58 \\
\hline 0.9 & 0.795 & & & 0.556 & 0.799 & 0.784 & 30.11 & 0.47 & 1.36 \\
\hline 1.0 & 0.809 & & & 0.554 & 0.813 & 0.799 & 31.50 & 0.45 & 1.20 \\
\hline 1.2 & 0.840 & & & 0.558 & 0.844 & 0.834 & 33.60 & 0.50 & 0.74 \\
\hline 1.4 & 0.876 & & & 0.569 & 0.880 & 0.873 & 35.04 & 0.48 & 0.33 \\
\hline 1.6 & 0.916 & & & 0.587 & 0.920 & 0.917 & 35.90 & 0.47 & 0.11 \\
\hline 1.8 & 0.960 & & & 0.611 & 0.965 & 0.965 & 36.31 & 0.47 & 0.55 \\
\hline 2.0 & 1.009 & & & 0.642 & 1.013 & 1.018 & 36.39 & 0.38 & 0.88 \\
\hline 2.5 & 1.147 & & & 0.745 & 1.152 & 1.169 & 35.09 & 0.45 & 1.88 \\
\hline 3.0 & 1.316 & & & 0.888 & 1.321 & 1.349 & 32.52 & 0.36 & 2.48 \\
\hline 3.5 & 1.518 & & & 1.078 & 1.523 & 1.561 & 29.00 & 0.33 & 2.85 \\
\hline 4.0 & 1.762 & & & 1.322 & 1.765 & 1.811 & 24.99 & 0.15 & 2.75 \\
\hline 4.5 & 2.040 & & & 1.629 & 2.053 & 2.101 & 20.16 & 0.62 & 3.01 \\
\hline 5.0 & 2.380 & & & 2.008 & 2.396 & 2.439 & 15.63 & 0.67 & 2.49 \\
\hline 5.5 & 2.770 & & & 2.468 & 2.805 & 2.830 & 10.91 & 1.25 & 2.18 \\
\hline 6.0 & 3.220 & & & 3.012 & 3.292 & 3.282 & 6.47 & 2.23 & 1.93 \\
\hline 6.938 & & & 4.308 & 4.251 & 4.473 & 4.320 & 1.31 & 3.83 & 0.29 \\
\hline 7.0 & & 4.38 & & 4.343 & 4.566 & 4.399 & 0.84 & 4.24 & 0.43 \\
\hline 7.930 & & & 5.844 & 5.879 & 6.232 & 5.747 & 0.60 & 6.63 & 1.65 \\
\hline 8.0 & & 5.9 & & 6.008 & 6.381 & 5.863 & 1.83 & 8.15 & 0.63 \\
\hline 9.0 & & 7.88 & & 8.103 & 8.977 & 7.761 & 2.83 & 13.92 & 1.51 \\
\hline 9.251 & & & 8.616 & 8.712 & 9.789 & 8.317 & 1.11 & 13.61 & 3.47 \\
\hline 10.0 & & 10.4 & & 10.761 & 12.702 & 10.195 & 3.47 & 22.13 & 1.97 \\
\hline 10.092 & & & 10.87 & 11.038 & 13.117 & 10.450 & 1.55 & 20.67 & 3.86 \\
\hline 11.0 & & 13.52 & & 14.113 & 18.065 & 13.284 & 4.38 & 33.61 & 1.74 \\
\hline 11.102 & & & 14.14 & 14.499 & 18.731 & 13.641 & 2.54 & 32.47 & 3.53 \\
\hline 12.0 & & 17.32 & & 18.280 & 25.813 & 17.159 & 5.54 & 49.04 & 0.93 \\
\hline 13.0 & & 21.9 & & 23.373 & 37.046 & 21.966 & 6.73 & 69.16 & 0.30 \\
\hline 14.0 & & 27.4 & & 29.488 & 53.382 & 27.859 & 7.62 & 94.82 & 1.67 \\
\hline 15.0 & & 34.0 & & 36.702 & 77.217 & 34.998 & 7.95 & 127.11 & 2.94 \\
\hline \multirow[t]{3}{*}{16.0} & & 42.3 & & 45.070 & 90.601 & 43.544 & 6.55 & 114.19 & 2.94 \\
\hline & & & & & & Average $^{f}$ & 19.71 & 0.40 & 1.39 \\
\hline & & & & & & Average $^{\mathrm{g}}$ & 14.24 & 14.21 & 1.55 \\
\hline
\end{tabular}

${ }^{a}$ Robinson and Stokes (1959). ${ }^{\mathrm{b}}$ Hamer and Wu (1972). ${ }^{\mathrm{c}}$ Cerquetti et al. (1968). ${ }^{\mathrm{d}}$ Used ASPEN Plus default values for Pitzer $\mathrm{HCl}$ binary values (see Table B1.). ${ }^{\mathrm{e}}$ Used $\mathrm{HCl}$ binary values regressed from Robinson and Stokes (1959), Hamer and $\mathrm{Wu}$ (1972), and Cerquetti et al. (1968) up to 16 molal: $\beta^{(0)}=0.203486, \beta^{(1)}=0.1516, C^{\phi}=-0.003646 .{ }^{\mathrm{f}}$ For $0-6$ molal. ${ }^{\mathrm{g}}$ For 0-16 molal. 
Table 3. Comparison Of Model Predictions For $\gamma_{ \pm, \text {st }}: \mathrm{HCl}-\mathrm{NaCl}-\mathrm{H}_{2} \mathrm{O}$ System.

\begin{tabular}{|c|c|c|c|c|c|c|c|c|c|}
\hline \multirow{2}{*}{\multicolumn{3}{|c|}{$\begin{array}{l}\text { Concentration } \\
\text { Molality }(\mathrm{mol} / \mathrm{kg})\end{array}$}} & \multicolumn{7}{|c|}{$\gamma_{ \pm, \text {st }(\mathrm{HCl})}$} \\
\hline & & & \multirow{2}{*}{ Data $^{a}$} & \multicolumn{3}{|c|}{ Predictions } & \multicolumn{3}{|c|}{ Percent Absolute Deviation } \\
\hline $\mathrm{HCl}$ & $\mathrm{NaCl}$ & $\begin{array}{c}\text { Ionic } \\
\text { Strength }\end{array}$ & & ENRTL & PITZER(AP) $)^{b}$ & $\operatorname{PITZER}(\mathrm{M})^{\mathrm{c}}$ & ENRTL & PITZER(AP) $)^{b}$ & PITZER(M) \\
\hline 4 & 0 & 4 & 1.750 & 1.321 & 1.764 & 1.810 & 24.50 & 0.80 & 3.44 \\
\hline 3.6 & 0.4 & 4 & 1.702 & 1.174 & 1.720 & 1.748 & 31.05 & 1.04 & 2.69 \\
\hline 3.2 & 0.8 & 4 & 1.652 & 1.124 & 1.677 & 1.690 & 31.98 & 1.52 & 2.25 \\
\hline 2.8 & 1.2 & 4 & 1.615 & 1.105 & 1.636 & 1.634 & 31.59 & 1.26 & 1.15 \\
\hline 2.4 & 1.6 & 4 & 1.573 & 1.100 & 1.595 & 1.581 & 30.04 & 1.43 & 0.54 \\
\hline 2 & 2 & 4 & 1.539 & 1.103 & 1.556 & 1.531 & 28.35 & 1.09 & 0.51 \\
\hline 1.6 & 2.4 & 4 & 1.502 & 1.110 & 1.517 & 1.484 & 26.14 & 0.99 & 1.24 \\
\hline 1.2 & 2.8 & 4 & 1.464 & 1.119 & 1.479 & 1.438 & 23.57 & 1.02 & 1.78 \\
\hline 0.8 & 3.2 & 4 & 1.433 & 1.131 & 1.443 & 1.396 & 21.03 & 0.70 & 2.59 \\
\hline 0.4 & 3.6 & 4 & 1.402 & 1.145 & 1.407 & 1.355 & 18.37 & 0.32 & 3.39 \\
\hline 5 & 0 & 5 & 2.367 & 2.006 & 2.395 & 2.438 & 15.21 & 1.20 & 3.04 \\
\hline 4.5 & 0.5 & 5 & 2.283 & 1.641 & 2.322 & 2.336 & 28.13 & 1.70 & 2.34 \\
\hline 4 & 1 & 5 & 2.194 & 1.505 & 2.251 & 2.241 & 31.39 & 2.57 & 2.11 \\
\hline 3.5 & 1.5 & 5 & 2.133 & 1.440 & 2.182 & 2.151 & 32.48 & 2.29 & 0.84 \\
\hline 3 & 2 & 5 & 2.060 & 1.405 & 2.115 & 2.067 & 31.78 & 2.68 & 0.35 \\
\hline 2.5 & 2.5 & 5 & 2.005 & 1.387 & 2.050 & 1.988 & 30.86 & 2.24 & 0.85 \\
\hline 2 & 3 & 5 & 1.945 & 1.378 & 1.988 & 1.915 & 29.15 & 2.21 & 1.54 \\
\hline 1.5 & 3.5 & 5 & 1.882 & 1.375 & 1.927 & 1.845 & 26.90 & 2.39 & 1.93 \\
\hline 1 & 4 & 5 & 1.831 & 1.378 & 1.868 & 1.780 & 24.74 & 2.01 & 2.76 \\
\hline 0.5 & 4.5 & 5 & 1.783 & 1.384 & 1.811 & 1.719 & 22.38 & 1.53 & 3.58 \\
\hline 6 & 0 & 6 & 3.236 & 3.008 & 3.291 & 3.281 & 7.03 & 1.71 & 1.41 \\
\hline 5.4 & 0.6 & 6 & 3.093 & 2.282 & 3.171 & 3.120 & 26.23 & 2.53 & 0.87 \\
\hline 4.8 & 1.2 & 6 & 2.942 & 2.005 & 3.056 & 2.971 & 31.86 & 3.87 & 0.98 \\
\hline 4.2 & 1.8 & 6 & 2.843 & 1.865 & 2.946 & 2.834 & 34.40 & 3.61 & 0.33 \\
\hline 3.6 & 2.4 & 6 & 2.722 & 1.783 & 2.737 & 2.706 & 34.50 & 0.56 & 0.58 \\
\hline 3 & 3 & 6 & 2.636 & 1.726 & 2.574 & 2.588 & 34.52 & 2.36 & 1.81 \\
\hline 2.4 & 3.6 & 6 & 2.539 & 1.692 & 2.450 & 2.479 & 33.35 & 3.48 & 2.36 \\
\hline 1.8 & 4.2 & 6 & 2.438 & 1.676 & 2.358 & 2.378 & 31.24 & 3.28 & 2.47 \\
\hline 1.2 & 4.8 & 6 & 2.360 & 1.664 & 2.290 & 2.284 & 29.48 & 2.93 & 3.20 \\
\hline 0.6 & 5.4 & 6 & 2.287 & 1.658 & 2.243 & 2.197 & 27.49 & 1.90 & 3.92 \\
\hline 7 & 0 & 7 & 4.461 & 4.337 & 4.564 & 4.398 & 2.79 & 2.31 & 1.43 \\
\hline 6.3 & 0.7 & 7 & 4.224 & 3.161 & 4.353 & 4.153 & 25.18 & 3.05 & 1.69 \\
\hline 5.6 & 1.4 & 7 & 3.974 & 2.467 & 3.739 & 3.804 & & & \\
\hline 4.9 & 2.1 & 7 & 3.815 & 2.087 & 3.285 & 3.371 & & & \\
\hline 4.2 & 2.8 & 7 & 3.620 & 1.885 & 2.951 & 3.038 & & & \\
\hline 3.5 & 3.5 & 7 & 3.487 & 1.773 & 2.707 & 2.783 & & & \\
\hline 2.8 & 4.2 & 7 & 3.335 & 1.712 & 2.529 & 2.587 & & & \\
\hline 2.1 & 4.9 & 7 & 3.177 & 1.682 & 2.401 & 2.437 & & & \\
\hline 1.4 & 5.6 & 7 & 3.058 & 1.673 & 2.310 & 2.322 & & & \\
\hline \multirow[t]{2}{*}{0.7} & 6.3 & 7 & 2.950 & 1.679 & 2.250 & 2.234 & & & \\
\hline & & & & & & Average & 26.80 & 1.96 & 1.87 \\
\hline
\end{tabular}

${ }^{a}$ Data from Jiang (1996a). ${ }^{\mathrm{b}}$ Using ASPEN Plus default values for binary parameters of $\mathrm{HCl}$ and $\mathrm{NaCl}$ (see Table B1). ${ }^{\mathrm{c}}$ Using $\mathrm{NaOH}$ default Pitzer binaries from Table $\mathrm{B} 1 ; \mathrm{HCl}$ binaries from this work, mixing parameters and $\mathrm{NaCl}$ binaries and $\mathrm{K}_{\mathrm{sp}}$ values from Weber (2000) in Table B2: $\left[\mathrm{NaOH}: \beta^{(0)}=0.0864, \beta^{(1)}=0.253, \mathrm{C}^{\phi}=0.0044 ; \mathrm{NaCl}: \beta^{(0)}=0.06743, \beta^{(1)}=\right.$ $0.3301, \mathrm{C}^{\phi}=0.00263, \mathrm{Ln}\left(\mathrm{K}_{\mathrm{sp}}\right)=3.6155 ; \mathrm{HCl}: \beta^{(0)}=0.203486, \beta^{(1)}=0.1516, \mathrm{C}^{\phi}=-0.003646 ; \theta:(\mathrm{H}, \mathrm{Na})=0.036,(\mathrm{Cl}, \mathrm{OH})=-$ $0.050 ; \psi:(\mathrm{H}, \mathrm{Na}, \mathrm{Cl})=-0.004,(\mathrm{Cl}, \mathrm{OH}, \mathrm{Na})=-0.006]$. 
Table 4. Comparison Of Pitzer Parameters For Solubility: HCl-NaCl- $\mathrm{H}_{2} \mathrm{O}$ System.

\begin{tabular}{|c|c|c|c|c|c|c|c|c|c|c|c|c|c|c|c|c|c|c|}
\hline \multicolumn{3}{|c|}{ Data $^{a}$} & \multicolumn{6}{|c|}{ Transformed Concentrations } & \multirow{2}{*}{\multicolumn{5}{|c|}{$\begin{array}{l}\text { Predicted } \mathrm{NaCl} \text { Saturation } \\
\text { Molality }(\mathrm{mol} / \mathrm{kg})\end{array}$}} & \multirow{2}{*}{\multicolumn{5}{|c|}{$\%$ Absolute Deviation }} \\
\hline \multirow{2}{*}{$\begin{array}{c}\text { Molarity } \\
\mathrm{HCl}\end{array}$} & \multirow{2}{*}{$\begin{array}{c}\text { Molarity } \\
\mathrm{NaCl}\end{array}$} & \multirow{2}{*}{ Density } & \multirow{2}{*}{$\begin{array}{c}\text { Molarity } \\
\mathrm{H} 2 \mathrm{O}\end{array}$} & \multicolumn{2}{|c|}{ Mol. Frac. } & \multicolumn{2}{|c|}{ Molality } & \multirow{2}{*}{\begin{tabular}{|c|} 
Ionic \\
Strength
\end{tabular}} & & & & & & & & & & \\
\hline & & & & $\mathrm{HCl}$ & $\mathrm{NaCl}$ & $\mathrm{HCl}$ & $\mathrm{NaCl}$ & & ENRTL & $\mathrm{B}^{\mathrm{b}}$ & $\mathrm{B}^{\mathrm{C}}$ & $\mathrm{B}^{\mathrm{d}}$ & $\mathrm{M}^{\mathrm{e}}$ & ENRTL & $\mathrm{B}^{\mathrm{b}}$ & $\mathrm{B}^{\mathrm{C}}$ & $\mathrm{B}^{\mathrm{d}}$ & $\mathrm{M}^{\mathrm{e}}$ \\
\hline 13.41 & 0.017 & 1.197 & 39.2483 & 0.2546 & 0.0003 & 18.9656 & 0.0240 & 18.99 & 0.0003 & 0.0027 & 0.0024 & 0.0020 & 0.0073 & 98.6 & 88.8 & 90.2 & 91.7 & 69.4 \\
\hline 9.236 & 0.091 & 1.1458 & 44.6139 & 0.1712 & 0.0017 & 11.4914 & 0.1132 & 11.60 & 0.0073 & 0.0291 & 0.0519 & 0.0501 & 0.0861 & 93.6 & 74.3 & 54.2 & 55.8 & 23.9 \\
\hline 7.976 & 0.158 & 1.1302 & 46.0807 & 0.1471 & 0.0029 & 9.6078 & 0.1903 & 9.80 & 0.0248 & 0.1021 & 0.1410 & 0.1388 & 0.2033 & 87.0 & 46.3 & 25.9 & 27.0 & 6.8 \\
\hline 7.073 & 0.293 & 1.1213 & \begin{tabular}{|l|}
46.9762 \\
\end{tabular} & 0.1302 & 0.0054 & 8.3577 & 0.3462 & 8.70 & 0.0645 & 0.2270 & 0.2756 & 0.2734 & 0.3655 & 81.4 & 34.4 & 20.4 & 21.0 & 5.6 \\
\hline 6.101 & 0.544 & 1.1158 & \begin{tabular}{|l|}
47.8239 \\
\end{tabular} & 0.1120 & 0.0100 & 7.0813 & 0.6314 & 7.71 & 0.2014 & 0.4864 & 0.5370 & 0.5350 & 0.6620 & 68.1 & 23.0 & 15.0 & 15.3 & 4.8 \\
\hline 5.253 & 0.907 & 1.116 & 48.3737 & 0.0963 & 0.0166 & 6.0278 & 1.0408 & 7.07 & 0.5769 & 0.8569 & 0.9001 & 0.8984 & 1.0464 & 44.6 & 17.7 & 13.5 & 13.7 & 0.5 \\
\hline 4.5 & 1.333 & 1.12 & \begin{tabular}{|l|}
48.7377 \\
\end{tabular} & 0.0825 & 0.0244 & 5.1251 & 1.5182 & 6.64 & 1.2066 & 1.3153 & 1.3474 & 1.3464 & 1.5085 & 20.5 & 13.4 & 11.2 & 11.3 & 0.6 \\
\hline 3.83 & 1.797 & 1.1282 & 49.0436 & 0.0701 & 0.0329 & 4.3349 & 2.0339 & 6.37 & 1.8899 & 1.8284 & 1.8510 & 1.8506 & 2.0189 & 7.1 & 10.1 & 9.0 & 9.0 & 0.7 \\
\hline 3.487 & 2.079 & 1.1319 & 49.0284 & 0.0639 & 0.0381 & 3.9479 & 2.3538 & 6.30 & 2.2485 & 2.1163 & 2.1348 & 2.1354 & 2.3031 & 4.5 & 10.1 & 9.3 & 9.3 & 2.2 \\
\hline 3.185 & 2.31 & 1.1352 & 499.0734 & 0.0584 & 0.0423 & 3.6027 & 2.6129 & 6.22 & 2.5782 & 2.3922 & 2.4076 & 2.4089 & 2.5742 & 1.3 & 8.4 & 7.9 & 7.8 & 1.5 \\
\hline 2.265 & 3.149 & 1.1511 & \begin{tabular}{|l|}
49.0962 \\
\end{tabular} & 0.0416 & 0.0578 & 2.5608 & 3.5603 & 6.12 & 3.6802 & 3.3229 & 3.3323 & 3.3360 & 3.4809 & 3.4 & 6.7 & 6.4 & 6.3 & 2.2 \\
\hline 0.886 & 4.483 & 1.1781 & 49.0583 & 0.0163 & 0.0824 & 1.0025 & 5.0724 & 6.07 & 5.5990 & 4.9403 & 4.9451 & 4.9512 & 5.0245 & 10.4 & 2.6 & 2.5 & 2.4 & 0.9 \\
\hline 0.503 & 4.88 & 1.1867 & 499.0229 & 0.0092 & 0.0897 & 0.5695 & 5.5256 & 6.10 & 6.1442 & 5.4273 & 5.4306 & 5.4366 & 5.4809 & 11.2 & 1.8 & 1.7 & 1.6 & 0.8 \\
\hline 0 & 5.4325 & 1.1981 & 48.8814 & 0.0000 & 0.1000 & 0.0000 & 6.1690 & 6.17 & 6.7968 & 6.0886 & 6.0886 & 6.0938 & 6.0938 & 10.2 & 1.3 & 1.3 & 1.2 & 1.2 \\
\hline & & & & & & & & & & & & & Average & 38.7 & 24.2 & 19.2 & 19.5 & 8.7 \\
\hline & & & & & & & & & & & & & Average $^{\dagger}$ & 34.1 & 19.2 & 13.7 & 14.0 & 4.0 \\
\hline
\end{tabular}

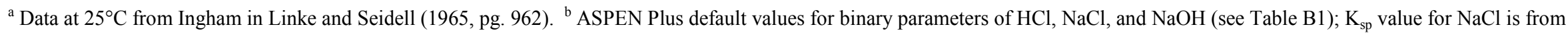

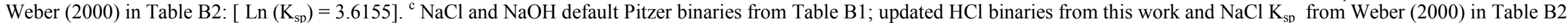

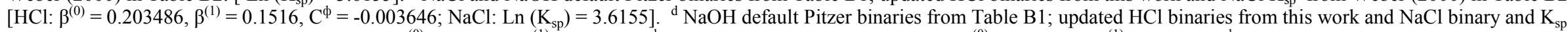

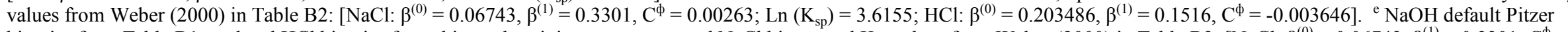

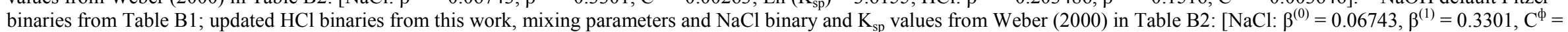

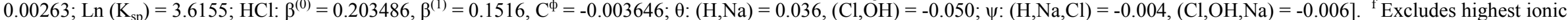
strength data point $(18.99 \mathrm{~mol} / \mathrm{kg})$. 
Table 5. Comparison of Model Predictions For $\gamma_{ \pm, \text {st }}$ : HCl-NaCl-KCl- $\mathrm{H}_{2} \mathrm{O}$ System.

\begin{tabular}{|c|c|c|c|c|c|c|c|c|c|c|c|c|c|}
\hline \multirow{2}{*}{\multicolumn{4}{|c|}{$\begin{array}{c}\text { Concentration } \\
\text { Molality }(\mathrm{mol} / \mathrm{kg})\end{array}$}} & \multicolumn{7}{|c|}{$\gamma_{ \pm, \text {st }(\mathrm{HCl})}$} & \multirow{3}{*}{$\mathrm{K}_{\mathrm{sp}}=$} & \multicolumn{2}{|c|}{ 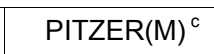 } \\
\hline & & & & \multirow{2}{*}{ Data $^{a}$} & \multicolumn{3}{|c|}{ Predictions } & \multicolumn{3}{|c|}{$\begin{array}{c}\text { Percent Absolute } \\
\text { Deviation }\end{array}$} & & \multirow{2}{*}{\begin{tabular}{|l|}
37.170 \\
$\mathrm{NaCl}$ \\
Activity
\end{tabular}} & \multirow{2}{*}{\begin{tabular}{|l|}
\multicolumn{1}{|c|}{7.499} \\
$\mathrm{KCl}$ \\
Activity
\end{tabular}} \\
\hline $\mathrm{HCl}$ & $\mathrm{NaCl}$ & $\mathrm{KCl}$ & $\begin{array}{l}\text { lonic } \\
\text { Strength }\end{array}$ & & ENRTL & \begin{tabular}{|c|} 
PITZER \\
$(\mathrm{AP})^{\mathrm{b}}$
\end{tabular} & $\begin{array}{l}\text { PITZER( } \\
M)^{c}\end{array}$ & ENRTL & $\begin{array}{c}\text { PITZER } \\
(\mathrm{AP})^{\mathrm{b}}\end{array}$ & \begin{tabular}{|c|} 
PITZER \\
$(\mathrm{M})^{\mathrm{c}}$
\end{tabular} & & & \\
\hline 3.20 & 0.80 & 0.00 & 4.00 & 1.66 & 1.12 & 1.68 & 1.69 & 32.25 & 1.11 & 1.84 & & 4.58 & \\
\hline 2.88 & 0.80 & 0.32 & 4.00 & 1.58 & 1.04 & 1.61 & 1.60 & 34.16 & 1.91 & 1.10 & & 4.01 & 0.89 \\
\hline 2.56 & 0.80 & 0.64 & 4.00 & 1.50 & 0.98 & 1.54 & 1.51 & 34.91 & 2.89 & 0.64 & & 3.53 & 1.63 \\
\hline 2.24 & 0.80 & 0.96 & 4.00 & 1.43 & 0.93 & 1.48 & 1.43 & 35.42 & 3.24 & 0.31 & & 3.11 & 2.24 \\
\hline 1.92 & 0.80 & 1.28 & 4.00 & 1.37 & 0.88 & 1.42 & 1.35 & 35.35 & 3.91 & 0.85 & & 2.75 & 2.75 \\
\hline 1.60 & 0.80 & 1.60 & 4.00 & 1.31 & 0.85 & 1.36 & 1.29 & 35.24 & 4.19 & 1.64 & & 2.43 & 3.16 \\
\hline 1.28 & 0.80 & 1.92 & 4.00 & 1.25 & 0.81 & 1.31 & 1.22 & 34.86 & 4.62 & 2.19 & & 2.16 & 3.50 \\
\hline 0.96 & 0.80 & 2.24 & 4.00 & 1.19 & 0.78 & 1.25 & 1.16 & 34.31 & 5.05 & 2.61 & & 1.92 & 3.77 \\
\hline 0.64 & 0.80 & 2.56 & 4.00 & 1.14 & 0.76 & 1.20 & 1.11 & 33.80 & 5.26 & 3.13 & & 1.71 & 3.99 \\
\hline 0.32 & 0.80 & 2.88 & 4.00 & 1.09 & 0.73 & 1.15 & 1.05 & 33.23 & 5.40 & 3.60 & & 1.53 & 4.17 \\
\hline 4.00 & 1.00 & 0.00 & 5.00 & 2.21 & 1.51 & 2.25 & 2.24 & 31.82 & 1.92 & 1.47 & & $\mid 10.41$ & \\
\hline 3.60 & 1.00 & 0.40 & 5.00 & 2.07 & 1.35 & 2.14 & 2.08 & 34.80 & 3.17 & 0.41 & & 8.81 & 1.64 \\
\hline 3.20 & 1.00 & 0.80 & 5.00 & 1.93 & 1.24 & 2.03 & 1.93 & 36.07 & 4.72 & 0.19 & & 7.49 & 2.94 \\
\hline 2.80 & 1.00 & 1.20 & 5.00 & 1.83 & 1.15 & 1.92 & 1.80 & 37.07 & 5.26 & 1.57 & & 6.38 & 3.96 \\
\hline 2.40 & 1.00 & 1.60 & 5.00 & 1.71 & 1.08 & 1.82 & 1.68 & 37.20 & 6.33 & 2.28 & & 5.46 & 4.76 \\
\hline 2.00 & 1.00 & 2.00 & 5.00 & 1.62 & 1.02 & 1.73 & 1.57 & 37.36 & 6.73 & 3.44 & & 4.69 & 5.38 \\
\hline 1.60 & 1.00 & 2.40 & 5.00 & 1.53 & 0.96 & 1.64 & 1.46 & 37.09 & 7.40 & 4.17 & & 4.04 & 5.86 \\
\hline 1.20 & 1.00 & 2.80 & 5.00 & 1.44 & 0.91 & 1.56 & 1.37 & 36.58 & 8.14 & 4.67 & & 3.49 & 6.22 \\
\hline 0.80 & 1.00 & 3.20 & 5.00 & 1.36 & 0.87 & 1.48 & 1.29 & 36.17 & 8.45 & 5.37 & & 3.03 & 6.50 \\
\hline 0.40 & 1.00 & 3.60 & 5.00 & 1.29 & 0.83 & 1.40 & 1.21 & 35.70 & 8.66 & 6.00 & & 2.64 & 6.71 \\
\hline 4.80 & 1.20 & 0.00 & 6.00 & 2.97 & 2.01 & 3.06 & 2.97 & 32.45 & 2.97 & 0.11 & & 21.95 & \\
\hline 4.32 & 1.20 & 0.48 & 6.00 & 2.74 & \begin{tabular}{|l|}
1.74 \\
\end{tabular} & 2.87 & 2.70 & 36.27 & 4.77 & 1.29 & & 17.91 & 2.73 \\
\hline 3.84 & 1.20 & 0.96 & 6.00 & 2.51 & 1.56 & 2.69 & 2.46 & 37.87 & 7.01 & 2.04 & & $\mid 14.69$ & 4.79 \\
\hline 3.36 & 1.20 & 1.44 & 6.00 & 2.34 & 1.42 & 2.52 & 2.25 & 39.21 & 7.80 & 3.88 & & 12.11 & 6.33 \\
\hline 2.88 & 1.20 & 1.92 & 6.00 & 2.17 & 1.31 & 2.37 & 2.06 & 39.42 & 9.37 & 4.77 & & $\mid 10.04$ & 7.48 \\
\hline 2.40 & 1.20 & 2.40 & 6.00 & 2.02 & 1.22 & 2.22 & 1.89 & & & & & 8.36 & 8.32 \\
\hline 1.92 & 1.20 & 2.88 & 6.00 & 1.88 & 1.14 & 2.08 & 1.74 & & & & & 7.00 & 8.93 \\
\hline 1.44 & 1.20 & 3.36 & 6.00 & 1.75 & 1.07 & 1.96 & 1.61 & & & & & 5.89 & 9.37 \\
\hline 0.96 & 1.20 & 3.84 & 6.00 & 1.63 & 1.00 & 1.83 & 1.49 & & & & & 4.98 & 9.68 \\
\hline 0.48 & 1.20 & 4.32 & 6.00 & 1.53 & 0.95 & 1.72 & 1.38 & & & & & 4.23 & 9.89 \\
\hline 5.60 & 1.40 & 0.00 & 7.00 & 4.02 & 2.47 & 3.74 & 3.80 & & & & & 42.59 & \\
\hline 5.04 & 1.40 & 0.56 & 7.00 & 3.64 & 2.16 & 3.60 & 3.50 & 40.73 & 1.14 & 3.97 & & 34.43 & 4.20 \\
\hline 4.48 & 1.40 & 1.12 & 7.00 & 3.28 & 1.95 & 3.48 & 3.12 & 40.56 & 5.94 & 4.90 & & 27.25 & 7.22 \\
\hline 3.92 & 1.40 & 1.68 & 7.00 & 3.01 & 1.75 & 3.34 & 2.80 & & & & & 21.71 & 9.37 \\
\hline 3.36 & 1.40 & 2.24 & 7.00 & 2.74 & 1.59 & 3.10 & 2.52 & & & & & 17.42 & 10.89 \\
\hline 2.80 & 1.40 & 2.80 & 7.00 & 2.53 & 1.45 & 2.88 & 2.27 & & & & & 14.08 & 11.94 \\
\hline 2.24 & 1.40 & 3.36 & 7.00 & 2.31 & 1.34 & 2.67 & 2.06 & & & & & 11.45 & 12.66 \\
\hline 1.68 & 1.40 & 3.92 & 7.00 & 2.12 & 1.24 & 2.47 & 1.87 & & & & & 9.38 & 13.14 \\
\hline 1.12 & 1.40 & 4.48 & 7.00 & 1.95 & 1.15 & 2.30 & 1.70 & & & & & 7.74 & 13.46 \\
\hline \multirow[t]{2}{*}{0.56} & 1.40 & 5.04 & 7.00 & 1.81 & 1.08 & 2.13 & 1.56 & & & & & 6.43 & 13.66 \\
\hline & & & & & & & Average & 35.92 & 5.09 & 2.53 & & & \\
\hline
\end{tabular}

${ }^{a}$ Data from Jiang (1996b). ${ }^{\mathrm{b}}$ Using ASPEN Plus default values for binary parameters of $\mathrm{HCl}, \mathrm{NaCl}, \mathrm{KCl}$, and $\mathrm{NaOH}$ (see Table B1). ${ }^{\mathrm{c}}$ Using $\mathrm{NaOH}$ default Pitzer binaries from Table $\mathrm{B} 1 ; \mathrm{HCl}$ binaries from this work, and all other parameter values are from Weber (2000) in Table B2: $\left[\mathrm{NaOH}: \beta^{(0)}=0.0864, \beta^{(1)}=0.253, \mathrm{C}^{\phi}=0.0044 ; \mathrm{NaCl}: \beta^{(0)}=0.06743, \beta^{(1)}=0.3301, \mathrm{C}^{\phi}\right.$ $=0.00263, \mathrm{Ln}\left(\mathrm{K}_{\mathrm{sp}}\right)=3.6155 ; \mathrm{HCl}: \beta^{(0)}=0.203486, \beta^{(1)}=0.1516, \mathrm{C}^{\phi}=-0.003646 ; \theta:(\mathrm{H}, \mathrm{Na})=0.036,(\mathrm{H}, \mathrm{K})=0.005,(\mathrm{~K}, \mathrm{Na})$ $=-0.012,(\mathrm{Cl}, \mathrm{OH})=-0.050 ; \psi:(\mathrm{H}, \mathrm{Na}, \mathrm{Cl})=-0.004,(\mathrm{~K}, \mathrm{Na}, \mathrm{Cl})=-0.0018,(\mathrm{H}, \mathrm{K}, \mathrm{Cl})=-0.01099,(\mathrm{Cl}, \mathrm{OH}, \mathrm{Na})=-0.006$,

$(\mathrm{Cl}, \mathrm{OH}, \mathrm{K})=-0.00317]$. 
Table 6. Dissociation And Activity Coefficient: $\mathrm{H}_{2} \mathrm{SO}_{4}-\mathrm{H}_{2} \mathrm{O}$ System.

\begin{tabular}{|c|c|c|c|c|c|c|c|c|c|c|c|c|c|c|c|c|c|c|}
\hline \multirow{2}{*}{\multicolumn{3}{|c|}{ Data }} & \multicolumn{8}{|c|}{$\alpha$} & \multicolumn{8}{|c|}{$\gamma_{ \pm, \mathrm{st}(\mathrm{H} 2 \mathrm{SO} 4)}$} \\
\hline & & & \multicolumn{4}{|c|}{ Predictions } & \multicolumn{4}{|c|}{$\%$ Abs. Dev. } & \multicolumn{4}{|c|}{ Predictions } & \multicolumn{4}{|c|}{ \% Abs. Dev. } \\
\hline \multirow{2}{*}{$\begin{array}{c}\mathrm{m} \mathrm{H}_{2} \mathrm{SO}_{4} \\
(\mathrm{~mol} / \mathrm{kg})\end{array}$} & \multirow{2}{*}{$\alpha^{\mathrm{a}}$} & \multirow{2}{*}{$\gamma_{ \pm, \text {st (H2SO4) }}{ }^{b}$} & \multirow{2}{*}{ ENRTL } & \multicolumn{3}{|c|}{ PITZER } & \multirow{2}{*}{ ENRTL } & \multicolumn{3}{|c|}{ PITZER } & \multirow{2}{*}{ ENRTL } & \multicolumn{3}{|c|}{ PITZER } & \multirow{2}{*}{ ENRTL } & \multicolumn{3}{|c|}{ PITZER } \\
\hline & & & & $\mathrm{AP}^{\mathrm{c}}$ & RAP $^{d}$ & $\mathrm{RP}^{\mathrm{e}}$ & & $\mathrm{AP}^{\mathrm{c}}$ & RAP $^{d}$ & $\mathrm{RP}^{\mathrm{e}}$ & & $\mathrm{AP}^{\mathrm{c}}$ & RAP $^{d}$ & $\mathrm{RP}^{\mathrm{e}}$ & & $\mathrm{AP}^{\mathrm{c}}$ & RAP $^{d}$ & $\mathrm{RP}^{\mathrm{e}}$ \\
\hline 0.001 & 0.88 & 0.8152 & 0.88 & 0.88 & 0.88 & 0.88 & 0.06 & 0.01 & 0.02 & 0.05 & 0.8168 & 0.8146 & 0.8148 & 0.8151 & 0.20 & 0.07 & 0.04 & 0.01 \\
\hline 0.002 & 0.80 & 0.7384 & 0.80 & 0.80 & 0.80 & 0.80 & 0.18 & 0.02 & 0.07 & 0.12 & 0.7404 & 0.7371 & 0.7377 & 0.7383 & 0.28 & 0.18 & 0.09 & 0.01 \\
\hline 0.01 & 0.67 & 0.6146 & 0.66 & 0.67 & 0.67 & 0.67 & 0.64 & 0.05 & 0.25 & 0.33 & 0.6164 & 0.6117 & 0.6136 & 0.6149 & 0.30 & 0.46 & 0.16 & 0.04 \\
\hline 0.01 & 0.56 & 0.5145 & 0.55 & 0.55 & 0.56 & 0.56 & 1.45 & 0.06 & 0.61 & 0.60 & 0.5150 & 0.5098 & 0.5134 & 0.5151 & 0.10 & 0.92 & 0.20 & 0.13 \\
\hline 0.02 & 0.45 & 0.4189 & 0.43 & 0.45 & 0.45 & 0.45 & 2.90 & 0.06 & 1.28 & 0.97 & 0.4168 & 0.4116 & 0.4179 & 0.4199 & 0.50 & 1.75 & 0.25 & 0.25 \\
\hline 0.05 & 0.33 & 0.3098 & 0.31 & 0.33 & 0.34 & 0.33 & 6.43 & 0.15 & 2.92 & 1.56 & 0.3022 & 0.2979 & 0.3092 & 0.3116 & 2.46 & 3.84 & 0.20 & 0.57 \\
\hline 0.10 & 0.27 & 0.2436 & 0.24 & 0.26 & 0.28 & 0.27 & 10.87 & 0.69 & 4.93 & 1.95 & 0.2305 & 0.2274 & 0.2437 & 0.2462 & 5.38 & 6.66 & 0.03 & 1.07 \\
\hline 0.20 & 0.22 & 0.1916 & 0.19 & 0.22 & 0.24 & 0.23 & 17.56 & 2.61 & 7.50 & 2.06 & 0.1720 & 0.1702 & 0.1926 & 0.1954 & 10.24 & 11.20 & 0.55 & 1.97 \\
\hline 0.30 & 0.21 & 0.1672 & 0.16 & 0.20 & 0.23 & 0.22 & 22.94 & 4.95 & 9.05 & 1.79 & 0.1437 & 0.1424 & 0.1690 & 0.1720 & 14.06 & 14.86 & 1.10 & 2.85 \\
\hline 0.40 & 0.21 & 1525 & 0.15 & 0.19 & 0.23 & 0.21 & \begin{tabular}{|l|}
27.64 \\
\end{tabular} & 7.36 & 10.01 & 1.36 & 0.1262 & 0.1250 & 0.1549 & 0.1580 & 17.22 & 18.06 & 1.59 & 3.64 \\
\hline 0.50 & 0.21 & 0.1425 & 0.14 & 0.19 & 0.23 & 0.21 & 31.90 & 9.69 & 10.57 & 0.86 & 0.1143 & 0.1127 & 0.1454 & 0.1488 & 19.81 & 20.91 & 2.07 & 4.39 \\
\hline 0.60 & 0.21 & 0.1353 & 0.13 & 0.18 & 0.23 & 0.21 & \begin{tabular}{|l|}
35.85 \\
\end{tabular} & 11.90 & 10.88 & 0.32 & 0.1055 & 0.1034 & 0.1387 & 0.1421 & 22.01 & 23.55 & 2.49 & 5.06 \\
\hline 0.70 & 0.21 & 0.1300 & 0.13 & 0.18 & 0.24 & 0.21 & \begin{tabular}{|l|}
39.54 \\
\end{tabular} & 13.97 & 10.97 & 0.25 & 0.0989 & 0.0961 & 0.1336 & 0.1373 & 23.93 & 26.07 & 2.79 & 5.59 \\
\hline 0.80 & 0.22 & 0.1259 & 0.12 & 0.18 & 0.24 & 0.21 & 43.03 & 15.90 & 10.89 & 0.84 & 0.0937 & 0.0901 & 0.1298 & 0.1336 & 25.54 & 28.41 & 3.10 & 6.10 \\
\hline 0.90 & 0.22 & 0.1228 & 0.12 & 0.18 & 0.24 & 0.22 & 46.32 & 17.70 & 10.69 & 1.44 & 0.0897 & 0.0851 & 0.1269 & 0.1308 & 26.97 & 30.69 & 3.30 & 6.50 \\
\hline 1.00 & 0.22 & 0.1204 & 0.11 & 0.18 & 0.25 & 0.22 & 49.46 & 19.39 & 10.37 & 2.05 & 0.0864 & 0.0808 & 0.1246 & 0.1286 & 28.21 & 32.86 & 3.47 & 6.85 \\
\hline 1.20 & 0.23 & 0.1173 & 0.10 & 0.18 & 0.25 & 0.23 & 55.25 & 22.46 & 9.46 & 3.30 & 0.0817 & 0.0739 & 0.1215 & 0.1258 & 30.31 & 37.03 & 3.61 & 7.28 \\
\hline 1.40 & 0.24 & 0.1157 & 0.10 & 0.18 & 0.26 & 0.23 & 60.46 & 25.20 & 8.27 & 4.58 & 0.0787 & 0.0684 & 0.1199 & 0.1245 & 31.94 & 40.88 & 3.66 & 7.58 \\
\hline 1.60 & 0.25 & 0.1153 & 0.09 & 0.18 & 0.27 & 0.24 & 65.13 & 27.69 & 6.86 & 5.90 & 0.0769 & 0.0640 & 0.1194 & 0.1241 & 33.28 & 44.53 & 3.55 & 7.64 \\
\hline 1.80 & 0.26 & 0.1157 & 0.08 & 0.18 & 0.27 & 0.24 & \begin{tabular}{|l|}
69.30 \\
\end{tabular} & 29.96 & 5.30 & 7.23 & 0.0760 & 0.0603 & 0.1197 & 0.1245 & 34.35 & 47.92 & 3.42 & 7.65 \\
\hline 2.00 & 0.27 & 0.1169 & 0.07 & 0.18 & 0.28 & 0.25 & \begin{tabular}{|l|}
72.99 \\
\end{tabular} & 32.05 & 3.64 & 8.55 & 0.0756 & 0.0571 & 0.1206 & 0.1256 & 35.30 & 51.14 & 3.14 & 7.46 \\
\hline 2.20 & 0.28 & 0.1186 & 0.07 & 0.18 & 0.29 & 0.25 & \begin{tabular}{|l|}
76.24 \\
\end{tabular} & 33.97 & 1.94 & 9.83 & 0.0758 & 0.0544 & 0.1220 & 0.1272 & 36.08 & 54.13 & 2.90 & 7.26 \\
\hline 2.40 & & 0.1209 & 0.06 & 0.19 & 0.29 & & & & & & 0.0764 & 0.0520 & 0.1240 & 0.1293 & 36.83 & 56.95 & 2.55 & 6.93 \\
\hline 2.60 & & 0.1237 & 0.05 & 0.19 & 0.29 & & & & & & 0.0773 & 0.0500 & 0.1264 & 0.1317 & 37.54 & 59.61 & 2.14 & 6.50 \\
\hline 2.62 & 0.34 & & 0.05 & 0.19 & 0.29 & 0.26 & 83.96 & 45.00 & 13.46 & 22.88 & 0.0774 & 0.0498 & 0.1266 & & & & & \\
\hline 2.80 & & 0.1269 & 0.05 & 0.19 & 0.30 & & & & & & 0.0784 & 0.0481 & 0.1291 & 0.1346 & 38.21 & 62.10 & 1.75 & 6.05 \\
\hline
\end{tabular}


Table 6 (Continued). Dissociation And Activity Coefficient: $\mathrm{H}_{2} \mathrm{SO}_{4}-\mathrm{H}_{2} \mathrm{O}$ System.

\begin{tabular}{|c|c|c|c|c|c|c|c|c|c|c|c|c|c|c|c|c|c|c|}
\hline \multirow{2}{*}{\multicolumn{3}{|c|}{ Data }} & \multicolumn{8}{|c|}{$\alpha$} & \multicolumn{8}{|c|}{$\gamma_{ \pm, \text {st }(\mathrm{H} 2 \mathrm{SO} 4)}$} \\
\hline & & & \multicolumn{4}{|c|}{ Predictions } & \multicolumn{4}{|c|}{$\%$ Abs. Dev. } & \multicolumn{4}{|c|}{ Predictions } & \multicolumn{4}{|c|}{$\%$ Abs. Dev. } \\
\hline \multirow{2}{*}{$\begin{array}{c}\mathrm{m} \mathrm{H}_{2} \mathrm{SO}_{4} \\
(\mathrm{~mol} / \mathrm{kg})\end{array}$} & \multirow{2}{*}{$\alpha^{a}$} & \multirow{2}{*}{$\gamma_{ \pm, \mathrm{st}(\mathrm{H} 2 \mathrm{SO} 4)}{ }^{\mathrm{b}}$} & \multirow{2}{*}{ ENRTL } & \multicolumn{3}{|c|}{ PITZER } & \multirow{2}{*}{ ENRTL } & \multicolumn{3}{|c|}{ PITZER } & \multirow{2}{*}{ ENRTL } & \multicolumn{3}{|c|}{ PITZER } & \multirow{2}{*}{ ENRTL } & \multicolumn{3}{|c|}{ PITZER } \\
\hline & & & & $\mathrm{AP}^{\mathrm{c}}$ & RAP $^{d}$ & $\mathrm{RP}^{\mathrm{e}}$ & & $\mathrm{AP}^{\mathrm{c}}$ & RAP $^{d}$ & $\mathrm{RP}^{\mathrm{e}}$ & & $\mathrm{AP}^{\mathrm{c}}$ & $\mathrm{RAP}^{\mathrm{d}}$ & $\mathrm{RP}^{\mathrm{e}}$ & & $\mathrm{AP}^{\mathrm{c}}$ & $\mathrm{RAP}^{\mathrm{d}}$ & $\mathrm{RP}^{\mathrm{e}}$ \\
\hline 2.91 & 0.25 & & 0.05 & 0.19 & 0.30 & 0.27 & 81.40 & 25.88 & 17.76 & 5.73 & 0.0792 & 0.0471 & 0.1309 & & & & & \\
\hline 3.00 & & 0.1306 & 0.05 & 0.19 & 0.30 & & & & & & 0.0798 & 0.0464 & 0.1322 & 0.1378 & 38.90 & 64.45 & 1.26 & 5.49 \\
\hline 3.20 & & 0.1347 & 0.04 & 0.19 & 0.30 & & & & & & 0.0814 & 0.0449 & 0.1357 & 0.1413 & 39.60 & 66.65 & 0.77 & 4.88 \\
\hline 3.40 & & 0.1393 & 0.04 & 0.19 & 0.31 & & & & & & 0.0831 & 0.0436 & 0.1396 & 0.1451 & 40.36 & 68.73 & 0.19 & 4.17 \\
\hline 3.60 & & 0.1443 & 0.03 & 0.19 & 0.31 & & & & & & 0.0849 & 0.0423 & 0.1437 & 0.1492 & 41.13 & 70.68 & 0.41 & 3.42 \\
\hline 3.76 & 0.26 & & 0.03 & 0.19 & 0.31 & 0.28 & 88.01 & 27.63 & 16.61 & 7.71 & 0.0865 & 0.0414 & 0.1473 & & & & & \\
\hline 3.80 & & 0.1498 & 0.03 & 0.19 & 0.31 & & & & & & 0.0869 & 0.0412 & 0.1482 & 0.1537 & 41.97 & 72.52 & 1.07 & 2.59 \\
\hline 4.00 & & 0.1556 & 0.03 & 0.19 & 0.31 & & & & & & 0.0890 & 0.0401 & 0.1530 & 0.1584 & 42.80 & 74.22 & 1.67 & 1.80 \\
\hline 4.11 & 0.30 & & 0.03 & 0.19 & 0.31 & 0.29 & 91.00 & 36.04 & 3.16 & 3.33 & 0.0902 & 0.0396 & 0.1559 & & & & & \\
\hline 4.20 & & 0.1620 & 0.03 & 0.19 & 0.31 & & & & & & 0.0912 & 0.0391 & 0.1581 & 0.1634 & 43.72 & 75.84 & 2.39 & 0.88 \\
\hline 4.40 & & 0.1687 & 0.02 & 0.19 & 0.31 & & & & & & 0.0934 & 0.0382 & 0.1636 & 0.1688 & 44.62 & 77.33 & 3.02 & 0.03 \\
\hline 4.60 & & 0.1758 & 0.02 & 0.19 & 0.31 & & & & & & 0.0957 & 0.0374 & 0.1694 & 0.1744 & 45.55 & 78.73 & 3.64 & 0.81 \\
\hline 4.66 & 0.27 & & 0.02 & 0.19 & 0.31 & 0.30 & 92.09 & 28.63 & 14.73 & 10.31 & 0.0965 & 0.0372 & 0.1712 & & & & & \\
\hline 4.80 & & 0.1833 & 0.02 & 0.19 & 0.31 & & & & & & 0.0981 & 0.0366 & 0.1755 & 0.1803 & 46.48 & 80.03 & 4.25 & 1.64 \\
\hline 5.00 & & 0.1912 & 0.02 & 0.19 & 0.31 & & & & & & 0.1005 & 0.0359 & 0.1820 & 0.1865 & 47.43 & 81.23 & 4.82 & 2.45 \\
\hline 5.09 & 0.29 & & 0.02 & 0.19 & 0.31 & 0.30 & 93.82 & 33.46 & 6.27 & 4.50 & 0.1016 & 0.0356 & 0.1850 & & & & & \\
\hline 5.20 & & 0.1994 & 0.02 & 0.19 & 0.31 & & & & & & 0.1030 & 0.0352 & 0.1888 & 0.1931 & 48.36 & 82.35 & 5.31 & 3.18 \\
\hline 5.40 & & 0.2080 & 0.02 & 0.19 & 0.31 & & & & & & 0.1054 & 0.0345 & 0.1960 & 0.1999 & 49.30 & 83.39 & 5.78 & 3.89 \\
\hline 5.60 & & 0.2168 & 0.01 & 0.19 & 0.30 & & & & & & 0.1080 & 0.0339 & 0.2035 & 0.2071 & 50.20 & 84.34 & 6.13 & 4.48 \\
\hline 5.62 & 0.30 & & 0.01 & 0.19 & 0.30 & 0.31 & 95.12 & 35.67 & 1.44 & 2.76 & 0.1083 & 0.0339 & 0.2044 & & & & & \\
\hline 5.80 & & 0.2259 & 0.01 & 0.19 & 0.30 & & & & & & 0.1105 & 0.0334 & 0.2114 & 0.2146 & 51.09 & 85.23 & 6.42 & 5.00 \\
\hline 6.00 & & 0.2352 & 0.01 & 0.19 & 0.30 & & & & & & 0.1130 & 0.0328 & 0.2197 & 0.2225 & 51.94 & 86.04 & 6.60 & 5.42 \\
\hline 6.65 & 0.29 & & 0.01 & 0.19 & 0.29 & 0.31 & 96.44 & 33.78 & 0.57 & 8.12 & 0.1214 & 0.0313 & 0.2493 & & & & & \\
\hline 6.69 & 0.27 & & 0.01 & 0.19 & 0.29 & 0.31 & 96.22 & 28.89 & 7.83 & 16.15 & 0.1218 & 0.0312 & 0.2510 & & & & & \\
\hline 7.83 & 0.26 & & 0.01 & 0.19 & 0.27 & 0.31 & 97.20 & 28.16 & 2.75 & 17.34 & 0.1363 & 0.0290 & 0.3138 & & & & & \\
\hline 8.52 & 0.26 & & 0.01 & 0.19 & 0.26 & 0.30 & 97.60 & 27.77 & 0.83 & 16.21 & 0.1446 & 0.0279 & 0.3586 & & & & & \\
\hline 9.07 & 0.26 & & 0.01 & 0.19 & 0.25 & 0.29 & 97.83 & 27.02 & 3.25 & 15.01 & 0.1512 & 0.0272 & 0.3987 & & & & & \\
\hline 10.00 & & 0.5270 & 0.005 & 0.18 & 0.23 & & & & & & 0.1615 & 0.0261 & 0.4747 & 0.4609 & 69.35 & 95.05 & 9.93 & 12.54 \\
\hline
\end{tabular}


Table 6 (Continued). Dissociation And Activity Coefficient: $\mathrm{H}_{2} \mathrm{SO}_{4}-\mathrm{H}_{2} \mathrm{O}$ System.

\begin{tabular}{|c|c|c|c|c|c|c|c|c|c|c|c|c|c|c|c|c|c|c|}
\hline \multirow{2}{*}{\multicolumn{3}{|c|}{ Data }} & \multicolumn{8}{|c|}{$\alpha$} & \multicolumn{8}{|c|}{$\gamma_{ \pm, \text {st }(\mathrm{H} 2 \mathrm{SO} 4)}$} \\
\hline & & & \multicolumn{4}{|c|}{ Predictions } & \multicolumn{4}{|c|}{ \% Abs. Dev. } & \multicolumn{4}{|c|}{ Predictions } & \multicolumn{4}{|c|}{$\%$ Abs. Dev. } \\
\hline \multirow{2}{*}{$\begin{array}{c}\mathrm{m} \mathrm{H}_{2} \mathrm{SO}_{4} \\
(\mathrm{~mol} / \mathrm{kg})\end{array}$} & \multirow{2}{*}{$\alpha^{a}$} & \multirow{2}{*}{$\gamma_{ \pm, \text {st (H2SO4) }}{ }^{b}$} & \multirow{2}{*}{ ENRTL } & \multicolumn{3}{|c|}{ PITZER } & \multirow{2}{*}{ ENRTL } & \multicolumn{3}{|c|}{ PITZER } & \multirow{2}{*}{ ENRTL } & \multicolumn{3}{|c|}{ PITZER } & \multirow{2}{*}{ ENRTL } & \multicolumn{3}{|c|}{ PITZER } \\
\hline & & & & $\mathrm{AP}^{\mathrm{c}}$ & RAP $^{d}$ & $\mathrm{RP}^{\mathrm{e}}$ & & $\mathrm{AP}^{\mathrm{c}}$ & RAP $^{d}$ & $\mathrm{RP}^{\mathrm{e}}$ & & $\mathrm{AP}^{\mathrm{c}}$ & RAP $^{d}$ & $\mathrm{RP}^{\mathrm{e}}$ & & $\mathrm{AP}^{\mathrm{c}}$ & RAP $^{d}$ & $\mathrm{RP}^{\mathrm{e}}$ \\
\hline 10.65 & 0.25 & & 0.004 & 0.18 & 0.22 & 0.26 & 98.35 & 27.80 & 13.75 & 3.53 & 0.1683 & 0.0254 & 0.5345 & & & & & \\
\hline 11.89 & 0.23 & & 0.003 & 0.18 & 0.19 & 0.23 & 98.51 & 24.00 & 16.22 & 1.10 & 0.1801 & 0.0244 & 0.6641 & & & & & \\
\hline 13.11 & 0.21 & & 0.003 & 0.17 & 0.17 & 0.20 & 98.58 & 18.79 & 16.90 & 4.49 & 0.1901 & 0.0235 & 0.8115 & & & & & \\
\hline 15.00 & & 1.0770 & 0.003 & 0.16 & 0.15 & & & & & & 0.2028 & 0.0224 & 1.0836 & 1.0052 & 81.17 & 97.92 & 0.62 & 6.67 \\
\hline 15.34 & 0.20 & & 0.002 & 0.16 & 0.15 & 0.16 & 98.77 & 18.65 & 26.39 & 20.03 & 0.2047 & 0.0223 & 1.1382 & & & & & \\
\hline 19.60 & 0.12 & & 0.002 & 0.14 & 0.11 & 0.11 & 98.37 & 19.78 & 9.38 & 10.01 & 0.2212 & 0.0207 & 1.9291 & & & & & \\
\hline 19.67 & 0.16 & & 0.002 & 0.14 & 0.11 & 0.11 & 98.78 & 10.33 & 32.33 & 32.88 & 0.2214 & 0.0206 & 1.9434 & & & & & \\
\hline 20.00 & & 1.7010 & 0.002 & 0.14 & 0.11 & & & & & & 0.2222 & 0.0206 & 2.0102 & 1.7970 & 86.94 & 98.79 & 18.18 & 5.65 \\
\hline 25.20 & 0.12 & & 0.002 & 0.12 & 0.08 & 0.08 & 98.55 & 3.40 & 32.17 & 36.72 & 0.2273 & 0.0194 & 3.0468 & & & & & \\
\hline 29.24 & 0.05 & & 0.002 & 0.11 & 0.07 & 0.06 & 96.61 & 124.54 & 39.75 & 29.20 & 0.2252 & 0.0188 & 3.5771 & & & & & \\
\hline 32.83 & 0.08 & & 0.002 & 0.10 & 0.06 & 0.06 & 97.87 & 29.68 & 20.85 & 25.89 & 0.2209 & 0.0184 & 3.6592 & & & & & \\
\hline 42.15 & 0.05 & & 0.002 & 0.08 & 0.05 & 0.06 & 96.32 & 75.90 & 11.20 & 14.26 & 0.2048 & 0.0177 & 2.2728 & & & & & \\
\hline & & & & & & Average & 64.26 & 22.88 & 10.09 & 8.28 & & & & & 33.45 & 49.96 & 2.97 & 4.19 \\
\hline
\end{tabular}

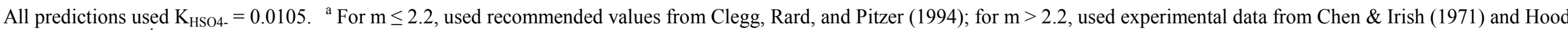

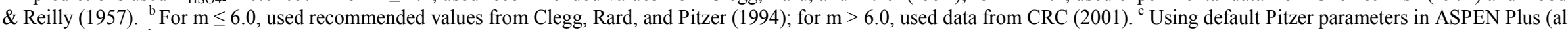

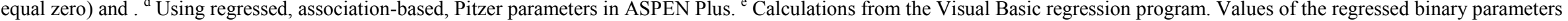
are listed in Table B2. 
Table 7. Regressed Dissociation And Activity Coefficient Data: $\mathrm{HNO}_{3}-\mathrm{H}_{2} \mathrm{O}$ System.

\begin{tabular}{|c|c|c|c|c|c|c|c|c|c|c|c|c|c|c|c|c|c|c|c|c|c|}
\hline & & Data $^{a}$ & & & & Data & $a_{1}$ & ns & & & $\alpha$ & & & & $\gamma_{ \pm}$ & st st & & & $\gamma_{\mathrm{HI}}$ & $\mathrm{NO} 3$ & \\
\hline Stoich & & & Molar & & & oich & M & $\mathrm{N}-\mathrm{B}$ & & & ions & $\% \mathrm{Abs}$ & s. Dev. & & ions & $\% \mathrm{~A}$ & Dev. & Predic & ions & $\% \mathrm{Abs}$ & Dev. \\
\hline M & $\alpha$ & $\mathrm{y}_{ \pm, \mathrm{st}}$ & $\mathrm{y}_{ \pm}$ & $\mathrm{y}_{\mathrm{HNO}}$ & & & $\gamma_{ \pm, \text {st }}$ & $\gamma_{ \pm}$ & $\gamma_{\mathrm{HNO} 3}$ & $\mathrm{RS}^{\mathrm{d}}$ & 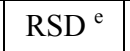 & $\mathrm{RS}^{\mathrm{d}}$ & e & $\mathrm{RS}^{\mathrm{d}}$ & e & $\mathrm{RS}^{\mathrm{d}}$ & $\mathrm{SD}^{\mathrm{e}}$ & $\mathrm{RS}^{\mathrm{d}}$ & $\mathrm{RSD}^{\mathrm{e}}$ & $\mathrm{RS}^{\mathrm{d}}$ & $\mathrm{RSD}^{\mathrm{e}}$ \\
\hline 0.001 & 0.99994 & 0.996 & 996 & 1.001 & 0.994 & 0.001 & 0.987 & 0.987 & 0.869 & 0.99995 & 0.99995 & 0.00 & 0.00 & 0.965 & 0.965 & 2.20 & 2.21 & 1.004 & 1.001 & 15.52 & 15.18 \\
\hline 02 & 9988 & 0.953 & נינה & - & ז & 002 & 944 & .944 & 95 & 99990 & 0.99990 & 0.00 & 0.00 & .952 & .952 & 0.80 & 0.79 & .007 & 1.001 & 6.61 & 5.89 \\
\hline 05 & 972 & 0.929 & 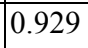 & & 0.994 & & 20 & 21 & & 977 & 0.99977 & 0.01 & & 927 & 927 & 75 & .73 & .017 & .003 & 5.59 & 3.87 \\
\hline 0.01 & 47 & 0.905 & 06 & 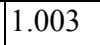 & 0.994 & 0 & 96 & 97 & 2 & 8 & 7 & 0.01 & 0.01 & 0.902 & 0.902 & 0.66 & 0.62 & 1.033 & 1.006 & 27.22 & 23.89 \\
\hline 02 & (1) & 876 & 77 & 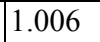 & 0.994 & 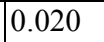 & 67 & 8 & 6 & 92 & 92 & 2 & & 71 & 71 & 5 & 8 & 63 & 011 & .88 & 5.45 \\
\hline 0.05 & 9910 & 0.829 & 831 & 015 & 0.995 & 0 & 820 & 822 & 0 & 984 & 902 & 6 & 0.04 & 2 & 821 & .21 & 6 & 148 & 6 & 0.02 & 5.23 \\
\hline 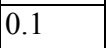 & טגו & 793 & 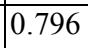 & 政 & . & 101 & ד & 101 & 24 & . & 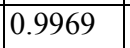 & 4 & & 年 & .779 & נI. & 等 & 279 & .050 & 5.19 & 27.48 \\
\hline 0.2 & 993 & 758 & 763 & 063 & 001 & 0.202 & 747 & 752 & 8 & .9961 & 9946 & 0.31 & 0.16 & 0.742 & 0.739 & 0.67 & 1.03 & 1.522 & 1.095 & 77.43 & 27.61 \\
\hline 0.0 & 2 & 3 & 1 & J & 1.012 & 0 & 4 & 4 & 3 & 0 & 19 & 1 & 0.38 & 10 & 55 & 2 & 1 & 37 & 20 & .38 & 0.69 \\
\hline 0.7 & 8 & 731 & 746 & 4 & 019 & 8 & 1 & 5 & 4 & 3 & 5 & 9 & 0.55 & 97 & .705 & 0.44 & 3 & 2.596 & 1.301 & 169.25 & 34.98 \\
\hline 1 & 973 & 746 & 766 & 6 & 150 & 35 & 719 & 39 & 54 & 991 & 50 & 35 & 0.13 & 719 & 717 & 0.04 & 4 & 3.168 & 1.426 & 200.68 & 35.37 \\
\hline 1.5 & 0.961 & 93 & 825 & 1.58 & 1.047 & 1.575 & 0.753 & 0.784 & 8 & 0.988 & 0.971 & 2.82 & 1.02 & 7 & 8 & 0.45 & 0.64 & 9 & 7 & 230.70 & 35.17 \\
\hline 2 & 948 & 0.859 & 906 & 1.84 & 064 & 2.132 & 0.804 & 848 & 408 & 0.984 & 0.960 & 3.85 & 1.28 & 0.810 & 0.815 & 0.83 & 1.42 & 4.798 & 1.890 & 240.74 & 34.23 \\
\hline 2.5 & 933 & 43 & 011 & 2.14 & 81 & 97 & 8 & 31 & 1 & 980 & 0.948 & 02 & 50 & 0.877 & 85 & 0. & 5 & 97 & 51 & 39.20 & 33.35 \\
\hline 3 & 914 & 05 & 149 & 49 & 98 & 3.302 & 0.951 & 041 & 48 & 974 & 0.934 & 6.56 & 2.14 & 0.954 & 0.965 & 0.29 & 1.45 & 6.145 & 2.463 & 232.52 & 33.28 \\
\hline 3.5 & 892 & 17 & 1.31 & 89 & 4 & 3.918 & .042 & 168 & .096 & 0.966 & 0.917 & 8.35 & 2.80 & 1.042 & 1.056 & 0.01 & 1.52 & 6.755 & 2.797 & 222.35 & 33.49 \\
\hline 4 & 66 & 315 & 52 & 35 & 30 & 57 & 51 & 29 & 96 & 7 & 0.898 & .52 & 3 & 10 & 56 & 0 . & 0.44 & 40 & 3.165 & 206.37 & 32.09 \\
\hline 4.5 & 0.839 & 1.465 & 1.75 & 3.88 & 1.145 & 5.222 & 1.259 & .500 & 2.733 & 0.945 & 0.875 & 12.68 & 4.34 & 1.247 & 1.264 & 0.95 & 0.42 & 7.905 & 3.561 & 189.20 & 30.28 \\
\hline 5 & 309 & 625 & 01 & 0 & 60 & 14 & 370 & 93 & 090 & 31 & 0 & 5.10 & 5. & .360 & 1.379 & 0. & 0.04 & 8.456 & 3.980 & 173.62 & 28.79 \\
\hline 5.5 & 0.78 & 1.79 & 2.3 & 5.19 & 1.175 & 6.636 & 1.479 & 896 & 3.511 & 0.914 & 0.821 & 17.20 & 5.20 & 1.479 & 1.497 & 0.01 & 1.21 & 8.993 & 4.409 & 156.18 & 25.58 \\
\hline 6 & 748 & 1.97 & 2.63 & 5.99 & 190 & 7.391 & 595 & 2.132 & 967 & 0.894 & 0.787 & 19.55 & 5.25 & 1.600 & 1.616 & 0.34 & 1.36 & 9.517 & 4.828 & 139.93 & 21.70 \\
\hline 6.5 & 0.716 & 2.16 & 3.02 & 6.91 & 204 & 8.181 & 1.711 & 2.390 & 487 & 0.872 & 0.750 & 21.72 & 4.69 & 1.721 & 1.731 & 0.55 & 1.18 & 10.026 & 5.210 & 123.46 & 16.12 \\
\hline 7 & 0.682 & 2.36 & 3.46 & 7.96 & 1.218 & 9.010 & 1.828 & 2.681 & 5.037 & 0.846 & 0.707 & 24.05 & 3.70 & 1.838 & 1.837 & 0.53 & 0.46 & 10.515 & 5.522 & 108.77 & 9.63 \\
\hline 7.5 & 0.651 & 2.565 & 3.94 & 9.10 & 1.232 & 882 & 941 & 82 & 5.675 & 010 & 0.660 & 25.67 & 1.39 & 1.950 & 1.924 & 0.44 & 0.86 & 10.983 & 5.726 & 93.54 & 0.91 \\
\hline
\end{tabular}


Table 7 (Continued). Regressed Dissociation And Activity Coefficient: $\mathrm{HNO}_{3}-\mathrm{H}_{2} \mathrm{O}$ System.

\begin{tabular}{|c|c|c|c|c|c|c|c|c|c|c|c|c|c|c|c|c|c|c|c|c|c|}
\hline \multicolumn{5}{|c|}{ Data $^{a}$} & \multicolumn{5}{|c|}{ Data Transformations } & \multicolumn{4}{|c|}{$\alpha$} & \multicolumn{4}{|c|}{$\gamma_{ \pm, \mathrm{st}}$} & \multicolumn{4}{|c|}{$\gamma_{\mathrm{HNO} 3}$} \\
\hline \multirow{2}{*}{$\begin{array}{c}\text { Stoich } \\
\mathrm{M}\end{array}$} & \multirow[b]{2}{*}{$\alpha$} & \multicolumn{3}{|c|}{ Molar-Based } & \multirow{2}{*}{$\rho^{b}$} & \multirow{2}{*}{$\begin{array}{c}\text { Stoich } \\
\mathrm{m}\end{array}$} & \multicolumn{3}{|c|}{ Molality-Based $^{c}$} & \multicolumn{2}{|c|}{ Predictions } & \multicolumn{2}{|c|}{$\%$ Abs. Dev. } & \multicolumn{2}{|c|}{ Predictions } & \multicolumn{2}{|c|}{$\%$ Abs. Dev. } & \multicolumn{2}{|c|}{ Predictions } & \multicolumn{2}{|c|}{$\%$ Abs. Dev. } \\
\hline & & $\mathrm{y}_{ \pm, \mathrm{st}}$ & $\mathrm{y}_{ \pm}$ & $\mathrm{y}_{\mathrm{HNO} 3}$ & & & $\gamma_{ \pm, \text {st }}$ & $\gamma_{ \pm}$ & $\gamma_{\mathrm{HNO} 3}$ & $\mathrm{RS}^{\mathrm{d}}$ & $\mathrm{RSD}^{\mathrm{e}}$ & $\mathrm{RS}^{\mathrm{d}}$ & $\mathrm{RSD}^{\mathrm{e}}$ & $\mathrm{RS}^{\mathrm{d}}$ & $\mathrm{RSD}^{\mathrm{e}}$ & $\mathrm{RS}^{\mathrm{d}}$ & $\mathrm{RSD}^{\mathrm{e}}$ & $\mathrm{RS}^{\mathrm{d}}$ & $\mathrm{RSD}^{\mathrm{e}}$ & $\mathrm{RS}^{\mathrm{d}}$ & $\mathrm{RSD}^{\mathrm{e}}$ \\
\hline 8 & 0.62 & 2.78 & 4.49 & 10.54 & 1.245 & 10.800 & 2.053 & 3.312 & 6.373 & 0.788 & 0.608 & 27.09 & 1.94 & 2.053 & 1.987 & 0.01 & 3.21 & 11.424 & 5.788 & 79.25 & 9.18 \\
\hline 8.5 & 0.589 & 3.005 & 5.1 & 12.1 & 1.258 & 11.771 & 2.164 & 3.673 & 7.131 & 0.756 & 0.552 & 28.35 & 6.35 & 2.147 & 2.018 & 0.74 & 6.74 & 11.834 & 5.686 & 65.95 & 20.27 \\
\hline & & & & & & & & & & & Average & 8.97 & 2.02 & & & 0.58 & 1.23 & & & 127.14 & 25.37 \\
\hline
\end{tabular}

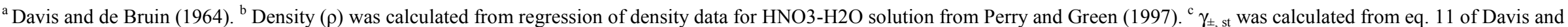

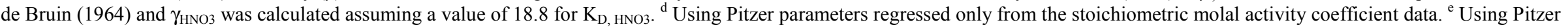

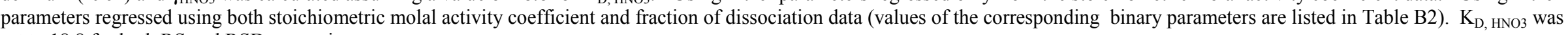
set to 18.8 for both RS and RSD regressions. 
Table 8. Comparison Of Our Pitzer Code With That Of ASPEN Plus: $\mathrm{H}_{2} \mathrm{SO}_{4}-\mathrm{H}_{2} \mathrm{O}$ System.

\begin{tabular}{|c|c|c|c|c|c|c|c|c|c|c|c|c|}
\hline $\begin{array}{l}\text { Stoich } \\
\text { Molality } \\
\mathrm{H}_{2} \mathrm{SO}_{4} \\
\end{array}$ & $\gamma_{\mathrm{HSO}-\text {,calc }}$ & $\gamma_{\text {HSO4-,Aspen }}$ & $\%$ Abs. Dev. & $\gamma_{\mathrm{SO} 4-2, \mathrm{calc}}$ & $\gamma_{\text {SO4-2,Aspen }}$ & $\%$ Abs. Dev. & $\gamma_{\mathrm{H}+\text {,calc }}$ & $\gamma_{\mathrm{H}+, \text { Aspen }}$ & $\%$ Abs. Dev. & $\gamma_{ \pm, \mathrm{st}(\mathrm{calc})}$ & $\gamma_{ \pm, \mathrm{st}(\text { Aspen })}$ & $\%$ Abs. Dev. \\
\hline 0.1 & 0.7906 & 0.7742 & 2.0783 & 0.2362 & 0.2229 & 5.6148 & 0.7488 & 0.7472 & 0.2050 & 0.2462 & 0.2412 & 2.0418 \\
\hline 0.2 & 0.7831 & 0.7622 & 2.6694 & 0.1556 & 0.1425 & 8.4125 & 0.7193 & 0.7174 & 0.2593 & 0.1951 & 0.1891 & 3.0546 \\
\hline 0.3 & 0.7916 & 0.7666 & 3.1553 & 0.1158 & 0.1038 & 10.3587 & 0.7067 & 0.7047 & 0.2828 & 0.1713 & 0.1648 & 3.7614 \\
\hline 0.4 & 0.8075 & 0.7785 & 3.5949 & 0.0917 & 0.0808 & 11.8414 & 0.7012 & 0.6991 & 0.2882 & 0.1569 & 0.1502 & 4.2984 \\
\hline 0.5 & 0.8281 & 0.7950 & 4.0048 & 0.0754 & 0.0656 & 13.0192 & 0.6994 & 0.6975 & 0.2794 & 0.1472 & 0.1402 & 4.7209 \\
\hline 0.7 & 0.8799 & 0.8380 & 4.7572 & 0.0552 & 0.0470 & 14.7651 & 0.7029 & 0.7013 & 0.2266 & 0.1349 & 0.1277 & 5.3293 \\
\hline 1.0 & 0.9794 & 0.9231 & 5.7423 & 0.0390 & 0.0326 & 16.4233 & 0.7194 & 0.7188 & 0.0736 & 0.1251 & 0.1178 & 5.8511 \\
\hline 1.5 & 1.2015 & 1.1172 & 7.0172 & 0.0267 & 0.0220 & 17.8049 & 0.7709 & 0.7735 & 0.3367 & 0.1193 & 0.1120 & 6.1166 \\
\hline 2.0 & 1.5003 & 1.3828 & 7.8277 & 0.0214 & 0.0174 & 18.3907 & 0.8546 & 0.8622 & 0.8879 & 0.1203 & 0.1131 & 5.9975 \\
\hline 2.5 & 1.8842 & 1.7300 & 8.1823 & 0.0189 & 0.0153 & 18.7535 & 0.9778 & 0.9928 & 1.5282 & 0.1259 & 0.1186 & 5.7403 \\
\hline 3.0 & 2.3602 & 2.1685 & 8.1216 & 0.0179 & 0.0144 & 19.2104 & 1.1504 & 1.1758 & 2.2121 & 0.1350 & 0.1276 & 5.4953 \\
\hline 3.5 & 2.9336 & 2.7072 & 7.7169 & 0.0177 & 0.0142 & 19.9364 & 1.3841 & 1.4242 & 2.8975 & 0.1475 & 0.1396 & 5.3585 \\
\hline 4.0 & 3.6107 & 3.3559 & 7.0571 & 0.0181 & 0.0143 & 21.0146 & 1.6930 & 1.7531 & 3.5464 & 0.1630 & 0.1542 & 5.3895 \\
\hline 4.5 & 4.4003 & 4.1260 & 6.2319 & 0.0188 & 0.0146 & 22.4686 & 2.0943 & 2.1807 & 4.1268 & 0.1816 & 0.1714 & 5.6227 \\
\hline 5.0 & 5.3156 & 5.0328 & 5.3207 & 0.0199 & 0.0151 & 24.2842 & 2.6085 & 2.7289 & 4.6145 & 0.2035 & 0.1911 & 6.0731 \\
\hline 5.5 & 6.3749 & 6.0952 & 4.3874 & 0.0214 & 0.0157 & 26.4213 & 3.2609 & 3.4238 & 4.9940 & 0.2288 & 0.2134 & 6.7404 \\
\hline \multirow[t]{2}{*}{6.0} & 7.6014 & 7.3369 & 3.4798 & 0.0232 & 0.0165 & 28.8275 & 4.0822 & 4.2968 & 5.2575 & 0.2579 & 0.2383 & 7.6140 \\
\hline & & Average & 5.37 & & Average & 17.50 & & Average & 1.88 & & Average & 5.25 \\
\hline
\end{tabular}

Subscript "calc" represents values calculated from the Pitzer subroutine of our regression program. Subscript "Aspen" represents values calculated from the Pitzer model in ASPEN Plus.

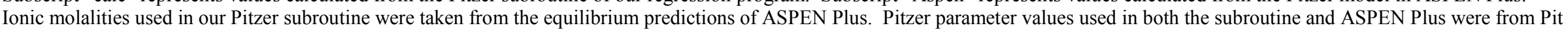


Table 9. Validation Of Pitzer Subroutine Of Regression Program: $\mathrm{H}_{2} \mathrm{SO}_{4}-\mathrm{H}_{2} \mathrm{O}$ System.

\begin{tabular}{|c|c|c|c|c|c|c|}
\hline $\begin{array}{l}\text { Stoich } \\
\text { Molality } \\
\mathrm{H}_{2} \mathrm{SO}_{4}\end{array}$ & $\gamma_{\text {HSO4-- }}{ }^{\mathrm{a}}$ & $\gamma_{\text {SO4-2 }}{ }^{\mathrm{a}}$ & $\gamma_{\mathrm{H}^{+}}{ }^{\mathrm{a}}$ & $\gamma_{ \pm, \text {st(calc) }}{ }^{\mathrm{a}}$ & $\gamma_{ \pm, \text {st(PRS) }}{ }^{\mathrm{b}}$ & $\%$ Abs. Dev. \\
\hline 0.1 & 0.79112 & 0.23727 & 0.75016 & 0.2441 & 0.2436 & 0.19 \\
\hline 0.2 & 0.78378 & 0.15689 & 0.72226 & 0.1924 & 0.1918 & 0.30 \\
\hline 0.3 & 0.79250 & 0.11788 & 0.71405 & 0.1666 & 0.1676 & 0.63 \\
\hline 0.4 & 0.80782 & 0.09315 & 0.70866 & 0.1532 & 0.1532 & 0.00 \\
\hline 0.5 & 0.82792 & 0.07674 & 0.70843 & 0.1436 & 0.1434 & 0.13 \\
\hline 0.7 & 0.87785 & 0.05640 & 0.71748 & 0.1307 & 0.1311 & 0.32 \\
\hline 1.0 & 0.97337 & 0.03987 & 0.73895 & 0.1212 & 0.1215 & 0.21 \\
\hline 1.5 & 1.18762 & 0.02708 & 0.79363 & 0.1163 & 0.1160 & 0.27 \\
\hline 2.0 & 1.47531 & 0.02148 & 0.88042 & 0.1176 & 0.1171 & 0.41 \\
\hline 2.5 & 1.84501 & 0.01883 & 1.00646 & 0.1231 & 0.1224 & 0.53 \\
\hline 3.0 & 2.30000 & 0.01767 & 1.18401 & 0.1317 & 0.1311 & 0.48 \\
\hline 3.5 & 2.87220 & 0.01745 & 1.41154 & 0.1446 & 0.1425 & 1.49 \\
\hline 4.0 & 3.46558 & 0.01747 & 1.74960 & 0.1568 & 0.1563 & 0.29 \\
\hline 4.5 & 4.21571 & 0.01809 & 2.15739 & 0.1741 & 0.1724 & 0.97 \\
\hline 5.0 & 4.97372 & 0.01859 & 2.71694 & 0.1895 & 0.1907 & 0.63 \\
\hline 5.5 & 5.93710 & 0.01969 & 3.38812 & 0.2109 & 0.2113 & 0.18 \\
\hline 6.0 & 7.02202 & 0.02101 & 4.23847 & 0.2339 & 0.2343 & 0.18 \\
\hline & & & & & Average & 0.42 \\
\hline
\end{tabular}

${ }^{a}$ Values calculated from the Pitzer subroutine of our regression program. ${ }^{\mathrm{b}}$ Values calculated by Pitzer, Roy, and Silvester (1977). Values of ionic molalities and Pitzer parameters used in the Pitzer subroutine were taken from Pitzer, Roy, and Silvester (1977). 
Table 10. Comparision Of ASPEN Plus vs. Pitzer Subroutine In The Debye-Huckle Limit.

\begin{tabular}{|c|c|c|c|}
\hline \multirow{2}{*}{ Ion $i$} & \multirow{2}{*}{ Molality of $i^{\text {a }}$} & \multicolumn{2}{|c|}{ Predicted $\gamma_{i}$} \\
\hline & & ASPEN Plus (AP) & Regression Program (RP) \\
\hline \multicolumn{4}{|c|}{$\mathrm{H}_{2} \mathrm{SO}_{4}$} \\
\hline $\mathrm{H}^{+}$ & 4.766 & $0.33505 \Rightarrow \ln \gamma_{\mathrm{i}} / \ln \gamma_{\mathrm{SO} 4-2}=0.229$ & \multirow{2}{*}{$0.32808=>\ln \gamma_{\mathrm{i}} / \ln \gamma_{\mathrm{SO} 4-2}=0.250$} \\
\hline $\mathrm{HSO}_{4}^{-}$ & 3.233 & $0.30478 \Rightarrow>\ln \gamma_{\mathrm{i}} / \ln \gamma_{\mathrm{SO} 4-2}=0.249$ & \\
\hline \multirow[t]{2}{*}{$\mathrm{SO}_{4}^{-2}$} & 0.767 & 0.00845 & 0.01159 \\
\hline & & $\gamma_{ \pm, \mathrm{st}(\mathrm{AP})}=0.019$ & $\gamma_{ \pm, \mathrm{st}(\mathrm{RP})}=0.044$ \\
\hline \multicolumn{3}{|r|}{$\mathrm{HCl}$} & Any Uni-Valent Dissociated Salt \\
\hline $\mathrm{H}^{+}$ & 4.000 & 0.35808 & \multirow{5}{*}{$\gamma_{\mathrm{i}}=\gamma_{+}=\gamma_{-}=0.35790$} \\
\hline $\mathrm{Cl}^{-}$ & 4.000 & 0.35808 & \\
\hline \multicolumn{3}{|r|}{$\mathrm{NaCl}$} & \\
\hline $\mathrm{Na}^{+}$ & 4.000 & 0.35808 & \\
\hline $\mathrm{Cl}^{-}$ & 4.000 & 0.35808 & \\
\hline
\end{tabular}

${ }^{\text {a }}$ Molalities were predicted by ASPEN Plus using the Pitzer property method; predicted molalities were then used as inputs to the Pitzer subroutine in the Regression Program. Initial stoichiometric molality of the single electrolyte in water is 4.0 mol/kg. $\beta^{(0)}=\beta^{(1)}=C^{\phi}=0$ for each salt (i.e., the Pitzer formalism was reduced to the Debye-Huckel limit). 
Table 11. Summary of Results: Percent Absolute Residuals Between Predicted And Experimental Values

\begin{tabular}{|c|c|c|c|}
\hline \multirow{2}{*}{ Aqueous System } & \multirow{2}{*}{ ENRTL } & \multicolumn{2}{|r|}{ PITZER } \\
\hline & & Only Binaries & Mixing Terms Included \\
\hline $\mathrm{NaCl}(\mathrm{m} \leq 6)$ & 1.411 & $0.145-0.717$ & $\mathrm{~N} / \mathrm{A}$ \\
\hline $\begin{array}{l}\mathrm{HCl} \\
\mathrm{m} \leq 6 \\
\mathrm{~m} \leq 16\end{array}$ & $\begin{array}{l}19.71 \\
14.24\end{array}$ & $\begin{array}{c}0.4 \\
1.55\end{array}$ & N/A \\
\hline $\mathrm{HCl}-\mathrm{NaCl}(\mathrm{I} \leq 6)$ & 26.80 & 1.96 & 1.87 \\
\hline $\mathrm{HCl}-\mathrm{NaCl}-\mathrm{KCl}(\mathrm{I} \leq 5)$ & 35.92 & 5.09 & 2.53 \\
\hline \multicolumn{4}{|c|}{ Salt Precipitation (Solid-Liquid Equilibrium) } \\
\hline $\begin{array}{l}\mathrm{HCl}-\mathrm{NaCl} \\
\mathrm{I} \leq 12 \\
\mathrm{I} \leq 19\end{array}$ & $\begin{array}{l}34.1 \\
38.7 \\
\end{array}$ & $\begin{array}{l}13.7-19.2 \\
19.2-24.2 \\
\end{array}$ & $\begin{array}{c}\text { (Symmetrical) } \\
4.0 \\
8.7 \\
\end{array}$ \\
\hline \multicolumn{4}{|c|}{ Association (Chemical Equilibrium) } \\
\hline $\begin{array}{l}\mathrm{H}_{2} \mathrm{SO}_{4} \\
\alpha(\mathrm{m} \leq 42) \\
\gamma_{ \pm, \text {st }}(\mathrm{m} \leq 20)\end{array}$ & $\begin{array}{l}64.3 \\
33.5\end{array}$ & $\begin{array}{l}8.3 \\
4.2 \\
\end{array}$ & $\begin{array}{c}\text { (Unsymmetrical: } \mathrm{HSO}_{4}{ }^{-} / \mathrm{SO}_{4}{ }^{-2} \text { ) } \\
\text { Not studied }\end{array}$ \\
\hline $\begin{array}{l}\mathrm{HNO}_{3}(\mathrm{~m} \leq 12) \\
\alpha \\
\gamma_{ \pm, \mathrm{st}}\end{array}$ & $\begin{array}{c}\text { Not } \\
\text { studied }\end{array}$ & $\begin{array}{l}2.02 \\
1.23\end{array}$ & $\mathrm{~N} / \mathrm{A}$ \\
\hline
\end{tabular}

